\title{
APPROACHES TO LEARNING, NEED FOR COGNITION, AND STRATEGIC FLEXIBILITY AMONG UNIVERSITY STUDENTS
}

\author{
by \\ CHRISTINA JANET EVANS
}

A thesis submitted to the Faculty of Education

in conformity with the requirements for

the degree of Master of Education

\author{
Queen's University \\ Kingston, Ontario, Canada \\ June, 2000
}

copyright $\odot$ Christina Janet Evans, 2000 
National Library

of Canada

Acquisitions and Bibliographic Services

395 Weltington Street Ottawa ON K1A ON4 Canada
Bibliothèque nationale du Canada

Acquisitions et services bibliographiques

395, rue Wellington Ottawa ON K1A ON4 Canada

Your tive volre reforence

The author has granted a nonexclusive licence allowing the National Library of Canada to reproduce, loan, distribute or sell copies of this thesis in microform, paper or electronic formats.

The author retains ownership of the copyright in this thesis. Neither the thesis nor substantial extracts from it may be printed or otherwise reproduced without the author's permission.
L'auteur a accordé une licence non exclusive permettant à la Bibliothèque nationale du Canada de reproduire, prêter, distribuer ou vendre des copies de cette thèse sous la forme de microfiche/film, de reproduction sur papier ou sur format électronique.

L'auteur conserve la propriété du droit d'auteur qui protège cette thèse. $\mathrm{Ni}$ la thèse ni des extraits substantiels de celle-ci ne doivent être imprimés ou autrement reproduits sans son autorisation. 


\begin{abstract}
The purpose of this study was to explore relationships among three existing questionnaires: the Study Process Questionnaire (SPQ) (Biggs, 1978), the Need for Cognition Scale (NCS) (Cacioppo \& Petty, 1982), and the Strategic Flexibility Questionnaire (SFQ) (Cantwell \& Moore, 1996). The SPQ measures three approaches to learning: deep, surface, and achieving. The NCS measures a one-dimensional construct of need for cognition. The SFQ measures three types of executive control of learning: adaptive, inflexible, and irresolute.

Underlying theory suggested strong similarities among need for cognition, the deep approach, and adaptive control, as well as similarities among the surface approach, inflexible control, and irresolute control. Further, surface, inflexible, and irresolute appeared to be opposites of need for cognition, deep, and adaptive. It was proposed that these scales might all be measuring one underlying construct such as self-regulated learning. As an alternative, there might be two negatively related constructs, selfregulated leaming and ineffective learning.

Participants were 226 first-year students at a Canadian military college who completed all three questionnaires. Exploratory factor analysis of the items from all three questionnaires resulted in a three factor solution with most of the deep, need for cognition, and adaptive items on one factor, surface and irresolute items on a second factor, and inflexible items on the third factor. Second order confirmatory factor analysis also supported the existence of three underlying factors. As initially hypothesized, one factor, called self-regulation, consisted of need for cognition, the deep approach, and adaptive
\end{abstract}


control. However, the hypothesized ineffective learning factor divided into two correlated factors. One, labelled surface/irresolute, consisted of irresolute control, the surface approach, and negative need for cognition. The other, labelled inflexibility, consisted of inflexible control and negative adaptive control. Although the scales do not appear to be measuring exactly the same thing at the item level, there are substantial relationships among them at the scaie level. This supports the need for further development of underlying theories. 


\section{ACKNOWLEDGEMENTS}

As with any large project, a number of people have contributed to the successful completion of this one. At the risk of omitting anyone who should have been included, I would like to thank a number of those people specifically.

First of all, a sincere thank you to my supervisor, Dr. John Kirby. A good deal of his time is invested in this thesis, in addition to the ideas, support, and encouragement he has given me, not to mention challenging my ideas when necessary. I appreciate it all!

My two committee members have also been very supportive. I was fortunate to take several classes with Dr. Robert (Bob) Wilson. As a result, his contributions have figured throughout the development of this project, and I thank him for his thoughtful comments, advice, and humour.

Dr. Leandre (Lee) Fabrigar is the best statistics teacher I have ever had, with an amazing ability to make multivariate stats fun. Being from outside the faculty, it would have been easy to turn me down when I asked him to be on my committee, and I am grateful that he did not. I appreciate his help and advice, and I promise I will never do a principal components analysis!

I would like to thank the director of the Military Psychology and Leadership department at Royal Military College, Lieutenant-Colonel Peter Bradley, and his staff for their support and assistance with my data collection. Special thanks to Dr. Charbonneau, Dr. Nicol, and Dr. St. John for allowing me class time to collect data.

I am grateful to the Canadian Forces for providing this incredible opportunity, and to the Personnel Selection Branch for sponsoring me to complete this degree. 
Special thanks to my friends Erin, Claude, and Andre for their translation skills. It was a big help.

Finally, thanks to my parents for a life-time of support, and for having the courage and patience to let me find my own way to higher education. Better late than never! 
TABLE OF CONTENTS

CHAPTER ONE - INTRODUCTION AND LITERATURE REVIEW

Introduction 1

Gothenburg Studies 3

Lancaster Studies $\quad 4$

Biggs' Study Process Questionnaire

Metacognition 11

$\begin{array}{ll}\text { Self-Regulation } & 12\end{array}$

$\begin{array}{ll}\text { Need for Cognition } & 16\end{array}$

$\begin{array}{ll}\text { Demographic Characteristics } & 19\end{array}$

The Present Study 21

CHAPTER TWO - METHOD

$\begin{array}{ll}\text { Participants } & 26\end{array}$

$\begin{array}{ll}\text { Materials } & 28\end{array}$

$\begin{array}{ll}\text { Procedure } & 29\end{array}$

CHAPTER THREE - RESULTS

$\begin{array}{ll}\text { Inspection of Data } & 30\end{array}$

Representativeness of the Data 31

Verification of Constructs 33

$\begin{array}{ll}\text { NCS } & 35\end{array}$

$\begin{array}{ll}\text { SFQ } & 38\end{array}$

$\begin{array}{lll}\text { SPQ } & 41\end{array}$ 
Combined Analysis - Exploratory Factor Analysis

$\begin{array}{lr}\text { Confirmatory Factor Analysis } & 57\end{array}$

$\begin{array}{ll}\text { Demographic Variables } & 68\end{array}$

CHAPTER FOUR - DISCUSSION

Overview

$\begin{array}{ll}\text { Demographic Variables } & 74\end{array}$

$\begin{array}{ll}\text { Scales and Constructs } & 77\end{array}$

Limitations of the Study $\quad 83$

$\begin{array}{ll}\text { Conclusions } & 85\end{array}$

$\begin{array}{ll}\text { References } & 87\end{array}$

APPENDICES

$\begin{array}{ll}\text { A - Questionnaires } & 93\end{array}$

B - Covering Letter to Participants 97

$\begin{array}{ll}\text { C - Consent Form } & 98\end{array}$

D - Descriptive Statistics for All Items 99

E - t-Tests for Gender and Primary Language 102

F - Standardized Factor Loadings for First Order Model, $\begin{array}{ll}\text { Confimatory Factor Analysis } & 105\end{array}$

G-1 - One Factor Second Order Model 107

G-2 - Two Factor Second Order Model 108

H - Descriptive Statistics for Scale Scores 109

J-1 - Scale Level Statistics for Faculty 110

vii 
J-3 - Scale Level Statistics for Language

J-4 - Frequency Distributions for Father's and Mother's Education 


\section{LIST OF TABLES}

Tables

1. Representation of the Sample by Gender and Language 28

2. Comparison Values for Mean Scale Scores on the SPQ 32

3. Comparison Values for Mean Scale Scores on the SFQ 33

4. Factor Loadings for the NCS, Single Factor Solution 37

5. Factor Loadings for the SFQ. Three Factor Solution 40

6. Factor Loadings for the SPQ, Four Factor Solution 43

7. Factor Loadings for the SPQ, Deep and Surface Items, Two Factors 46

8. Cronbach's Alpha for the SPQ 47

9. Combined Analysis, 81 Items, Four Factor Solution 50

10. Combined Analysis, Without Achieving Items, Three Factor Solution 54

11. Fit Indices for First and Second Order Confirmatory Factor Analyses 58

12. Correlations Between First Order Factors 60

13. Factor Loadings for Three Factor EFA Solution, Based on First Order $\begin{array}{ll}\text { CFA Correlation Matrix } & 62\end{array}$

14. Fit Indices for One, Two, and Three Factor Second Order Models 68

15. Correlations Between Demographic Variables and Scale Scores 71 


\section{LIST OF FIGURES}

Figures

1. Model Depicting Relationships for a Single Construct 22

2. Model Depicting Relationships for Two Constructs 24

3. Scree Plot for the Need for Cognition Scale (NCS) 36

4. Scree Plot for the Strategic Flexibility Questionnaire (SFQ) 39

5. Scree Plot for the Study Process Questionnaire (SPQ) 42

6. Scree Plot for the Study Process Questionnaire (Without Achieving Items) 45

7. Scree Plot for All 81 Items 49

8. Scree Plot for 67 Items (Achieving Items Omitted) 53

9. Scree Plot for Analysis of Correlation Matrix, First Order Model 61

10. Proposed Second Order Factor Model 64

11. Second Order Factor Model With Standardized Solutions 66

12. Model of Self-Regulation 81 
Chapter One

Introduction and Literature Review

The study of student approaches to learning has been an area of research for about three decades. Earlier models of learning focused on situational factors and stable individuai differences. Biggs and Kirby (1984) provided an overview of three earlier models: behaviourist, individual differences, and aptitude-treatment interaction. The behaviourist model ignores individual differences and focuses on improving performance by manipulating the learning environment through reinforcement. The individual differences model holds that variations in performance can be attributed to underlying differences in mental abilities. Finally, the aptitude-treatment interaction model suggests that the situation and individual differences and their interaction are all important. For example, some students may learn better in a structured format with lectures, while other students may learn better through independent study.

Biggs and Kirby (1984) suggested, however, that even the aptitude-treatment interaction model is inadequate to explain research results. They proposed that the model required the addition of what they called intervening variables which link stable individual differences to the learning task. These intervening variables are more situation-specific than the individual difference variables, and Biggs and Kirby proposed that they consist of motives and strategies which the student brings to bear upon the learning task. This indicates that learners play an active role in determining. what they will learn and how they will learn it, and marks a shift to an experiential or phenomenological perspective in which learning is defined by the individuals engaged in learning (Schmeck, 1988). The situation 
and individual differences provide the context in which the leamer makes decisions about the task. This idea that students make decisions about what they will learn and choose strategies for learning implies that they will also allocate resources to achieve those strategies. This suggests an executive or self-regulatory role in learning, which will be elaborated in subsequent sections of this paper.

The shift from focusing on stable individual differences in ability to focusing on factors which are under the control of students marks a recognition that academic performance varies according to the ways in which students perceive and value their own performance (Biggs, 1987). This could be seen as a shift in focus from skills, to a focus on strategies or styles. Kirby (1988) defined skills as existing cognitive routines for performing specified tasks, closely related to and limited by abilities. By contrast, strategies involve choices among skills. The strategy domain ranges from tactics, which are decisions to employ a particular skill; to strategies, which involve combinations or choices of tactics to solve a problem; to styles, which refer to habitual use of similar strategies (Kirby). The terms "approaches" and "orientations" have also been used with similar connotations as this definition of "styles". However, the notion that approaches involve decisions and intentions on the part of the learner suggests that approaches go beyond habits. According to Biggs (1985), approaches to learning are composed of motives and strategies. Approaches are subject to situational influences, and individuals are generally predisposed to adopt one approach in preference to another, but approaches also involve choice, or an executive decision-making role. Biggs (1985) suggested that the dynamic link between personal, situational, approach, and outcome variables is a 
metacognitive process. Metacognition will be discussed in more detail later.

The history of research into student approaches to learning has led to some remarkably consistent results, as will be discussed in the following sections.

\section{Gothenburg Studies}

Among the early researchers to begin studying different approaches to learning by students were a group working at the University of Gothenburg, Sweden. Marton and Saljo (1976a) reported a research project which had led them to become dissatisfied with traditional research methods of assessing learning. These traditional methods had been concerned strictly with quantitative learning, in other words, with how much students had learned. Marton and Saljo chose to focus instead on qualitative differences between what students had learned. (Note that this reference to qualitative and quantitative differences in leaming does not necessarily imply qualitative and quantitative methods of research.) In one study, participants were given lengthy passages (three chapters) of prose to read, without time limits, and were subsequently questioned on what they had read. Marton and Saljo found four discernable levels of comprehension: those who had grasped the intentional content of the author's argument complete with subtleties, those who grasped part of the intentional content, those who grasped the topic of the argument but missed the main point, and those who apparently lacked any understanding of what they had read.

Using this and other studies, Marton and Saljo (1976a) identified two distinguishable levels of processing, which they called deep-level and surface-level. In surface-level processing, they argued that students direct their attention to learning the text itself in a reproductive conception of learning. Deep-level processors, by contrast, 
focus on the intentional content of the text, in pursuit of comprehension. Marton and Saljo found that deep and surface levels of learning led to the corresponding levels of outcome (comprehension) previously described, where deep learners grasped the intentional content but surface learners did not. Their article did not, however, address why some deep-level processors were more successful than others in grasping the full intent of the passage, or similarly why some surface-level processors achieved somewhat more understanding than others.

Marton and Saljo (1976b) elaborated this connection between level of processing and outcome. They concluded that students may adopt an approach of deep or surface level processing based on their expectations of what is required of them in the learning context. In other words, situational demands such as the anticipated format of evaluation may influence a student to adopt a deep or surface level of processing. This puts a focus on student intentions: what students intend to get out of a learning task influences the approach they adopt and the resulting outcomes.

\section{Lancaster Studies}

Spurred on by the Gothenburg. studies and other research, Entwistle, Ramsden, and their colleagues at Lancaster University set out to develop an inventory to measure approaches to and styles of studying. The first step, however, was to obtain firmer evidence of the existence of contrasting styles or approaches to studying, and to determine how stable these characteristics were (Entwistle \& Ramsden, 1982).

Earlier work done at Lancaster had resulted in the development of a series of inventories used to predict levels of academic performance. Some of the items in these 
inventories became the basis for a new inventory. "The purpose in developing a new inventory was not to improve levels of prediction of academic success; it was instead an attempt to understand students' approaches to learning" (Entwistle \& Ramsden, 1982, p. 35). Additional items were developed to reflect the concepts identified by Marton and his colleagues, as well as items developed to tap a strategic approach to learning, or "cue consciousness" (Miller \& Parleth, 1974, as cited in Entwistle \& Ramsden). Interviews with students led to other items, as did discussions with Biggs, who was at the same time pursuing similar research which led to development of the Study Behaviour Questionnaire (Biggs, 1976) and subsequent Study Process Questionnaire (Biggs, 1978).

A series of tests and refinements to the inventory eventually resulted in the Approaches to Studying Inventory, which identified the following four orientations: Meaning, Reproducing, Achieving, and Nonacademic (Entwistle \& Ramsden, 1982). Entwistle and Ramsden chose the term "orientation" to indicate that students tend to exhibit a consistency of approach, as well as the existence of both approach and motive components of three of the orientations (Meaning, Reproducing, and Achieving) (Entwistle, 1988). As described by Entwistle (1988), the Meaning orientation consists of the deep approach, in which students intend to extract meaning from the text, intrinsic motivation to learn, and specific learning strategies of relating new ideas to existing knowledge and the use of evidence to form opinions. The Reproducing orientation consists of the surface approach in which students focus on verbatim recall of the text or facts contained in it, extrinsic motivation to obtain a qualification or motivation from fear of failure, and strategies such as rote memorization. The Achieving orientation consists of 
the strategic approach (the previously mentioned search for cues to maximize performance), which is linked to competitive achievement motivation. The Nonacademic orientation consists of disorganized study methods and negative attitudes toward studying. Entwistle (1988) acknowledged that the factor structures for the Achieving and Nonacademic orientations were less distinct than for the Meaning and Reproducing orientations.

Entwistle and Ramsden (1982) found that while the Reproducing orientation was related to elements of study pathologies (disorganized study methods, negative attitudes), the Meaning orientation was not. They also discovered that, in some cases, students who adopt the surface approach (reproducing orientation) recognize that the approach can be rather ineffective, because the lack of personal meaning in the learning results in brief retention. Entwistle (1988) suggested that by making students aware of their own approaches to learning, and the implications of those approaches, it may be possible to improve the quality of learning outcomes. However, he pointed out that situational demands of educational institutions also play a role in determining the approach adopted. Biggs' Study Process Questionnaire

At the same time as Entwistle and Ramsden were developing the ASI, Biggs, in Australia, was developing questionnaires to measure approaches to learning. Biggs (1987) developed a three-stage model of student learning that accounts for both personal and situational influences. The three stages in his model are presage, process, and product (or performance). Presage factors are those which exist before the student enters the learning situation, and include both personal and situational influences. The process stage 
is presumed to refer primarily to the student's motives and strategies for learning. This stage encompasses the intervening variables referred to previously (Biggs \& Kirby, 1984). According to Biggs, each motive and strategy combination then defines an approach to learning. This approach is seen as being typical of a given learner, but it is not rigidly applied; it is negotiable, sensitive to context, and affected by student intentions (Biggs, 1993). That is, a student who usually employs a deep approach may nonetheless choose surface strategies for a topic that is of little interest.

In order to study the processing stage of learning ${ }_{2}$ Biggs initially developed a 10 scale Study Behaviour Questionnaire (Biggs, 1976). However, the ten scales proved too unwieldy for practical use. Second order factor analysis produced three higher order factors, each with an affective and cognitive component relating to motive and strategy. This led to the development of the Study Process Questionnaire (SPQ) (Biggs, 1978), designed to measure three distinct approaches to studying, originally labelled internalising, utilising, and achieving. Biggs (1987) subsequently relabelled the factors Deep, Surface and Achieving, to bring them into line with other researchers, such as Marton and Saljo (1976a). (The SPQ is used with university students. Biggs has also developed a similar Learning Process Questionnaire for secondary school students.)

In Biggs' (1987) conceptualization, students using the deep approach are intrinsically motivated to learn. They engage in study because they are interested in the material and want to increase their level of competence in it. The strategies which they employ are aimed at maximizing understanding by focusing on meaning: they read widely and try to integrate new learning with previous relevant knowledge. A sample item from 
the SPQ is, "I try to relate new material, as I am reading it, to what I already know on that topic."

By contrast, students using the surface approach are motivated by factors which are external to the learning task (Biggs, 1993). Two motives are addressed by the SPQ: the desire to obtain a qualification, and the fear of failure. The accompanying strategies involve satisficing, or investing the minimum amount of time and energy necessary to meet requirements. A common method of accomplishing this is to rote learn selected content without understanding it. However, Biggs (1993) emphasized that the presence of rote learning by itself does not necessarily imply that the student is using a surface approach. In some circumstances, rote learning may be entirely appropriate and may in fact be a component of a deep approach. The decision to satisfice the learning task is a better indicator of the surface approach. A sample item from the SPQ is, "I generally restrict my study to what is specifically set as I think it is unnecessary to do anything extra."

Students using the achieving approach are motivated to excel regardless of interest. The approach is based on the ego-enhancement that results from visible success, particularly high grades (Biggs, 1993). Strategies involve organizing time and workspace to gain maximum benefits from study efforts. Students using this approach will seek cues from professors as to what is expected, make systematic use of study skills, plan ahead, and prioritize (Biggs, 1993). A sample item from the SPQ is, "One of the most important considerations in choosing a course is whether or not I will be able to get top marks in it." Biggs (1993) noted that, of the three approaches, only the deep approach is taskfocused. Surface and achieving are more subject to environmental influences such as 
sanctions and rewards offered by the educational institution. Biggs (1985) concluded that the deep approach has the closest links to personality factors, while the surface approach is most susceptible to situational pressures. Biggs (1985) also noted that the achieving approach is distinctly different from the other two. The strategies employed in deep and surface approaches describe ways in which students engage the content of the task, whereas achieving strategies describe ways in which students organize the context of the task. As a result, it is possible for the achieving approach to be combined with either the deep or surface approach, but deep and surface approaches appear to be mutually exclusive for any specific learning task. However, individuals may vary in their approaches to different tasks.

Biggs (1993) summarized independent studies of the SPQ and concluded that the three-factor model has generally been well confirmed. Biggs (1987) has suggested that the SPQ can have applications for teaching and counselling. Teachers could use knowledge of their students' approaches when making decisions regarding objectives and instructional and evaluational processes, so as to encourage the deep approach. Counsellors can intervene to remediate strategy deficiencies.

Although the SPQ and the ASI were developed some time ago, both continue to be used and investigated currently (Knapper, 1995; Andrews, Violato, Rabb, \& Hollingsworth, 1994; Kember, Wong, \& Leung, 1999).

Other researchers have identified similar constructs to the deep and surface approaches to leaming. For example, Dweck (1986) discussed what she called leaming or mastery orientation versus performance orientation. Mastery orientation is characterized 
by students seeking to increase their competence, understand or master something new, and attain personally challenging goals. Performance orientation, by contrast, refers to students who seek to gain favourable judgments of their competence, or avoid unfavourable judgments. Performance goals can lead to selecting less challenging tasks in order to avoid failure. The similarities between mastery or learming orientation and the deep approach to learning seem evident. Both characterize a student who is intrinsically motivated to learn and is willing to work to increase understanding. Likewise, performance orientation and the surface approach share a fear of failure and an attempt to minimize effort.

In reviewing the research on approaches to learning, the convergence of findings is notable. Despite widely different methods, ranging from Marton and Saljo's (1976) qualitative approach using intensive interviews with a few participants, to Entwistle and Ramsden (1982) and Biggs (1987) who used quantitative approaches with questionnaires and large samples, the descriptions of student approaches to learning are very similar, particularly with respect to the deep and surface approaches.

An important, and consistent, aspect of the various conceptualizations of student approaches to learning has been the focus on students' intentions: what students learn is influenced in large measure by what they intend to learn. This seems particularly true of the deep approach. Students using the deep approach are pursuing meaning and integration of knowledge. The strategies associated with the deep approach are resourceintensive: reading widely, thinking about what one has read, and making connections with prior knowledge all require time and mental effort. If students using this approach are 
going to be successful, this implies the ability to monitor their own learning progress and allocate mental resources. This leads to the topic of metacognition.

\section{Metacegnition}

In general terms, metacognition refers to monitoring of one's own memory, comprehension, and other cognitive enterprises (Flavell, 1979). More precisely, Schoenfeld (1987) defined three separate but related categories of intellectual behaviour that comprise metacognition. These are knowledge about one's own thought processes (accuracy in describing one's own thinking), control or self-regulation (self-observations of what one is doing while solving problems and using those observations to guide actions) and beliefs and intuitions (specifically, their role in shaping actions).

For any type of problem solving activity, the second category, control or selfregulation, becomes very important. Schoenfeld (1987) compared this to a management role, with several important steps: ensuring the problem is understood, planning, monitoring progress, and allocating resources such as time and effort. He cited several examples involving mathematical problems in which novice problem-solvers, despite adequate technical knowledge, tended to latch onto their first idea and pursue it doggedly even though it led nowhere. Expert problem-solvers, by contrast (even if they had less technical knowledge), were more apt to solve the problem because they monitored their own progress and abandoned unproductive avenues. He found that expert problemsolvers spent much more time thinking and analyzing the problem than novices, who tended to rush into action.

Although Schoenfeld was interested primarily in mathematical problems, his ideas 
can be generalized to other areas. For example, learning any unfamiliar topic, or preparing a demanding assignment can be seen as examples of problem-solving. Using Schoenfeld's (1987) examples, inexpert learners are likely to seize on the first strategy that occurs to them and stick to it, regardless of outcomes. Expert learners are more likely to think about the task, analyze it, and choose an appropriate strategy, which then may still be abandoned or modified if it does not yield the expected results. This seems analogous to a deep approach to learning, in which learners think about and try to make sense of the learning task. By extension, surface learners may be similar to inexpert problem-solvers, relying on familiar methods of learning even in the face of poor results. Expert learners evidently also engage in thinking and reflection, and are able to select a method or strategy which suits the task at hand. These topics will be explored in more depth later.

\section{Self-Regulation}

Self-regulatory practices, as an aspect of metacognition, have received increasing focus in research. Bouffard, Boisvert, Vezeau, and Larouche (1995) identified three major components of self-regulation: cognitive strategies required for learning, memorizing, and understanding; metacognitive strategies to supervise cognition during task execution; and motivation, which determines the amount of effort to expend. They suggested that students who engage in self-regulated learning deliberately plan each step, select strategies, and control and evaluate the effectiveness of the strategies. Bouffard et al. argued that self-regulation of learning is effortful, and therefore students are unlikely to engage in it unless they are intrinsically motivated to learn. This would suggest that students adopting the deep approach are more apt to self-regulate. 
Snow (1989) suggested that the desired end state of learning is that learners are equipped to display articulated, deep understanding of a domain, possess the ability to reason and explain aspects of that domain in causal terms, and to adopt multiple viewpoints about a phenomenon. He argued that in order to achieve this state of complex learning, a student requires deep understanding, higher order skill in learning strategies, strategic flexibility in selecting strategies, adaptive control of attention and cognition, and achievement motivation, all of which can be subsumed under self-regulation. This viewpoint is supported by the findings of Bouffard et al. (1995). They found that reported use of self-regulation was the best predictor of academic performance among their sample of university students, but in addition, students who were most apt to use self-regulating strategies were those who were preoccupied both with increasing knowledge as well as achieving a certain level of performance. Similar results were found with younger students by Pintrich and DeGroot (1990). This description of self-regulating students would appear highly similar to Biggs' (1987) description of the deep approach to learning, combined with achievement motivation.

Winne (1995) described activities of self-regulating learners. He stated that they allocate resources to tasks, seek information in the task domain, monitor progress toward study goals, and adjust their plans as needed. He argued that monitoring one's comprehension requires making inferences. Again, there is a clear connection to deep learners who habitually draw inferences from their learning in their search for meaning. Similarly, Zimmerman and Martinez-Pons (1988) concluded that self-regulating learners actively seek out information, and assistance when needed. Once again, this description 
corresponds to the deep approach to learning.

Winne (1995) sounded a cautionary note, however, that self-regulation is not always beneficial. He pointed out that monitoring cognitions is costly, in terms of attentional resources. Furthermore it is likely to be particularly costly for less knowledgeable or less able students. Lacking knowledge, they are more apt to make errors, resulting in more need for monitoring. Secondly, for less skilled students, monitoring processes are less likely to have become automatic, thereby requiring more cognitive resources. As a result, Winne argued that the mental costs of self-regulation are too high during the early stages of learning, especially for low ability, low priorknowledge students. Consequently, and particularly if there are performance demands, it may be more adaptive for these students to "fall back to a more productive but slower approach, apply algorithmic and superficial solutions to new problems, and ... not complicate matters by trying new strategies and regulating their use" (Winne, 1995, p. 178). For some students, then, surface strategies for learning may be an adaptive choice, at least at early stages of learning.

Building on previous theory and research, Cantwell and Moore (1996) accepted an argument by Winne (1995) that all learners self-regulate, albeit with varying degrees of proficiency. They suggested that one aspect of these variations in proficiency may be the individual learner's understanding of how, when, and where self-regulatory knowledge should be used. This means focusing on the individual's executive control processes, or what Snow (1989) referred to as adaptive control. Cantwell and Moore hypothesized that learners may hold either adaptive beliefs about executive control that lead to flexible 
planning and monitoring of cognitive activity, or maladaptive beliefs which may result either in inflexible use of self-regulatory processes, or confusion and uncertainty regarding the use of these processes.

Cantwell and Moore (1996) developed the Strategic Flexibility Questionnaire (SFQ) to test their hypotheses. They produced a 21 -item questionnaire which identifies three factors. The first factor, which they labelled Adaptive executive control, contained items related both to planning and monitoring of cognitive strategies. As an example, one item states, "Before starting work on a particular problem I like to play with a number of possible ways of attacking it." The second factor, Irresolute executive control, related to uncertainty and confusion in strategic behaviours ("I find that I am easily distracted from my line of thought as I am working, and this often makes my work disjointed and uneven"), while the third factor, Inflexible executive control, indicated a predisposition to use a fixed strategy regardless of task ("Once I have found a satisfying way of approaching my study, I feel it is safest to stick with this method.").

Cantwell and Moore (1998) again used the SFQ, this time in conjunction with Biggs' SPQ. The same factor structure was reported for the SFQ as in their previous (1996) study. In addition, as they had predicted, Adaptive control on the SFQ was associated with both Deep $(r=.60)$ and Achieving $(r=.38)$ approaches to learning on the SPQ. Irresolute control was associated with the Surface approach $(\Sigma=.36)$ and negatively associated with the Achieving approach $(r=-.17)$. Inflexible control was associated with the Surface approach $(r=.37)$. These associations all follow logically from Snow's (1989) discussion of factors involved in complex learning. The very high correlation between the 
Adaptive control and Deep approach scales is notable.

Need for Cognition

While educational theorists and researchers focus on cognitive activities as they pertain to learning, psychologists are interested in cognitive processes more generally. Cacioppo and Petty (1982) set out to investigate differences among individuals in their tendency to engage in and enjoy thinking. They labelled this characteristic "Need for Cognition," where "need" is used in the sense of a likelihood or tendency, rather than in a biological sense.

Cacioppo and Petty (1982) developed a questionnaire to assess need for cognition by testing items against a group of university faculty members (hypothesized high need for cognition) and a group of factory assembly-line workers (hypothesized low need for cognition). Factor analysis of the resulting 34 items produced a single factor representing people's reported tendency to engage in and enjoy thinking. Sample items include, "I like to have the responsibility of handling a situation that requires a lot of thinking" and "I like tasks that require little thought once I've learned them" (reverse coded). Follow-up studies confirmed the single-factor structure and established that neither test anxiety nor social desirability were problematic biases, providing that confidentiality of responses was assured (Cacioppo \& Petty, 1982). Subsequently, Cacioppo, Petty, and Kao (1984) produced an 18-item version of the Need for Cognition Scale (NCS), which has also been shown to replicate the single factor structure, and produces reliability coefficients almost identical to the longer version.

Since the initial development of the questionnaire, it has been used extensively in a 
variety of fields (Cacioppo, Petty, Feinstein, \& Jarvis, 1996), and descriptions of those high versus low in need for cognition have been elaborated. Cacioppo et al. (1996) suggested that although everyone must make sense of their world, those who are high in need for cognition (referred to as cognizers) tend to derive meaning, adopt positions, and solve problems differently than those who are low in need for cognition (cognitive misers). Specifically, Individuals high in need for cognition were proposed to naturally tend to seek, acquire, think about, and reflect back on information to make sense of stimuli, relationships, and events in their world. Individuals low in need for cognition, in contrast, were characterized as more likely to rely on others (e.g., celebrities and experts), cognitive heuristics, or social comparison processes to provide this structure (Cacioppo et al., 1996, p. 198).

The similarities between this description of differing levels of need for cognition and deep and surface approaches to learning can hardly be overlooked. Students employing the deep approach, like those high in need for cognition, seek out information, think about it and reflect on it to make sense of the information and to make connections with prior knowledge. Students using the surface approach, by contrast, focus on rote learning and other heuristics, in avoidance of elaborative processing. Notwithstanding that deep and surface approaches to learning are conceptualized as separate factors, whereas high and low need for cognition are seen as opposite ends of the same continuum, there appears to be considerable overlap between the constructs.

Similarly, parallels exist between need for cognition and Cantwell and Moore's 
(1996) ideas of strategic flexibility. Winne's (1995) discussion of mental resources required for cognitive monitoring suggests that cognizers, with their habit of engaging in mental reflection, would have the advantage over cognitive misers. Cognitive monitoring processes would be more likely to have become automatic, to use Winne's term, for those who are high in need for cognition. Consequently, the required mental resources for monitoring would be reduced, increasing the ability to engage in self-regulated learning, or in Cantwell and Moore's terms, to demonstrate adaptive executive control. Likewise, Snow (1989) referred to the mental effort investment necessary for self-regulated learning. He stated that some learners display a high level of mental effort avoidance, which might be construed as low need for cognition. Cantwell (1994) equated need for cognition and strategic flexibility, by classifying both as "third order" self-regulatory control schemes. Cantwell defined these third order schemes as executive level, concerned with problem identification, goal setting, and monitoring of goal-consistent progress. In contrast, first order schemes refer to specific knowledge and procedures used for goal attainment, while second order schemes act on these procedures and knowledge in goal-related cognitions such as learning strategies. Referring back to Kirby's (1988) definitions cited previously, Cantwell's first order schemes relate to tactics and second order schemes relate to strategies. The executive nature of third order schemes places them closer to Biggs' (1985) definition of approaches than to Kirby's definition of styles.

Following up on this hypothesized connection between need for cognition and strategic flexibility, Cantwell and Monfries (1999) compared responses on the 34-item NCS to a version of the SFQ modified to reflect self-regulatory control of strategies for 
social situations rather than academic ones. As predicted, Need for Cognition was positively associated with Adaptive control $(\Sigma=.23)$ and negatively associated with Irresolute control $(\mathrm{I}=-.15)$. Somewhat surprisingly, Need for Cognition was not correlated with Inflexible control. However, the authors speculated that this may have been due to the modifications which they made to the SFQ.

At this point, it is helpful to refer back to Schoenfeld's (1987) description of expert problem solvers, and the extensions that were drawn to expert learners. It was proposed that expert learners would spend time thinking about the task (need for cognition), would attempt to understand the learning and draw meaning from it (deep approach), and would select appropriate strategies (adaptive control) in order to accomplish this. Inexpert learners might fail at any of these steps: failure to think about the task, not motivated to seek meaning in it, reliance on an inappropriate strategy, or inability to select a good strategy. Linkages between need for cognition, approaches to leaming, and strategic control become apparent.

Demographic Characteristics

A variety of demographic variables have been studied relating to the SPQ and NCS. To date, no information has been reported in this respect for the SFQ. It should be noted that, in all of the following reported findings, studies with the SPQ involved exclusively university students, while studies with the NCS involved more varied populations.

The NCS has been shown to be gender neutral (Cacioppo et al., 1996). The SPQ, on the other hand, has indicated that male university students are higher on the surface 
approach while females are higher on the achieving approach (Biggs, 1987).

Need for cognition has shown a weak but significant positive correlation with education level (Cacioppo et al., 1996). The SPQ produced a more complicated picture with interactions between faculty and year of study, but the most striking aspect is a decline in the deep approach for Science students across years of study (Biggs, 1987). (Although Biggs' data were from cross-sectional studies, Watkins and Hattie [1983, as cited in Biggs, 1987] found the same pattern in a longitudinal study employing Entwistle and Ramsden's [1982] Approaches to Studying Inventory.) With respect to faculty in general, the SPQ showed Science students higher on the surface and achieving approaches, and Arts students higher on the deep approach (Biggs, 1987).

According to Cacioppo et al. (1996), only one published study has looked at socioeconomic status and the NCS; it reported no significant correlation between income and need for cognition. For the SPQ, children of parents with post-secondary education scored lower on the surface approach and higher on the deep approach (Biggs, 1987).

Finally, the NCS has shown a small negative correlation between need for cognition and age (Cacioppo et al., 1996). The SPQ, by contrast, showed a sharp increase in both deep and achieving approaches and an accompanying decline in the surface approach beyond approximately age 22 (Biggs, 1987). Again, it must be remembered that the SPQ sample consisted of only university students, so this finding referred to mature students. Mature students are probably not typical of the average population. They have often given up a lot to attend university and are highly motivated to learn. It seems reasonable that if the NCS were administered to this select group, the results would not 
show the same decline in need for cognition, but, perhaps, an increase comparable to the increase in the deep approach to learning.

The Present Study

Overall, based on descriptions of the constructs as well as evidence from previous studies, there appear to be a great many linkages between the constructs measured by the deep approach from the SPQ, need for cognition, and adaptive control from the SFQ. Notwithstanding that both the SPQ and SFQ were designed to have orthogonal factors, the description of the surface approach carries a suggestion of being the opposite, or the absence, of the deep approach, and irresolute and inflexible control have a similar sense of representing the opposite or absence of adaptive control. It should be noted that previously reported studies of the SPQ and SFQ have generally relied on varimax factor rotation, which precludes factors from being correlated. A question arises, therefore, as to whether it is possible that the three questionnaires are actually measuring the same construct(s). To date, no one has conducted a study directly comparing all three questionnaires, and it appears that no one has done a direct comparison of just the SPQ and NCS. It seems possible that the Deep, Surface, Need for Cognition, Irresolute, Inflexible, and Adaptive scales might all be acting as indicators of a single underlying factor. Figure 1 , for example, might offer a reasonable representation of relationships among the various scales and sub-scales in relation to a single factor, where the deep approach, need for cognition, and adaptive control would load positively, while the surface approach, inflexible control, and irresolute control would load negatively. The achieving approach has been left out of this model, because it appears to be qualitatively 
different from the other constructs. The underlying motivation for the achieving approach appears to be ego-enhancement which sets it in a different category from the other constructs. No specific predictions are therefore made with respect to it.

Figure 1. Model depicting relationships for a single construct.

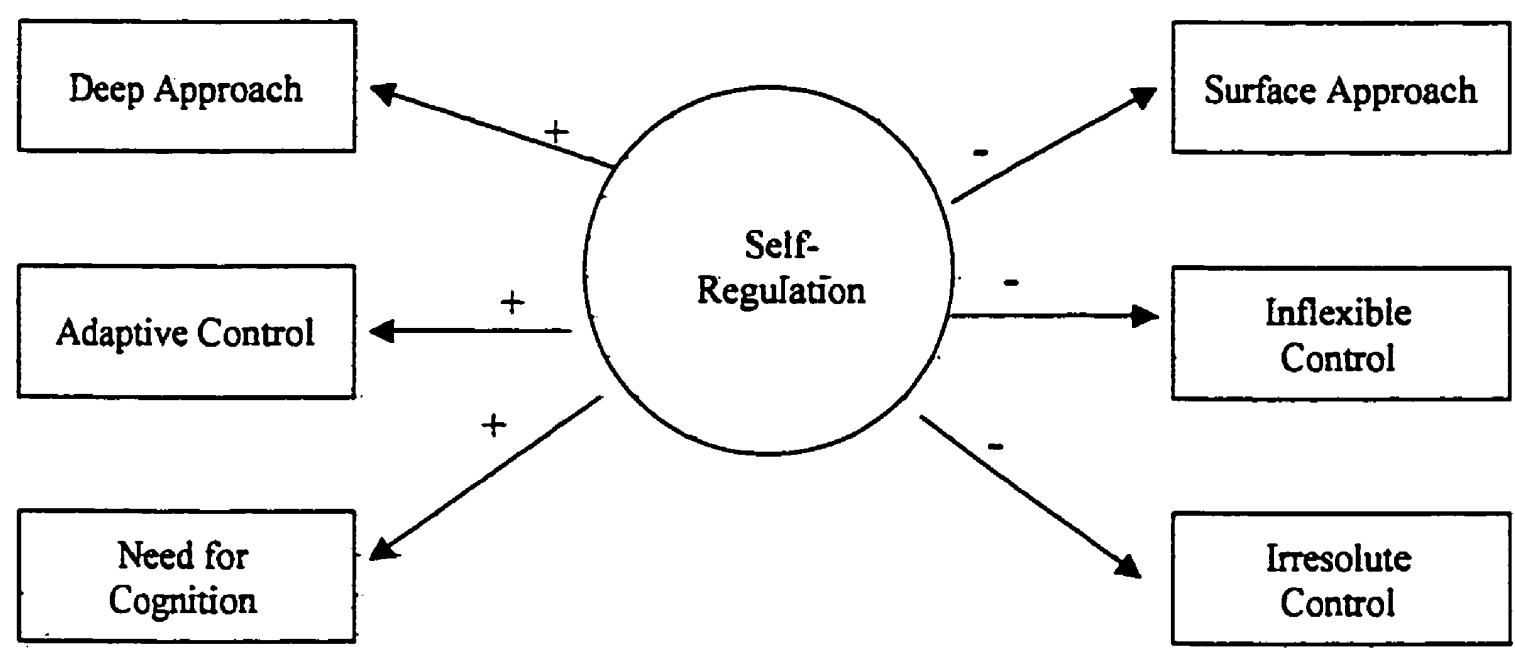

If the model in Figure 1 is an accurate representation, the underlying construct would describe someone with the following characteristics: seeks meaning, thinks about concepts, makes connections between new and prior learning, is flexible in approaching learning tasks, and is intrinsically motivated to learn. The person would not tend to 
satisfice or minimize effort, would not be extrinsically motivated, would not be confused or overwhelmed by learning tasks, and would not rely on just one or two preferred methods for studying. The positive aspects of this construct appear to reflect Bouffard et al.'s (1995) description of a self-regulated learner and the label has been chosen accordingly. The negative aspects, on the other hand, would represent something that might be called "ineffective learning", which in this model is hypothesized to be the opposite of self-regulated learning. This label has been chosen because of Winne's (1995) contention that effective learning is self-regulated, whereas the surface approach, inflexible control, and irresolute control clearly do not represent self-regulated learning.

On the other hand, if the deep approach is not the opposite of surface, and adaptive control is not the opposite of inflexible or irresolute, a two factor solution might explain the relationships. As shown in Figure 2, this model would have deep, need for cognition, and adaptive loading on one factor, while surface, inflexible, and irresolute load on the other. The two factors might or might not be negatively correlated. The main difference between the models in Figure 1 and Figure 2 is that the model in Figure 2 does not necessarily imply that ineffective learning is the opposite of self-regulated learning, although they would probably be negatively correlated. 
Figure 2. Model depicting relationships for two constructs.

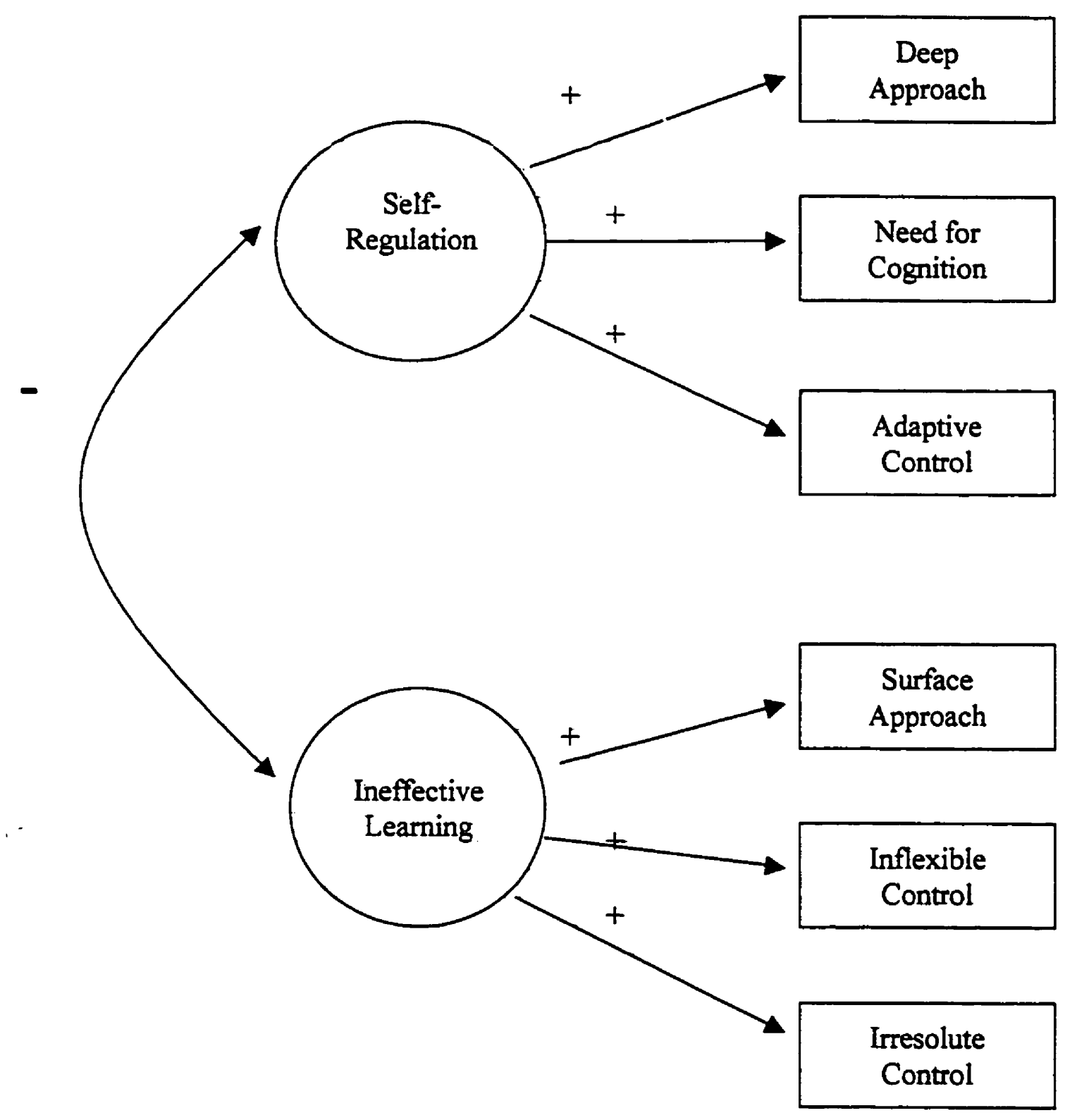


If the scales are not all measuring the same things, one potential area of difference between the NCS and the other two questionnaires is that need for cognition may represent a more general characteristic, whereas approaches to learning and selfregulatory control may be more specific to the context of academics. As a result, selfreports of academic performance will be collected in an attempt to clarify this relationship. In theory, need for cognition should show a weaker correlation with academic performance if it is less closely tied to the academic context.

The purpose of this study therefore is to undertake a comparison of the SPQ, the SFQ, and the NCS, to determine the relationships among the constructs measured by the three questionnaires, with the hypotheses that the six scales of interest (Deep, Need for Cognition, Adaptive, Surface, Inflexible, and Irresolute) may all be tapping one construct related to Self-Regulation, or, alternatively, two constructs, a Self-Regulating factor and an Ineffective Learning factor. It will also investigate relationships between the scales and various demographic characteristics, and will provide validity evidence for the SFQ. Thus far the SFQ has only been used with Australian samples; the present study will investigate whether the constructs which it measures can be reproduced in a Canadian sample.

There are several reasons for doing this study. One reason is to investigate possible redundancy among the questionnaires if they are measuring the same things. Another reason is to provide a link between similar constructs from the disciplines of education and psychology. Finally, if the scales are not measuring the same things, the study may serve to elaborate the constructs by enhancing knowledge of the relationships among them. 


\section{Chapter Two}

\section{Method}

\section{Participants}

Two of the three questionnaires, the SPQ and the SFQ, were specifically designed for university students. Accordingly, a sample of university students was sought, and was found among students at a Canadian military college. This institution is a fully accredited university, granting degrees in the faculties of Arts, Sciences, and Engineering. Undergraduate students attend a four-year programme. The college offers students paid tuition, a small salary while attending university, and guaranteed employment on graduation. This incentive ensures that the college is able to select quality students from a large applicant pool.

Most undergraduate students at the college enrol directly on completion of high school. However, in-service programmes allow serving members of the Canadian Forces to compete for the opportunity to attend university full time. This results in a few older ("mature") undergraduate students. In addition, a part-time programme has recently been inaugurated for serving members, adding a few more older students to the classes.

Participants in the study were first year students at the college enrolled in mandatory introductory psychology classes. Participants were offered a chance to enter a draw for a $\$ 25.00$ gift certificate from a local restaurant.

A total of 230 students completed the questionnaire. Of those, 81 completed it in French and 149 completed it in English. For the most part, respondents reported that their primary language was the same as the language in which they completed the questionnaire. 
Exceptions were as follows: two participants who completed the questionnaire in French claimed English as their primary language, three who completed the questionnaire in English claimed French as their primary language, and three participants (one who completed the questionnaire in French and two who completed it in English) indicated other primary languages (Korean, Chinese, and Hungarian). All students completed the questionnaire in the same language as the class in which they were enrolled. In other words, the three who completed the questionnaire in English, but claimed French as their primary language, were also attending class in English, by choice. Since the total percentage of mismatches is small (3.5\%), for the sake of convenience, those who completed the questionnaire in French will be referred to as francophones, and those who completed it in English will be referred to as anglophones. Sixty-six students were female, 163 were male, and one student did not indicate gender. Four response forms had to be discarded due to missing data (details reported under Results). Coincidentally these consisted of one francophone male and female, and one anglophone male and female. Consequently, this left 64 females, 161 males, and one unknown gender, and 79 francophones and 147 anglophones, as shown in Table 1.

Students ranged in age from 17 to 43 years. However, the vast majority (202, or $89 \%$ ) were between 17 and 20 years of age. An additional $16(7 \%)$ were between 21 and 29 years of age. 
Table 1.

Representation of the Sample by Gender and Language

Language

Male

English

French

Total
108

53

161
Gender

Female

39

25

64
Unknown Total

0

147

1

79

226

\section{Materials}

Participants were provided with a booklet which included, in the following order, a covering letter, demographic questions, the 18-item NCS, the 42-item SPQ, and the 21item SFQ. The NCS was placed first to avoid artificially introducing a context, since need for cognition is hypothesized to be a more general characteristic, not specifically related to academic study as is the case for the constructs measured by the SPQ and SFQ.

Since the college is bilingual (English/French), all questionnaires were translated into French for this study. Although back translation was not done, the translated items were independently verified twice, once by a bilingual francophone and once by a bilingual anglophone. Booklets were handed out in the language of the class, but students were advised that booklets were available in the other official language if they preferred. As noted, all students completed the questionnaires in the same language as the class in which 
they were enrolled.

All responses were indicated on a five point scale, where $(1)=$ strongly disagree, (2) = disagree, $(3)=$ neutral, $(4)=$ agree, and (5) = strongly agree. Responses were circled directly in the question booklets. Half of the items in the NCS are negatively worded: all items in the SPQ and SFQ are positively worded.

The instructions preceding the SPQ and SFQ advised that, if students felt a particular answer would depend on the context, they should answer with respect to courses in their major.

Two of the questionnaires, the NCS and the SFQ, are shown in Appendix A. The SPQ is not, because it is protected by copyright. The items are published in Biggs (1987). Procedure

Permission was obtained to administer the questionnaires to students during class time in their introductory psychology classes. All data were collected by the researcher who was unknown to the students. The three professors who provided class time stressed to their students that participation was voluntary and carried no academic implications. This was reiterated by the researcher and in the covering letter (Appendix B). Participants signed a consent form (Appendix C).

Data were collected from seven classes, ranging in size from approximately 17 to approximately 55 . In all cases, the overwhelming majority of students chose to participate. The number of students who chose not to participate was not recorded, but would have totalled no more than 10 to 15 . 


\section{Chapter Three}

Results

\section{Inspection of Data}

A preliminary inspection of the response forms revealed that there was very little missing data. Four response forms were discarded as three respondents had failed to finish the questionnaires and one had missed a page of items. All four were missing responses to more than $10 \%$ of the total items, so it was felt that any attempt to replace the data would risk introducing unacceptable bias.

Of the remaining 226 individuals, only 17 had missed items on any of the three questionnaires. Sixteen of these participants had missed only one item, and one participant had missed two items. Out of the total number of responses to items $(18,306)$, this means that missing data represented less than $.10 \%$. There did not appear to be any patterns in the missing data, as only two items (item 6 on the NCS and item 31 on the SPQ) were missed by more than one person. Those items were each missed by two people.

Since the missing data were few and appeared to be random, they were replaced with the group means for the respective items. The mean is non-biasing, and it was felt that there was no need to waste large quantities of good data because of very small amounts of missing data.

To assess the extent to which item responses for the three questionnaires were normally distributed, means, standard deviations, skewness and kurtosis values were calculated, along with standard errors for skew and kurtosis. The results appear in 
Appendix D. As can be seen, responses to many items were skewed, or kurtotic, or both. However, many analyses are robust with respect to violations of normality, providing that samples are reasonably large (Glass \& Hopkins, 1996). Specific criteria, described later, were used to assess normality for the purposes of factor analysis.

\section{Representativeness of the Data}

Given that the sample was drawn from a somewhat unique population (military college students), it was desirable to assess whether the data were similar to results from other populations. This could only be done by comparing total scores on some of the scales.

Normative values have not been established for the NCS; comparisons of "high" and "low" need for cognition have been done purely on a relative basis (J. Cacioppo, personal communication, February 2, 2000). Consequently, there was no way to compare the current sample.

Several comparisons were available for the scales on the SPQ. Means (and standard deviations, where they were available) from previous studies are shown in Table 2. As can be seen, students in the current study indicated higher use of both the deep and achieving approaches than was typical of reported values for Australian or British students. However, their scores on those two scales are very similar to first and second year diploma nursing students at a Canadian college, studied by Doherty (1991). 
Table 2.

Comparison Values for Mean Scale Scores on the SPQ

\begin{tabular}{lcccc} 
Scale & Australian $^{\mathrm{a}}$ & British $^{2}$ & Canadian College $^{\mathrm{b}}$ & Current Sample \\
& $\mathrm{N}=2240$ & $\mathrm{~N}=181$ & $\mathrm{~N}=91$ & $\mathrm{~N}=226$ \\
Deep Approach & 44.0 & 45.2 & $48.8(3.42)$ & $48.8(6.79)$ \\
Surface Approach & 43.4 & 42.2 & $47.9(6.67)$ & $44.8(7.45)$ \\
Achieving Approach & $40.1^{\circ}$ & 39.4 & $45.5(7.08)$ & $46.5(6.61)$ \\
\hline
\end{tabular}

Biggs, 1987

b Doherty, 1991

The SFQ is still a very new scale, so comparison groups were limited. Previously the SFQ had only been used in Australia. Cantwell (1994) provided means for two groups of students. These are shown in Table 3, along with means from the current study. As can be seen, students in the current study obtained similar results to Cantwell's nursing students on inflexible and irresolute control, but obtained higher scores on adaptive control. 
Table 3.

Comparison Values for Scale Scores on the SFQ

\begin{tabular}{lccl}
\hline Scale & $\begin{array}{l}\text { Australian } \\
\text { BEd Students }\end{array}$ & $\begin{array}{l}\text { Australian } \\
\text { Nursing Students }\end{array}$ & $\begin{array}{l}\text { Current } \\
\text { Study }\end{array}$ \\
\hline Adaptive Control & $\mathrm{N}=101$ & $\mathrm{~N}=207$ & $\mathrm{~N}=226$ \\
Inflexible Control & $18.39(4.98)$ & $20.12(4.66)$ & $22.98(3.89)$ \\
Irresolute Control & $21.76(4.91)$ & $23.04(5.35)$ & $23.58(4.53)$ \\
\hline 2antrell (1994) & $19.42(5.17)$ & $20.41(5.35)$ & $20.40(4.22)$ \\
\hline
\end{tabular}

\section{Verification of Constructs}

Since the French versions of the questionnaires were created for this study and had not previously been validated, it was necessary to assess whether the data for anglophones and francophones could be combined. Additionally, the numerical imbalance between males and females led to some concerns, although there was no reason to suspect gender differences based on previous research with all three questionnaires. Finally, it was necessary to ensure that the data from this study conformed to the hypothesized underlying factor structure for each of the three questionnaires.

Initially t-tests were conducted to test for item differences based on gender and language. The results are shown in Appendix E. Using an alpha of .01, five items (6.2\%) were significantly different for males and females, and fourteen items (17.3\%) were significantly different for anglophones and francophones. However, for the most part 
differences appeared to be quantitative rather than qualitative. That is, means tended to be in the same direction from the mid-point, but were more extreme for one group. These items were noted for possible problems in factor analysis.

Exploratory factor analyses were conducted on all three questionnaires separately, to investigate whether the expected factor structure had been replicated. In all cases, analyses were conducted three times: with anglophone data only $(N=147)$, with male data only $(N=161)$, and with the full data set $(N=226)$. This was done to see if adding the francophone data or the female data changed the factor structure. There were insufficient numbers of francophones, females, or even male anglophones to conduct meaningful factor analyses on these groups alone. Except as noted, in all cases, factor structures reported below were replicated regardless of whether anglophone data, male data, or the full data set was used. In all cases, structure was cleanest when the full data set was used, no doubt due to the increased sample size.

The use of exploratory factor analysis could be questioned in this context because the intent was to confirm the presence of constructs the scales are designed to measure. However, exploratory analysis was chosen in preference to confirmatory factor analysis because the exploratory methods are driven by the data whereas confirmatory methods are used to test the fit of models specified by the researcher, and are best used to compare a small number of competing models (Fabrigar, Wegener, MacCallum, \& Strahan, 1999). If the hypothesized constructs were not well represented in the current data, there was no theoretical basis on which to propose an alternate model to test with confirmatory techniques. Therefore exploratory techniques appeared to be the better choice. 
All factor analyses reported were done in SPSS using the Maximum Likelihood (ML) method of factor extraction, except where noted. The ML method was chosen because it allows computation of indices of goodness of fit of the model (Fabrigar et al., 1999). A measure of chi-square is calculated in the ML solution, but this is not the best test of the model's fit because chi-square is susceptible to sample size. However, the value of chi-square, degrees of freedom, and sample size can be used to compute Root Mean Square Error of Approximation (RMSEA). RMSEA is an estimate of the discrepancy between the model and the data per degree of freedom for the model (Fabrigar et al., 1999). This provides a test of model fit which is less sensitive to sample size.

A limitation of $\mathrm{ML}$ is that it rests on the assumption of multivariate normality (Fabrigar et al., 1999). However, empirical tests have shown ML to yield appropriate solutions providing that univariate normality is not severely violated (e.g., skew statistic > 2; kurtosis > 7; West, Finch, \& Curran, 1975; as cited in Fabrigar et al., 1999). The data for the present study were checked for univariate normality and none of the items reached or exceeded these criteria, as can be seen from Appendix D.

Where more than one factor was extracted, rotation was done using the direct quartimin (direct oblimin with delta equal to zero) method. This method allows, but does not constrain, factors to be correlated.

NCS

The NCS was analyzed first. The scree plot, shown in Figure 3, clearly supported one dominant factor. (All scree plots show eigenvalues from the unreduced correlation matrices.) This factor accounted for $21.74 \%$ of the variance which is comparable to 
results reported previously (Cacioppo et al., 1996). Only two items ( 8 and 18) failed to achieve loadings of at least .30 . Neither of these items resulted in t-test differences for either gender or language.) Cronbach's alpha for the 18 items was calculated at .82 , which again corresponds to previous research. Deletion of either item 8 or 18 resulted in only trivial increments to alpha.

Figure 3. Scree Plot for the Need for Cognition Scale (NCS)

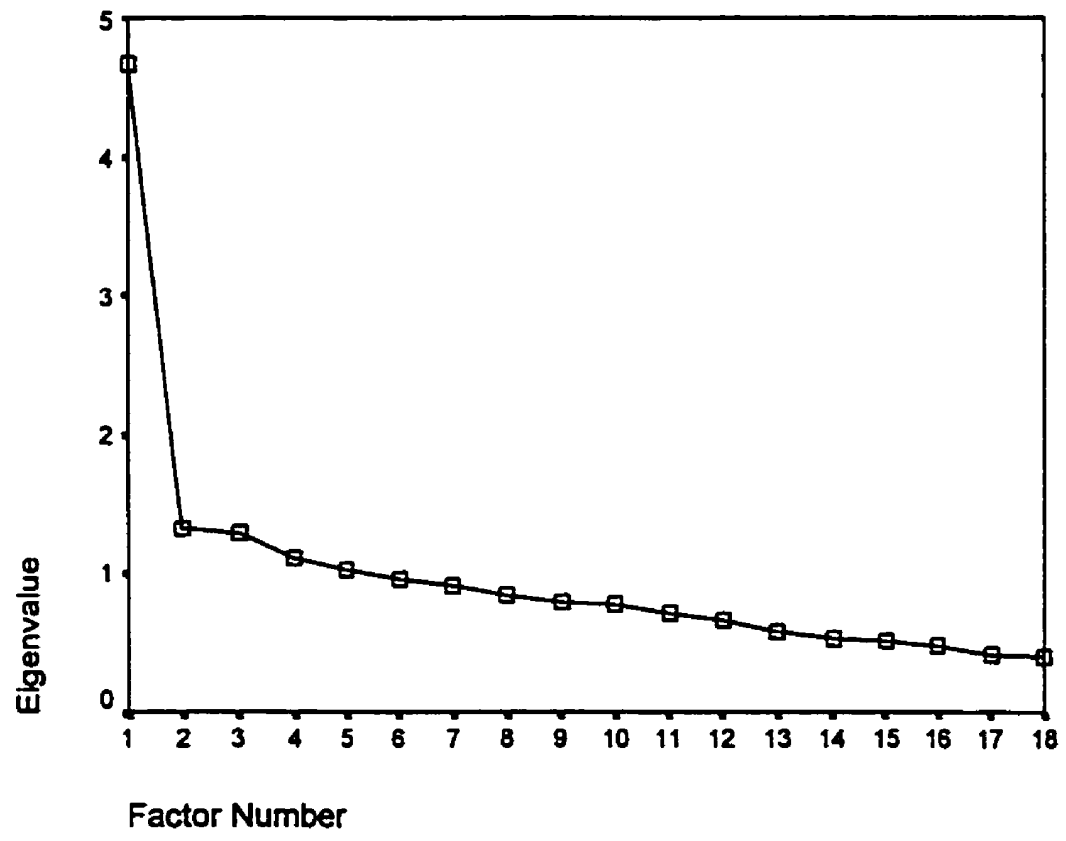

A value for RMSEA was calculated using the program FITMOD (Browne, 1992). It has been suggested that values of RMSEA less than .05 represent good fit, values between .05 and .08 represent acceptable fit, values between .08 and .10 represent marginal fit, and values greater than .10 represent poor fit (Fabrigar et al., 1999). For a single factor solution ( $95 \%$ confidence intervals are shown in brackets), $\mathrm{RMSEA}=.051$ 
$(.035, .066)$, indicating acceptable fit. When RMSEA was calculated for solutions with more than one factor, the fit index improved ( 2 factors, RMSEA = .047 $(.027, .063)$;

3 factors, RMSEA $=.039(.012, .058))$; however, the confidence intervals overlap indicating that improvement is, at best, marginal. Furthermore, the two and three factor solutions were uninterpretable and contrary to theory. Therefore, the single factor solution appears to be appropriate. Factor loadings for the one factor solution are shown in Table 4. Abbreviated versions of the items have been included for clarity.

Table 4.

Eactor Loadings for the NCS. Single Factor Solution

Item

Factor Loading

1. Prefer complex problems

2. Situations requiring thought

3. Thinking is not fun*

4. Prefer ... little thought*

5. Avoid deep thinking*

6. Enjoy deliberating

7. Only think as hard as have to*

8. Prefer small projects*

9. Like ... little thought*

10. Like to think way to the top

11. Enjoy finding new solutions

12. Don't like new ways to think*

13. Prefer life filled with puzzles

14. Thinking abstractly appeals

15. Prefer intellectual tasks

16. Relief after mental effort* 
SFQ

The SFQ was analyzed next. The scree plot, shown in Figure 4, clearly supported three factors, which collectively accounted for $36.35 \%$ of the variance. This is substantially lower than the $49 \%$ reported by Cantwell and Moore (1996, Study 2 ) or the 46.2\% reported by Cantwell and Monfries (1999). This may be due to the use of ML factor extraction instead of principal components. Principal components analysis produces higher estimates of variance accounted for because it does not distinguish between common and unique variance (Fabrigar et al., 1999).

The three factor solution resulted in an almost textbook-perfect correspondence of items to factors. Only two items (\#2 and \#19) failed to achieve loadings of .30 or greater, and those items still achieved their highest loading on the appropriate factors (Irresolute and Adaptive, respectively). Neither of these items had produced t-test differences for either gender or language. All items loaded on the appropriate factors and no items loaded highly on more than one factor. Factor loadings and correlations are shown in Table 5. In this and subsequent tables, in addition to short forms of the items, an indication has been given of the factor the item is intended to load on. Abbreviations are as follows: $\mathbb{N}=$ Inflexible, $\mathbb{R}=$ Irresolute, and $A D=$ Adaptive. Factor loadings of .300 or higher have been shown in bold. Factors were correlated minimally, with Inflexible and Irresolute showing a positive correlation while both were negatively correlated with Adaptive. A four factor solution was attempted, as a check on the number of factors extracted, and accounted for $39.10 \%$ of the variance. However, this solution resulted in overfactoring, as one Inflexible item (negative loading) and one Adaptive item split off to 
form the fourth factor.

Figure 4. Scree Plot for the Strategic Flexibility Questionnaire (SFQ)

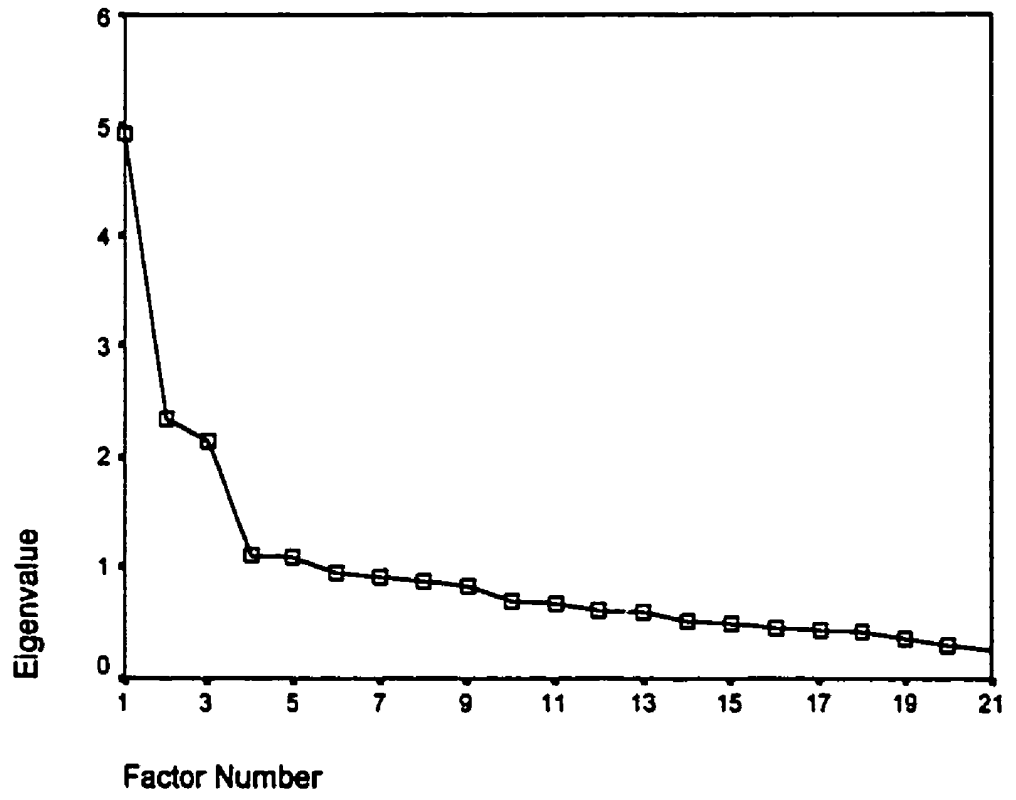

RMSEA was calculated using FITMOD, and produced a value of $.052(.037, .066)$ for the three factor solution, indicating acceptable fit. For the four factor solution, RMSEA $=.047(.029, .062)$. The substantial overlap in confidence intervals suggests that any improvement in fit is, at best, marginal. Therefore the three factor solution appears optimal.

Cronbach's alpha was calculated for each of the subscales of the SFQ. For Inflexible, alpha $=.83 ;$ for Irresolute, alpha $=.72 ;$ and for Adaptive, alpha $=.73$ (using the 
whole data set). These values are lower than reported for Cantwell and Moore (1996) for the Irresolute and Adaptive scales, but still respectable.

Table 5.

Eactor Loadings for the SFQ. Three Factor Solution

Item

Factor $1 \quad$ Factor $2 \quad$ Factor 3

Inflexible Irresolute Adaptive

1. One method for assignments (IN)

.438

.172

2. Get confused by new ideas (IR)

$-.068$

.112

.124

3. Adjust study methods (AD)

.621

.228

$-.068$

4. Stick to trusted study methods (IN)

.641

.018

.479

5. Stick with normal work methods (IN)

$-.080$

.038

.056

6. Think of different approaches (AD)

.035

$-.122$

7. Hard to fit material to assignment plan (IR)

.150

$-.112$

.544

8. Hardest part of assignment is how to do (IR)

.019

9. Different ways to study ... challenging (AD)

10. Use usual study methods (IN)

11. Like exploring different ways $(A D)$

$-.001$

12. Stick to satisfying study approach (IN)

.134

.323

.074

$-.215$

.536

$-.126$

.600

13. Rarely change the way I study (IN)

.778

.110

$-.111$

14. Enjoy finding new methods $(A D)$

$-.133$

$-.012$

$-.085$

15. Difficulty ... how to use information (IR)

.022

.589

$-.186$

.736

$-.069$

16. Lose focus dealing with detail (IR)

$-.108$

.699

17. New ways to do assignments (AD)

18. Use same study methods (IN)

$-.042$

$-.039$

.715

.796

$-.025$

$-.052$

$-.287$

$-.100$

20. Know general ideas about topics (IR)

21. Easily distracted while working (IR)

.002

.560

$-.058$

Correlations:

Factor 1 (Inflexible)

Factor 2 (Irresolute)

Factor 3 (Adaptive) 
SPQ

It proved somewhat more difficult to establish an acceptable solution for the SPQ that was stable across all three analyses (anglophones, males, whole data set). The scree plot, shown in Figure 5, was inconclusive, but supported three or four factors. A three factor solution was attempted first, based on theory, and it accounted for $24.29 \%$ of the variance. Comparisons were sought in the literature, but it appears that percentage of variance accounted for has not commonly been reported for item level analyses with the SPQ. The three factor solution was not easily interpreted, as one factor consisted of predominantly Surface items, but Deep and Achieving items were mixed on the other two factors. Based on this result, a two factor solution was attempted which accounted for $20.34 \%$ of the variance. For the entire data set, this was more or less interpretable in terms of Surface-Competitive (Surface items and Achieving items which related to competition), and Deep-Achieving. However, this factor structure was not stable when applied to anglophone data only or male data only.

A four factor solution was then attempted. This accounted for $27.55 \%$ of the variance, and produced a reasonably stable solution when applied to anglophone data, male data, or the full data set. The resulting factors were interpretable as Surface, Deep, Achieving Motive, and Achieving Strategy, and this structure replicated for males and anglophones. This solution is reasonably consistent with theory. Factor loadings and correlations are shown in Table 6 . In this and subsequent tables, $\mathrm{S}=$ Surface approach, $\mathrm{D}=$ Deep approach, and $\mathrm{A}=$ Achieving approach. Correlations between factors were low, with the highest correlations appearing between Deep and Surface (negative 
Figure 5. Scree Plot for the Study Process Questionnaire (SPQ)

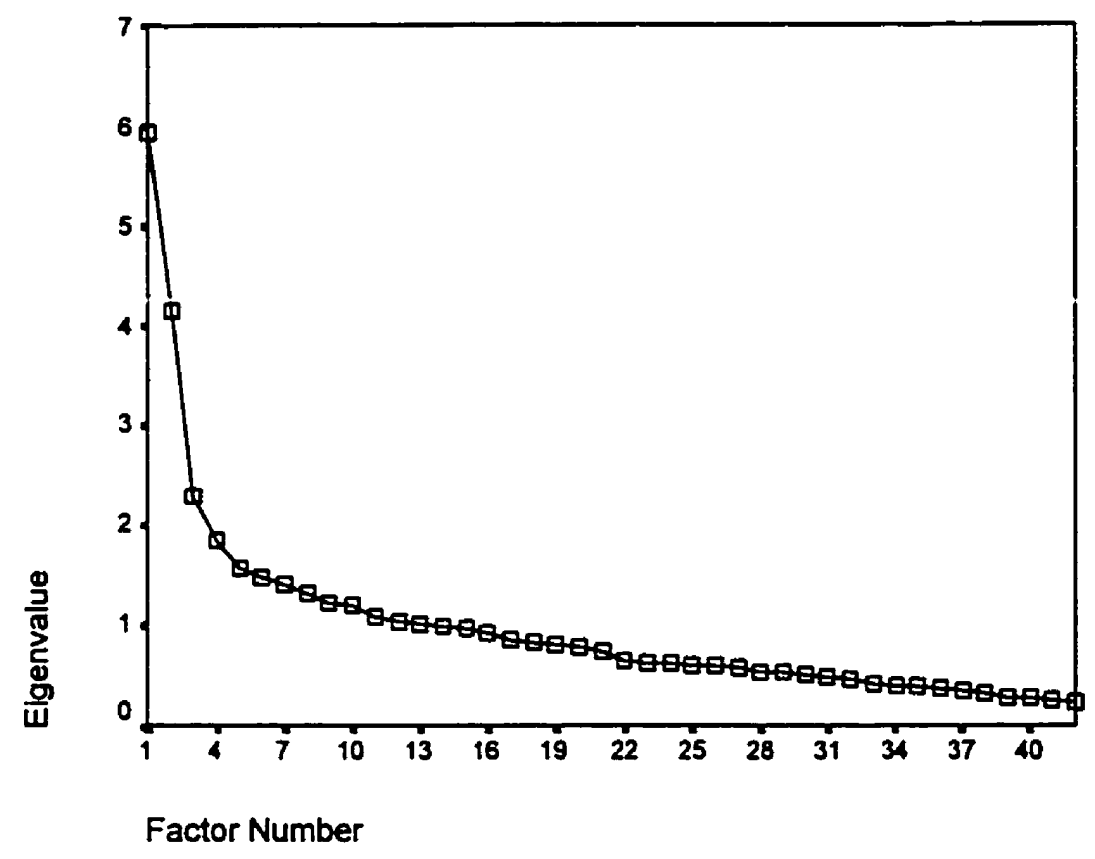

correlation) and between Deep and Achieving Motive (positive correlation). A

five factor solution was also attempted, which accounted for $29.87 \%$ of the variance. However, the main difference between the four factor and five factor solutions was that the Surface factor split in two. This indicates that the solution was overfactored, based on theory.

The Achieving scale on the SPQ was not really of interest in this study, so because the Achieving items appeared to be causing problems for the factor analyses, factor analyses were also conducted using only the Deep and Surface items. The scree plot supported two or three factors as shown in Figure 6. A three factor solution accounted for $26.7 \%$ of the variance. The three factors were roughly interpretable as Surface, 
Table 6.

Eactor Loadings for the SPQ. Four Factor Solution

\begin{tabular}{|c|c|c|c|c|}
\hline Item & $\begin{array}{l}\text { Factor } 1 \\
\text { Achieve } \\
\text { Strategy }\end{array}$ & $\begin{array}{l}\text { Factor } 2 \\
\text { Surface }\end{array}$ & $\begin{array}{l}\text { Factor } 3 \\
\text { Deep }\end{array}$ & $\begin{array}{l}\text { Factor } 4 \\
\text { Achieve } \\
\text { Motive }\end{array}$ \\
\hline 1. Study program based on joos (S) & -.144 & .503 & -.001 & .195 \\
\hline 2. Studying gives satisfaction (D) & .325 & -.120 & .134 & .155 \\
\hline 3. Top grades to get a good job (A) & -.001 & -.044 & -.079 & .750 \\
\hline 4. Only study what is assigned (S) & -.217 & .456 & -.125 & .024 \\
\hline 5. Think of real life applications (D) & -.094 & .080 & .477 & -.034 \\
\hline 6. Summarize suggested readings (A) & .389 & .029 & -.030 & .149 \\
\hline 7. Poor test mark discourages me (S) & .082 & .414 & .079 & .123 \\
\hline 8. Discover personal truths (D) & -.216 & -.135 & .365 & .175 \\
\hline 9. Want to excel in studies (A) & -.034 & -.030 & -.025 & .826 \\
\hline 10. Learn some things by rote $(S)$ & .247 & .394 & -.075 & .166 \\
\hline 11. New material reminds of previous (D) & .044 & -.080 & .444 & .096 \\
\hline 12. Work consistently through term (A) & .517 & -.039 & .034 & .213 \\
\hline 13. Education leads to a good job (S) & .015 & .265 & .201 & .337 \\
\hline 14. Any topic can be interesting (D) & .277 & -.038 & .372 & -.055 \\
\hline 15. I am ambitious (A) & .068 & .091 & .070 & .485 \\
\hline 16. Choose factual subjects (S) & .104 & .232 & -.169 & -.004 \\
\hline 17. Need to form own viewpoint (D) & .175 & .026 & .315 & .130 \\
\hline 18. Try to do assignments early (A) & .542 & -.006 & -.027 & .177 \\
\hline 19. Tests worry me (S) & .186 & .310 & .104 & -.046 \\
\hline 20. Studying can be exciting (D) & .265 & -.349 & .182 & .036 \\
\hline 21. Sacrifice popularity for success (A) & .087 & -.181 & .004 & .202 \\
\hline 22. Restrict study to assigned (S) & -.218 & .611 & -.029 & -.053 \\
\hline 23. Relate one subject to another (D) & -.124 & -.028 & .796 & -.083 \\
\hline 24. Reread notes for understanding (A) & .543 & .025 & .054 & -.040 \\
\hline 25. Shouldn't study non-tested material (S) & -.130 & .503 & -.022 & -.046 \\
\hline 26. Increasingly absorbed as I work (D) & .160 & -.210 & .321 & .033 \\
\hline 27. Choose courses to get top marks (A) & .176 & .374 & -.080 & -.006 \\
\hline 28. Learn best if profs outline points (S) & .111 & .353 & -.032 & -.042 \\
\hline 29. Find new topics interesting (D) & .290 & -.335 & .094 & .074 \\
\hline 30. Test myself to understand topic (A) & .230 & .025 & .225 & .144 \\
\hline 31. Resent time at university (S) & -.003 & .395 & -.075 & -.063 \\
\hline 32. Need to discover my philosophy (D) & .086 & -.074 & .343 & .126 \\
\hline 33. Grades are competition to win (A) & .072 & .193 & -.034 & .517 \\
\hline 34. Rarely question profs (S) & .293 & .343 & -.079 & -.091 \\
\hline 35. Free time reading class topics (D) & .266 & -.398 & .147 & .012 \\
\hline 36. Read suggested readings (A) & .424 & -.295 & -.014 & .075 \\
\hline 37. At university to get better job (S) & -.020 & .667 & -.007 & .100 \\
\hline
\end{tabular}

Table 6 continues 
Table 6. (continued)

\begin{tabular}{|c|c|c|c|c|}
\hline Item & $\begin{array}{l}\text { Factor } 1 \\
\text { Achieve } \\
\text { Strategy }\end{array}$ & $\begin{array}{l}\text { Factor } 2 \\
\text { Surface }\end{array}$ & $\begin{array}{l}\text { Factor } 3 \\
\text { Deep }\end{array}$ & $\begin{array}{l}\text { Factor } 4 \\
\text { Achieve } \\
\text { Motive }\end{array}$ \\
\hline 38. Studies changed philosophy of life (D) & .171 & -.070 & .146 & -.034 \\
\hline 39. Schools should reflect competition (A) & -.045 & .321 & .036 & .087 \\
\hline 40. Accept profs' judgment (S) & .338 & .343 & -.138 & -.113 \\
\hline 41. Relate new material to previous (D) & .041 & .092 & .766 & -.070 \\
\hline 42. Keep neat, well-organized notes (A) & .471 & .090 & .022 & .056 \\
\hline \multicolumn{5}{|l|}{ Correlations } \\
\hline Factor 1 (Achieving Strategy) & - & & & \\
\hline Factor 2 (Surface) & -.001 & - & & \\
\hline Factor 3 (Deep) & .201 & -.298 & - & \\
\hline Factor 4 (Achieving Motive) & .243 & .015 & .288 & - \\
\hline
\end{tabular}

Deep Motive, and Deep Strategy, but the solution was not clean and the split of Deep items is counter to theory. A two factor solution accounted for $22.5 \%$ of the variance and the solution was cleaner. Factor loadings and correlations for the two factor solution are shown in Table 7. Items loaded as theorized on the two factors with three exceptions: item 4 loaded negatively on the Deep factor as well as positively on the Surface factor, item 13 loaded positively on both factors, and item 35 loaded negatively on the Surface factor as well as positively on Deep. None of these three items had produced t-test differences for gender or language. The two factors showed a small negative correlation. The structure was replicated for anglophones and males. 
Figure 6. Scree Plot for the Study Process Questionnaire (Without Achieving Items)

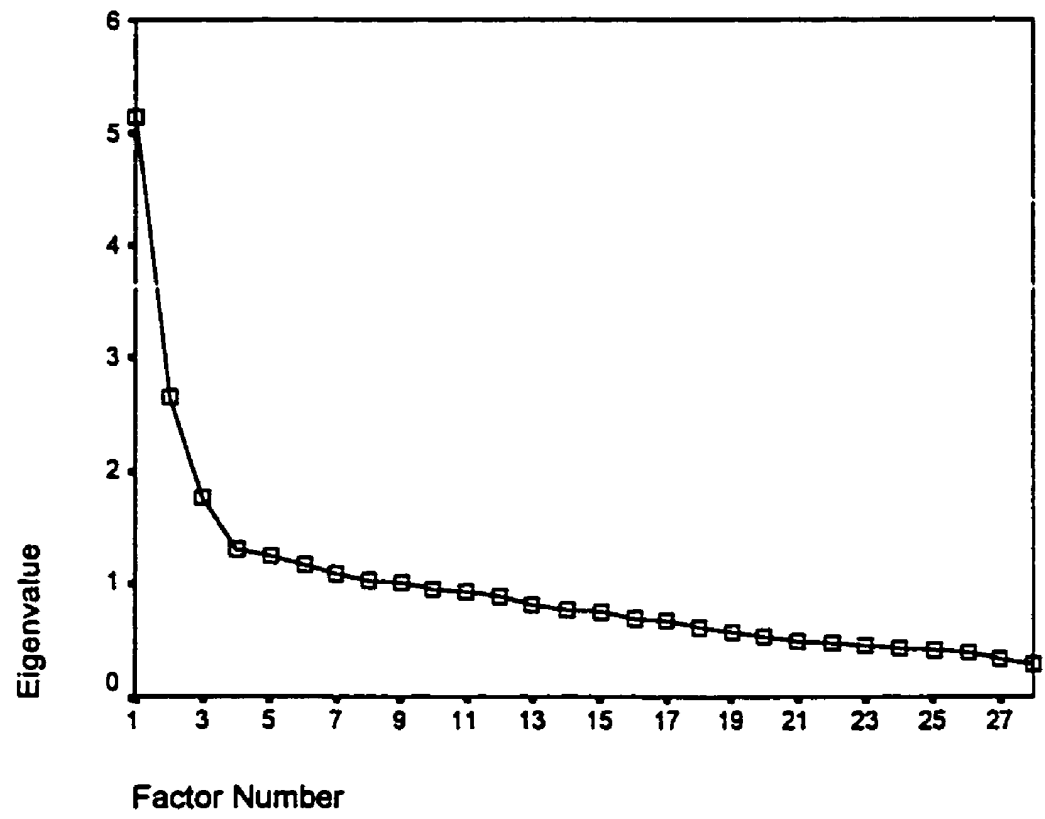

RMSEA was calculated using FITMOD, for the various solutions attempted. For the complete set of SPQ items, RMSEA (2 factors) $=.054(.048, .061)$; RMSEA (3 factors $)=.046(.039, .053)$; and RMSEA (4 factors) $=.038(.029, .046)$. This indicates that the four factor solution selected is a good fit, is better than the two factor solution, and may be slightly better than the three factor solution. For the analyses using only Surface and Deep items, RMSEA ( 2 factors) $=.053(.042, .062)$; and RMSEA ( 3 factors) $=.038(.024, .049)$. However, the $95 \%$ confidence intervals for the two solutions overlap. Although RMSEA values suggest that the three factor solution might be a better fit, the improvement is only modest and the more parsimonious two factor solution selected on the basis of interpretability has acceptable fit. 
Table 7.

Factor Loadings for the SPQ. Deep and Surface Items. Two Factors

\begin{tabular}{cll} 
Item & Factor 1 & Factor 2 \\
& Deep & Surface \\
\hline
\end{tabular}

1. Study program based on jobs (S)

2. Studying gives satisfaction (D)

4. Only study what is assigned (S)

$-.023$

.540

5. Think of real life applications (D)

.408

.002

7. Poor test mark discourages me (S)

$-.326$

.354

.389

.068

8. Discover personal truths (D)

.159

.469

10. Learn some things by rote (S)

.377

$-.060$

11. New material reminds of previous (D)

.041

.427

13. Education leads to a good job (S)

.453

. .056

14. Any topic can be interesting (D)

.332

.357

.511

.050

16. Choose factual subjects (S)

$-.141$

.229

17. Need to form own viewpoint (D)

.476

.099

19. Tests worry me (S)

.329

20. Studying can be exciting (D)

.127

$-.235$

22. Restrict study to assigned (S)

.420

.500

23. Relate one subject to another (D)

$-.265$

$-.067$

25. Shouldn't study non-tested material (S)

.588

.419

26. Increasingly absorbed as I work (D)

$-.179$

$-.147$

28. Learn best if profs outline points (S)

.447

$-.020$

.384

29. Find new topics interesting (D)

.333

$-.249$

31. Resent time at university (S)

$-.142$

.375

.467

$-.031$

34. Rarely question profs (S)

$-.041$

.332

35. Free time reading class topics (D)

.377

$-.305$

37. At university to get better job (S)

$-.052$

.689

38. Studies changed philosophy of life (D)

.262

$-.011$

40. Accept profs' judgment (S)

$-.049$

.377

41. Relate new material to previous (D)

.652

.080

Correlation: 
Cronbach's alpha was calculated for the subscales of the SPQ, and values are reported in Table 8 with comparison values from ONeil and Child (1984). As can be seen, the present study has produced lower values for Achieving (full set) and Achieving Motive, but a higher value for Surface. The values for Deep and Achieving Strategy are comparable.

Table 8.

Cronbach's Alpha for the SPQ

\begin{tabular}{lccc}
\hline & & \multicolumn{2}{c}{ Alpha } \\
\cline { 3 - 4 } Scale & No. of Items & Current Study & $\begin{array}{c}\text { ONeil \& Child } \\
(1984)\end{array}$ \\
\hline Surface & 14 & .76 & .69 \\
Deep & 14 & .78 & .76 \\
Achieving & 14 & .71 & .78 \\
Achieving Motive & 7 & .59 & .72 \\
Achieving Strategy & 7 & .71 & .73 \\
\hline
\end{tabular}

In summary, preliminary analyses indicated that the expected factor structures have been adequately reproduced in the data collected for this study, particulariy if the Achieving items are omitted from the SPQ. Without this, there would have been little point in pursuing further analyses. Replication of results using only anglophone data, only male data, or all data was taken as evidence that the francophone data and female data 
were not substantially different from the anglophone and male data. Consequently, the full data set was used for subsequent analyses.

Combined Analysis - Exploratory Factor Analysis

To this point, the analyses have focused on ensuring that data from the current sample had replicated the hypothesized constructs underlying each of the questionnaires. Having done so, the next step was to investigate the primary question in this study, whether all of the scales were tapping the same construct(s). To this end, exploratory factor analyses were conducted using the data from all three questionnaires combined. This was done to investigate whether items measuring purportedly different constructs, from different questionnaires, would load on the same factor. For example, would items from Need for Cognition, Deep, and Adaptive load together, as hypothesized?

First, factor analyses were conducted on the total 81 items. The scree plot, shown in Figure 7, was inconclusive but suggested about five factors. A five factor solution was attempted, which accounted for $27.87 \%$ of the variance. The factors were roughly interpretable as Deep/Need for Cognition, Achieving, Inflexible, Irresolute, and Deep/Adaptive. Problems with this solution were that the Deep scale divided itself among two factors (but this division did not correspond to motive and strategy), the Surface scale disintegrated, and several Achieving items loaded on the Deep/Adaptive factor. The Deep/Need for Cognition and Deep/Adaptive factors were correlated at $\mathrm{I}=.299$. The next highest correlations were between Deep/Need for Cognition and Irresolute $(r=$ .258) and between Irresolute and Inflexible $(r=.249)$. All other correlations were less than $\mathrm{I}=.200$. 
Figure 7. Scree Plot for All 81 Items

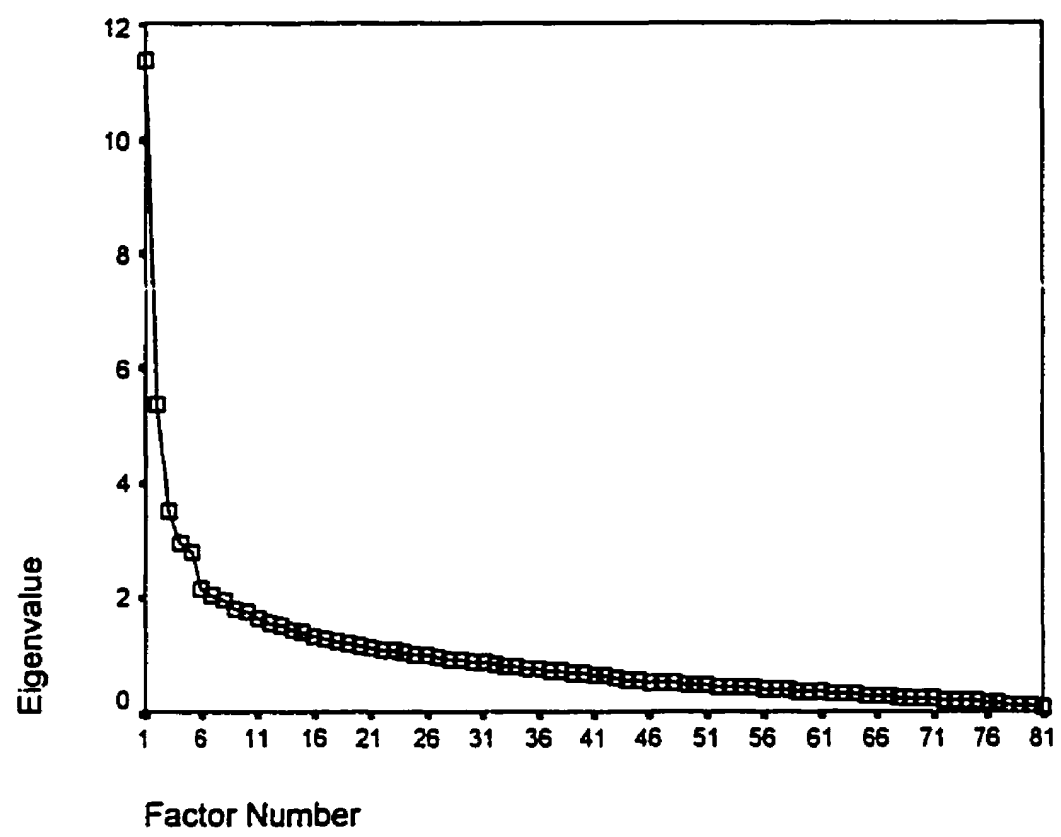

A four factor solution was attempted next and accounted for $25.04 \%$ of the variance. These factors were interpretable as Deep/Need for Cognition/Adaptive, Inflexible, Surface/Irresolute, and Achieving. Factor loadings and correlations are shown in Table 9. The Surface scale still disintegrated, with five items loading with Irresolute, one with Achieving, two loading negatively with Deep/Need for Cognition/Adaptive, and seven items achieving only small loadings on any factor. Although this solution is not perfect, it is more interpretable than the five factor solution. The Deep/Need for Cognition/Adaptive factor showed small negative correlations with Inflexible and Surface/Irresolute, and a small positive correlation with Achieving. Inflexible and Surface/Irresolute also showed a small positive correlation. 
Table 9.

Combined Analysis, 81 Items, Four Factor Solution

Item

Factor 1 Factor 2 Factor $3 \quad$ Factor 4

Deep, etc. Inflexible Achieving Surface/

Irresolute

Need for Cognition Scale

1. Prefer complex problems

2. Situations requiring thought

3. Thinking is not fun*

4. Prefer ... little thought*

5. Avoid deep thinking*

6. Enjoy deliberating

7. Only think as hard as have to*

8. Prefer small projects*

9. Like ... little thought*

10. Like to think way to the top

11. Enjoy finding new solutions

12. Don't like new ways to think*

13. Prefer life filled with puzzles

14. Thinking abstractly appeals

15. Prefer intellectual tasks

16. Relief after mental effort*

17. Don't care how things work*

18. Think about issues

Study Process Questionnaire

1. Study program based on jobs (S)

2. Studying gives satisfaction (D)

3. Top grades to get a good job (A)

4. Only study what is assigned (S)

5. Think of real life applications (D)

6. Summarize suggested readings (A)

7. Poor test mark discourages me (S)

8. Discover personal truths (D)

9. Want to excel in studies (A)

10. Learn some things by rote (S)

11. New material reminds of previous (D)

12. Work consistently through term (A)

13. Education leads to a good job (S)

14. Any topic can be interesting (D)

15. I am ambitious (A)

16. Choose factual subjects (S)

17. Need to form own viewpoint (D)
.477

.559

.405

.353

.421

.366

.364

.114

.170

.441

.455

.441

.586

.474

.295

.215

.370

.318

$-.148$

.308

.145

$-.318$

.382

-.060
.097
-.083
-.054
.118
.035
.060
-.057
-.051
.160
-.093
-.078
-.079
-.122
.002
.073
-.090
-.017

$-.069$

$-.016$

$-.132$

$-.050$

$-.154$

$-.168$

$-.093$

$-.060$

$-.115$

$-.219$

.111

$-.076$

$-.019$

$-.095$

.176

$-.067$

$-.032$

$-.293$

.050

$-.157$

$-.062$

$-.137$

.018

.027

. .041

$-.004$

$-.038$

$-.179$

.041

$-.164$

$-.085$

$-.307$

$-.098$

$-.091$

$-.011$

$-.072$

$-.032$

.047

.441

.242

$-.200$

.415

.042

.145

.436

.213

.109

.030

.372

$-.047$

$-.123$

.171

.335

.197

$-.053$

$-.048$

.160

.485

.085

$-.172$

.115

.425

$-.058$

$-.153$

.297

.035

$-.046$

.145

.368

.230

.132

.592

.227

$-.099$

$-.070$

137

.092

.089

.109

.167

$-.065$

$-.190$

.218

.242

.294

.119

$-.055$

.277

.069 
Table 9. (continued)

Item

Factor $1 \quad$ Factor $2 \quad$ Factor $3 \quad$ Factor 4

Deep, etc. Inflexible Achieving Surface/

Irresolute

18. Try to do assignments early (A)

19. Tests worry me (S)

$-.069$

.036

$-.009$

.006

$-.177$

20. Studying can be exciting (D)

21. Sacrifice popularity for success (A)

.439

$-.011$

.652

.446

.220

$-.059$

22. Restrict study to assigned (S)

.139

.128

$-.072$

$-.309$

.096

.060

23. Relate one subject to another (D)

.636

$-.034$

$-.068$

.271

24. Reread notes for understanding (A)

.043

$-.137$

.091

.105

25. Shouldn't study non-tested material (S)

$-.202$

.216

.515

.023

26. Increasingly absorbed as I work (D)

.471

$-.106$

. .051

.177

27. Choose courses to get top marks (A)

$-.236$

.072

.110

.004

28. Learn best if profs outline points (S)

$-.150$

.230

.268

.376

$-.211$

.086

.185

29. Find new topics interesting (D)

.202

$-.065$

31. Resent time at university (S)

.166

.179

.128

$-.144$

.024

32. Need to discover my philosophy (D)

.428

33. Grades are competition to win (A)

.116

.152

$-.182$

.230

35. Free time reading class topics (D)

.392

$-.037$

36. Read suggested readings (A)

.137

$-.126$

$-.258$

37. At university to get better job (S)

.223

38. Studies changed philosophy of life (D)

.194

39. Schools should reflect competition (A)

$-.033$

40. Accept profs' judgment (S)

$-.237$

.041

.199

.186

41. Relate new material to previous (D)

.600

42. Keep neat, well-organized notes (A)

.097

$-.057$

.064

.358

.068

$-.013$

$-.012$

.121

.308

.286

.042

250

.109

.093

.130

$-.106$

.348

$-.066$

.148

.282

.128

$-.043$

.078

.119

.250

.108

.024

.089

Strategic Flexibility Questionnaire

1. One method for assignments (IN)

.098

$-.104$

2. Get confused by new ideas (IR)

.188

3. Adjust study methods (AD)

.143

4. Stick to trusted study methods (IN)

.022

5. Stick with normal work methods (IN)

.372

6. Think of different approaches (AD)

$-.014$

7. Hard to fit material to assignment plan (IR)

$-.011$

9. Different ways to study ... challenging (AD)

.320

10. Use usual study methods (IN)

.066

.417

.153

$-.240$

.599

.682

$-.260$

.101

.042

.059

.681

.310

$-.234$

$-.002$

.582

12. Stick to satisfying study approach (IN)

024

773

.500

$-.081$

.252

$-.028$

$-.017$

.239

.260

.113

. .033

.067

$-.064$

.005

.163

$-.018$

.108

.470

$-.009$

.385

.148

.056

$-.216$

$-.008$

.253

.145

$-048$

$-003$

Table 9 continues 
Table 9. (continued)

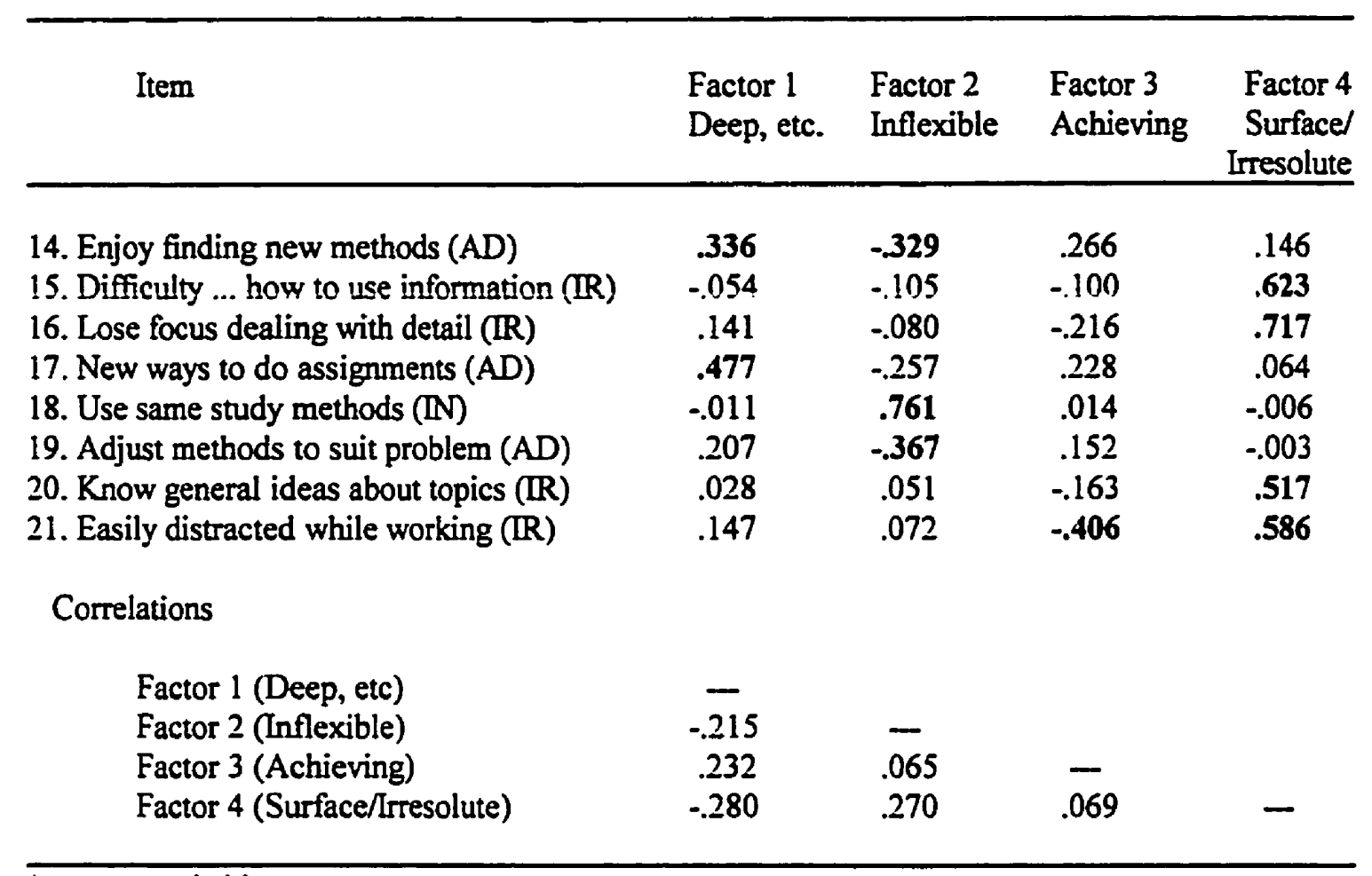

* reverse coded items

A three factor solution was also attempted, which accounted for $22.17 \%$ of the variance. The factors were not interpretable, however, and this was clearly an inadequate solution.

Values for RMSEA were calculated using FITMOD. Confidence intervals (95\%) are shown in brackets. For the five factor solution, RMSEA $=.036(.032, .040)$, while for the four factor solution, RMSEA $=.041(.037, .045)$. Although the fit of the five factor model is slightly better, the confidence intervals overlap. The more parsimonious four factor model is also a good fit and is more interpretable based on theory. 
The 14 Achieving items were then removed and the analysis was repeated using the remaining 67 items. Again, the scree plot, shown in Figure 8, was inconclusive but suggested two or three factors. A three factor solution was attempted first and accounted for $23.86 \%$ of the variance. The factors were roughly interpretable as Deep/Need for Cognition/Adaptive, Inflexible, and Surface/Irresolute. Factor loadings and correlations appear in Table 10. A total of twelve items, six of them from the Surface scale, achieved only small loadings on any factor in this solution. The Inflexible factor correlated positively with the Surface/Irresolute factor. The Deep factor showed a small negative correlation with the other two factors.

Figure 8. Scree Plot for 67 Items (Achieving Items Omitted)

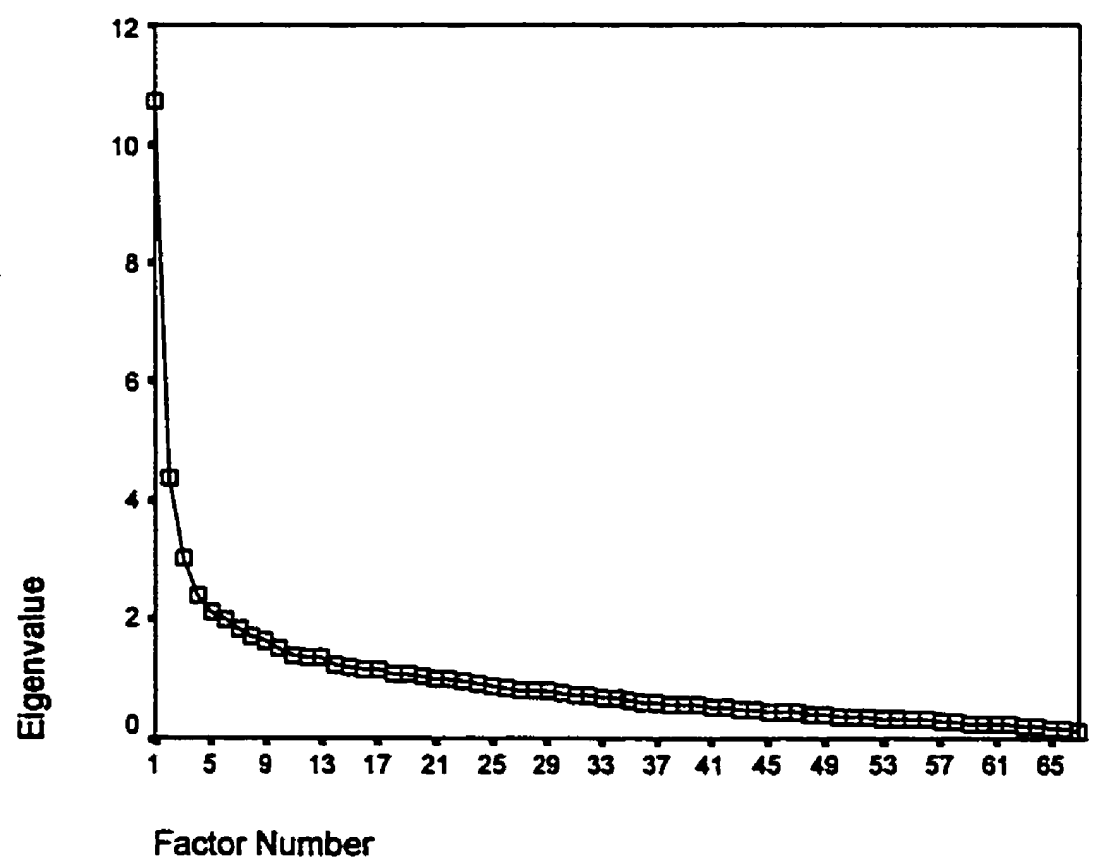


Table 10.

Combined Analysis, Without Achieving Items. Three Factor Solution

\begin{tabular}{|c|c|c|c|}
\hline Item & $\begin{array}{l}\text { Factor } 1 \\
\text { Deep, etc. }\end{array}$ & $\begin{array}{l}\text { Factor } 2 \\
\text { Inflexible } \\
\end{array}$ & $\begin{array}{l}\text { Factor } 3 \\
\text { Surface/Irresolute } \\
\end{array}$ \\
\hline \multicolumn{4}{|l|}{ Need for Cognition Scale } \\
\hline 1. Prefer complex problems & .388 & -.066 & -.227 \\
\hline 2. Situations requiring thought & .487 & .086 & -.145 \\
\hline 3. Thinking is not fun ${ }^{*}$ & .293 & -.076 & -.274 \\
\hline 4. Prefer ... little thought* & .248 & -.066 & -.162 \\
\hline 5. Avoid deep thinking* & .280 & .108 & -.334 \\
\hline 6. Enjoy deliberating & .412 & .044 & -.083 \\
\hline 7. Only think as hard as have to* & .323 & .066 & -.150 \\
\hline 8. Prefer small projects* & .208 & -.029 & -.031 \\
\hline 9. Like ... little thought* & .113 & -.036 & -.346 \\
\hline 10. Like to think way to the top & .397 & .134 & -.204 \\
\hline 11. Enjoy finding new solutions & .347 & -.097 & -.250 \\
\hline 12. Don't like new ways to think* & .421 & -.087 & -.032 \\
\hline 13. Prefer life filled with puzzles & .487 & -.099 & -.114 \\
\hline 14. Thinking abstractly appeals & .402 & -.124 & -.266 \\
\hline 15. Prefer intellectual tasks & .276 & .001 & -.197 \\
\hline 16. Relief after mental effort ${ }^{*}$ & .111 & .072 & -.368 \\
\hline 17. Don't care how things work* & .265 & -.091 & -.189 \\
\hline 18. Think about issues & .307 & -.001 & -.116 \\
\hline \multicolumn{4}{|l|}{ Study Process Questionnaire } \\
\hline 1. Study program based on jobs (S) & -.124 & .059 & .410 \\
\hline 2. Studying gives satisfaction (D) & .422 & .158 & -.008 \\
\hline 4. Only study what is assigned (S) & -.340 & .000 & .222 \\
\hline 5. Think of real life applications (D) & .361 & .038 & .100 \\
\hline 7. Poor test mark discourages me (S) & .108 & .073 & .442 \\
\hline 8. Discover personal truths (D) & .315 & -.083 & -.069 \\
\hline 10. Learn some things by rote (S) & .012 & .075 & .348 \\
\hline 11. New material reminds of previous (D) & .439 & .005 & -.111 \\
\hline 13. Education leads to a good job (S) & .222 & .097 & .142 \\
\hline 14. Any topic can be interesting (D) & .530 & .134 & .101 \\
\hline 16. Choose factual subjects (S) & -.123 & .236 & .183 \\
\hline 17. Need to form own viewpoint (D) & .442 & -.057 & .132 \\
\hline 19. Tests worry me (S) & .175 & .010 & .505 \\
\hline 20. Studying can be exciting (D) & .490 & .027 & -.098 \\
\hline 22. Restrict study to assigned (S) & -.315 & .097 & .301 \\
\hline 23. Relate one subject to another (D) & .562 & -.029 & -.008 \\
\hline 25. Shouldn't study non-tested material (S) & -.208 & .172 & .206 \\
\hline 26. Increasingly absorbed as I work (D) & .511 & -.090 & -.025 \\
\hline
\end{tabular}


Table 10. (continued)

\begin{tabular}{|c|c|c|c|}
\hline Item & $\begin{array}{l}\text { Factor } 1 \\
\text { Deep, etc. }\end{array}$ & $\begin{array}{l}\text { Factor } 2 \\
\text { Inflexible } \\
\end{array}$ & $\begin{array}{l}\text { Factor } 3 \\
\text { Surface/Iresolute }\end{array}$ \\
\hline 28. Learn best if profs outline points ( $S$ ) & -.086 & .225 & .188 \\
\hline 29. Find new topics interesting (D) & .450 & -.181 & .042 \\
\hline 31. Resent time at university (S) & -.119 & .148 & .312 \\
\hline 32. Need to discover my philosophy (D) & .470 & .023 & .029 \\
\hline 34. Rarely question profs $(S)$ & -.031 & .229 & .205 \\
\hline 35. Free time reading class topics (D) & .457 & .009 & -.128 \\
\hline 37. At university to get better job (S) & -.173 & .178 & .370 \\
\hline 38. Studies changed philosophy of life (D) & .281 & .059 & -.004 \\
\hline 40. Accept profs' judgment (S) & -.072 & .203 & .225 \\
\hline 41. Relate new material to previous (D) & .580 & .104 & .012 \\
\hline \multicolumn{4}{|l|}{ Strategic Flexibility Questionnaire } \\
\hline 1. One method for assignments (IN) & .200 & .395 & .044 \\
\hline 2. Get confused by new ideas (IR) & -.077 & .151 & .259 \\
\hline 3. Adjust study methods (AD) & .356 & -.226 & .187 \\
\hline 4. Stick to trusted study methods (IN) & .143 & .610 & .058 \\
\hline 5. Stick with normal work methods (IN) & -.020 & .684 & -.012 \\
\hline 6. Think of different approaches (AD) & .453 & -.232 & -.022 \\
\hline 7. Hard to fit material to assignment plan (IR) & .091 & .103 & .511 \\
\hline 8. Hardest part of assignment is how to do (IR) & .010 & .036 & .379 \\
\hline 9. Different ways to study ... challenging (AD) & .353 & .080 & .114 \\
\hline 10. Use usual study methods (IN) & -.070 & .668 & -.032 \\
\hline 11. Like exploring different ways (AD) & .462 & -.189 & .031 \\
\hline 12. Stick to satisfying study approach (IN) & .005 & .565 & .155 \\
\hline 13. Rarely change the way I study (IN) & .002 & .787 & -.007 \\
\hline 14. Enjoy finding new methods (AD) & .496 &.- .304 & .199 \\
\hline 15. Difficulty ... how to use information (IR) & -.068 & -.131 & .595 \\
\hline 16. Lose focus dealing with detail (IR) & .050 & -.098 & .599 \\
\hline 17. New ways to do assignments (AD) & .603 & -.229 & .074 \\
\hline 18. Use same study methods (IN) & .005 & .779 & .018 \\
\hline 19. Adjust methods to suit problem (AD) & .271 & -.361 & -.026 \\
\hline 20. Know general ideas about topics (IR) & -.007 & .037 & .474 \\
\hline 21. Easily distracted while working (IR) & -.034 & .041 & .429 \\
\hline \multicolumn{4}{|l|}{ Correlations: } \\
\hline Factor 1 (Deep, etc) & - & & \\
\hline Factor 2 (Inflexible) & -.171 & - & \\
\hline Factor 3 (Surface/Irresolute) & -.269 & .308 & - \\
\hline
\end{tabular}

* reverse coded items 
A two factor solution was then attempted, which accounted for $20.14 \%$ of the variance. The factors were roughly interpretable as Deep/Need for Cognition/Adaptive, and Surface/Irresolute/Inflexible. However, 18 items failed to achieve loadings of at least .300 on either factor. The two factors correlated negatively, $r=-.294$.

A one factor solution was also attempted. It only accounted for $14.76 \%$ of the variance, but was nonetheless interesting. With the exception of item 13 on the SPQ, all items loaded in the direction that would be expected. That is, Deep, Need for Cognition, and Adaptive items all loaded positively, while Surface, Inflexible, and Irresolute items all loaded negatively. Fourteen items had loadings below .300 .

Finally, a four factor solution was attempted as a check on the number of factors extracted. Fifteen items failed to achieve loadings of at least .300 on any factor. More seriously, the Deep items split between two factors, a split which did not correspond to motive and strategy. Based on theory, this solution appeared to be overfactored.

Values for RMSEA were calculated using FITMOD. For the three factor solution, RMSEA $=.042(.038, .047)$. For the two factor solution, RMSEA $=.049(.044, .052)$. For the one factor solution, RMSEA $=.058(.054, .062)$. The three factor solution is a marginally better fit, and was also somewhat cleaner. It therefore appears to be the better choice.

Although the three factor solution is optimal, it is not perfect. Few items achieved very high loadings, and as noted, twelve items achieved only small loadings on any factor. Five Need for Cognition items did not load above .300 on any factor, and three Need for Cognition items loaded negatively on the Surface/Irresolute factor instead of positively on 
the Deep factor. Two Adaptive items loaded negatively on the Inflexible factor, only one of which also loaded positively on the Deep factor. As a result, it would be an overstatement to suggest that these items are measuring the same constructs, for instance, to suggest that Deep items and Need for Cognition items are measuring the same thing. Nonetheless, there are clearly strong relationships among the items and scales.

\section{Confirmatory Factor Analyses}

The preceding item-level exploratory factor analyses suggest relationships among the various scales. However, thus far individual items have been free to load on factors other than their hypothesized scales. At the next step of the analysis the interest lay in determining whether relationships held for the complete scales as written. For this stage of the analysis, confirmatory factor analysis was used. The program EQS was used, with Maximum Likelihood (ML) factor extraction.

As a preliminary step, a first order model was tested, using the 67 items representing the six scales of interest (Need for Cognition, Deep, Surface, Adaptive, Inflexible, Irresolute). A six factor model was specified with each factor representing one scale as defined by the authors of the questionnaires. In other words, the 18 items from the NCS were each allowed to load only on the Need for Cognition factor, etc. However, the six factors were allowed to correlate. In order to achieve identification of the model, variances of the factors were fixed to 1.0 (Mueller, 1996).

The model achieved the fit indices as shown in Table 11. Hu and Bentler (1998) conducted a comparison of the efficacy of various fit indices used in structural equation modelling. They concluded by recommending that Standardized Root Mean Square 
Table 11 .

Fit Indices for First and Second Order Confimatory Factor Analyses

Fit Index

First Order Model

Second Order Model

Bentler-Bonett Nonnormed

Fit Index (NNFI)

.698

.697

Bollen (IFI)

.715

.713

Standardized Root Mean Square

Residual (SRMR)

.073

.073

RMSEA

.049

.049

RMSEA $90 \%$ confidence interval

$.045, .052$

$.045, .052$

Residual (SRMR) should always be reported, plus at least one more fit index from a list which included the Nonnormed Fit Index (NNFI -- also known as the Tucker-Lewis Index), the Bollen fit index, and RMSEA. Accordingly, those four indices have been reported. Hu and Bentler particularly recommended the SRMR when sample sizes are less than 250.

For the model to be considered a good fit, $\mathrm{Hu}$ and Bentler (1998) recommended a fit index of .95 or higher for the NNFI and Bollen, an index of .08 or lower for SRMR, and an index of .06 or lower for RMSEA. As can be seen from Table 11, the NNFI and Bollen indices failed to meet this standard, but SRMR and RMSEA achieved it. This discrepancy is due to the fact that the NNFI and Bollen are incremental (or comparative) 
fit indices, which compare the target model to a more restricted baseline model. SRMR and RMSEA are absolute fit indices which directly assess how well the model reproduces the sample data, and compare the target model to a saturated model (Hu \& Bentler, 1998). The incremental models may show poorer fit because some items did not load highly on their intended factor, and some items would have loaded on other factors if allowed to do so, as shown by the exploratory factor analyses. As stated above, with small samples Hu and Bentler recommend SRMR, which showed good fit in the present instance.

The standardized loadings for each item on its respective factor are shown in Appendix F.

The correlations among the six factors in this first order model are shown in Table 12. These correlations have had random error removed by the confirmatory factor analysis process. As can be seen, correlations are particularly high between Deep and Need for Cognition $(\Sigma=.781)$ and between Deep and Adaptive $(r=.782)$.

The correlation matrix from Table 12 was then subjected to an exploratory factor analysis to see if higher order factors were indicated. Non-iterated Principal Axis Factors (PAF) extraction was used for this analysis. PAF was chosen because the correlation matrix does not consist of traditional Pearson correlation coefficients, and therefore may not follow the same distributional assumptions as traditional correlations. The noniterated version of PAF was used to try to avoid Heywood cases, or situations in which a communality for a measured variable is estimated to be at or greater than 1.0 (Fabrigar et al., 1999). It should be noted that this analysis was very exploratory in nature, intended 
only to get an initial idea of whether a higher order model might be reasonable.

Table 12.

Correlations Between First Order Factors

\begin{tabular}{|c|c|c|c|c|c|c|}
\hline Factor & 1 & 2 & 3 & 4 & 5 & 6 \\
\hline 1. Need for Cognition & - & & & & & \\
\hline 2. Deep & .781 & -- & & & & \\
\hline 3. Surface & -.601 & -.505 & $\cdots$ & & & \\
\hline 4. Adaptive & .585 & .782 & -.504 & -- & & \\
\hline 5. Inflexible & -.314 & -.143 & .496 & -.452 & - & \\
\hline 6. Irresolute & -.459 & -.246 & .579 & -.277 & .275 & $\cdots$ \\
\hline
\end{tabular}

The scree plot from the non-iterated principal axis factors analysis, shown in Figure 9, suggested either one or three factors. One, two, and three factor solutions were obtained. Direct quartimin rotation was used for the two and three factor solutions. The one factor solution accounted for $51.52 \%$ of variance. Deep, Need for Cognition, and Adaptive loaded positively, while Inflexible, Surface, and Irresolute loaded negatively. Inflexible had the smallest loading, at -.490 . 
Figure 9. Scree Plot for Analysis of Correlation Matrix, First Order Model

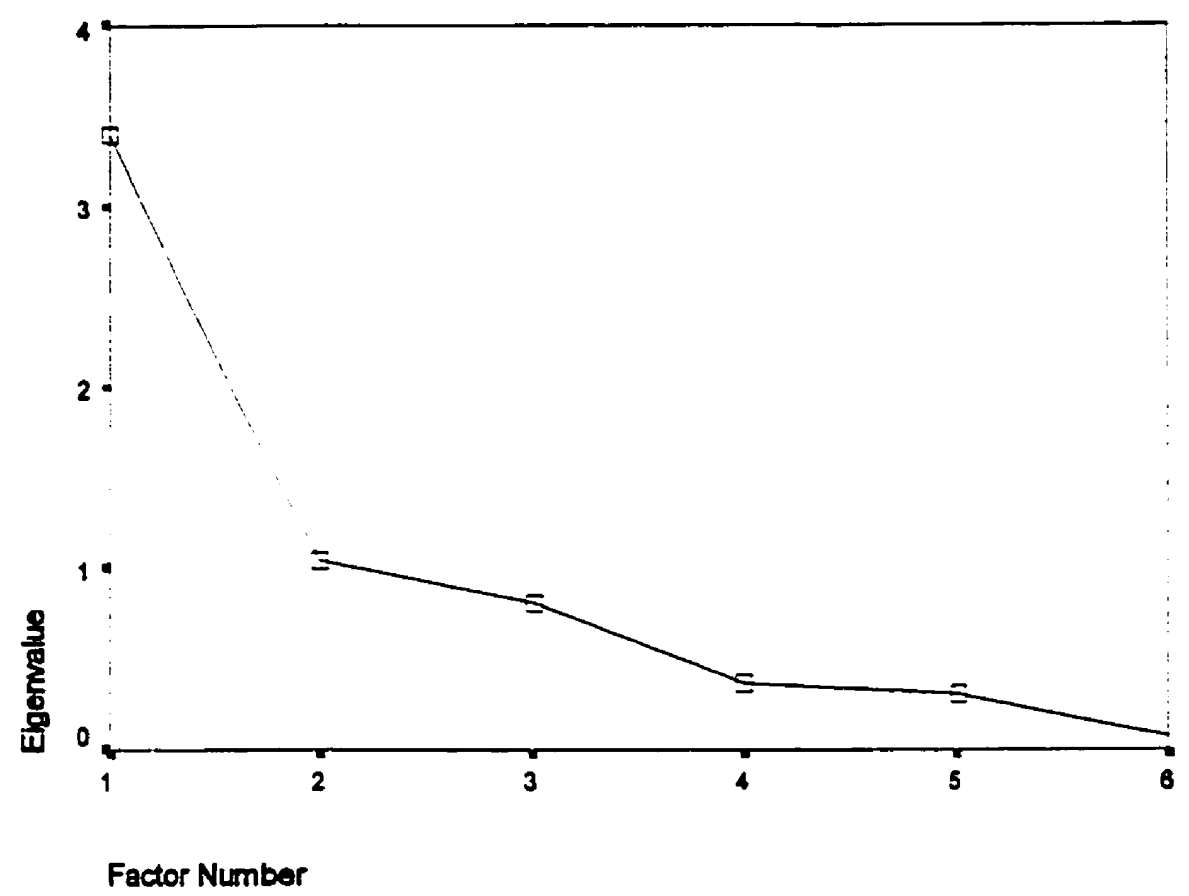

The two factor solution accounted for $62.80 \%$ of variance, but Deep obtained a loading greater than 1.0. Although this is troublesome, it might represent only sample variance, if the "true" value for Deep in the population is close to 1.0.

The three factor solution accounted for $68.93 \%$ of variance and produced a relatively clean solution. Factor loadings are shown in Table 13. As can be seen, Deep, Need for Cognition, and Adaptive formed one factor; Surface, Irresolute, and negative Need for Cognition formed a second factor; while Inflexible and negative Adaptive formed the third factor. This same pattern can be seen from the item level exploratory factor analysis in Table 10. The three factor solution appears to be the optimal choice, based on 
structure and variance accounted for.

Table 13.

Factor Loadings for Three Factor EEA Solution, Based on First Order CFA Correlation Matrix

\begin{tabular}{lccc}
\hline First Order Factor & Factor 1 & Factor 2 & Factor 3 \\
\hline Need for Cognition & .584 & -.463 & -.087 \\
Deep & .965 & -.055 & .137 \\
Surface & -.182 & .581 & .235 \\
Inflexible & .005 & .150 & .674 \\
Irresolute & .042 & .679 & .045 \\
Adaptive & .761 & .107 & -.370 \\
\hline
\end{tabular}

Referring back to the hypothesized models of underlying constructs (e.g. Figure 2), the first factor in Table 13 (Deep, Need for Cognition, and Adaptive) represents the hypothesized construct Self-Regulation. However, the hypothesized construct of Ineffective Learning has split into two factors. The factor (factor 3 ) consisting of Inflexible and the negative loading of Adaptive might be called Inflexibility, because it represents a reliance on one or two preferred study methods regardless of task demands. Factor 2 in Table 13 consists of Irresolute, Surface, and negative Need for Cognition. This suggests a combination of being confused or overwhelmed by study demands, unsure 
of how to proceed with assignments, reluctance to engage in thinking or reflection, extrinsic motivation to learn, fear of failure, and surface strategies. This is a complex amalgam of largely undesirable learning characteristics, but it is not the same as the proposed "Ineffective Learning" factor. Since it is predominantly composed of the surface approach and irresolute control, it may simply be labelled Surface/Irresolute.

Based on the results of the preceding exploratory factor analysis, a second order factor model was specified as shown in Figure 10. For simplicity, item level indicators have not been shown in the diagram. Items were specified to load on the first order factors as hypothesized by the authors of the questionnaires.

This second order model was tested in EQS using ML extraction. In order to identify the model, two separate steps were necessary. For the first order factors, one item per factor was set as a reference variable. That is, the path from the factor to the indicator variable was fixed at 1.0 (Mueller, 1996). In each case, the item with the highest loading from the first order analysis was selected as the reference variable. For the second order factors, variances were fixed at 1.0. In making these decisions, for the first order factors there was no choice: variances could not be fixed to 1.0 because the model implies that first order factor variances are caused by second order factors. For second order factors, the alternative would have been to fix a first order factor as a reference "variable" for each second order factor. However, since the second order factor loadings were of primary interest in this analysis, fixing three of the paths would have been counterproductive. As a result, variances were fixed to 1.0. 
Figure 10. Proposed Second Order Factor Model

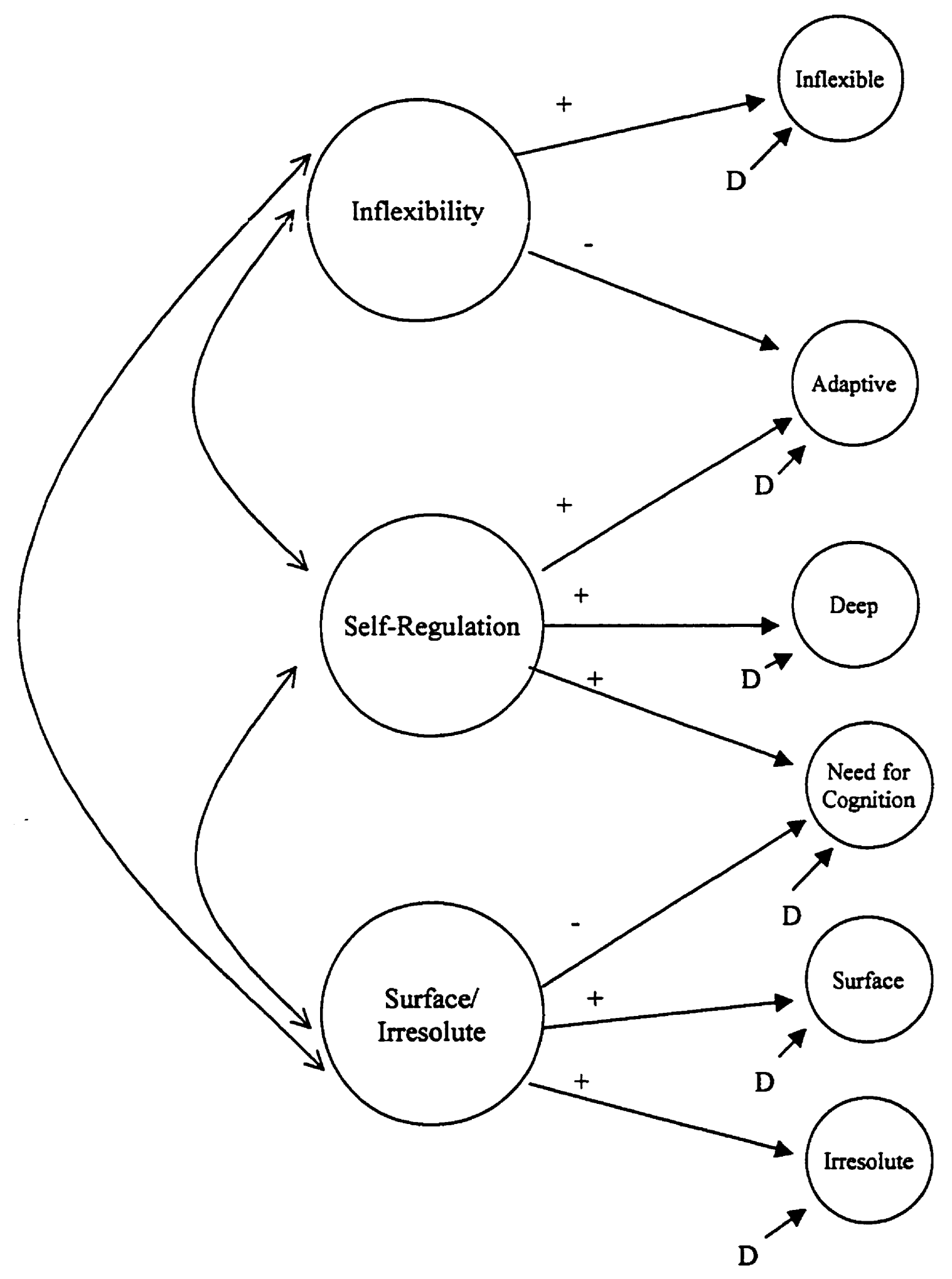


Some difficulties were encountered fitting this model, in that the model attempted to generate structural coefficients greater than 1.0 for two paths: the loading of Inflexible on its second order factor, and the loading of Deep on its second order factor. (EQS constrains these values at 1.0 .) These problems are probably due to the sample size, as confirmatory factor analysis generally works better with very large samples (Mueller, 1996). The analyses should be replicated with a larger sample before placing too much confidence in these results.

The fit indices obtained for the second order model were reported in Table 11. Once again, comparative fit indices did not meet the standard, but absolute fit indices are good. Furthermore, as noted by Marsh and Hocevar (1985), the goodness of fit of a higher order model can never exceed that of the corresponding first order model. This is because the higher order factors are being used in an attempt to explain the variation among the first order factors in a more parsimonious way.

In this instance, the fit indices for the second order model are virtually identical to the fit indices of the first order model. This shows that the lack of fit indicated by the comparative fit indices occurs in the measurement of the first order factors, rather than in the specification of the second order factors (Marsh \& Hocevar, 1985). Consequently, if the existence of structural coefficients greater than 1.0 can be attributed to sampling error, then the model appears to explain relationships among the scales quite well. As noted, however, this should be confirmed through replication with a larger sample. Figure 11 shows the model with the standardized solutions for the paths. Once again, item level paths have been omitted for the sake of simplicity. 
Figure 11. Second Order Factor Model With Standardized Solutions

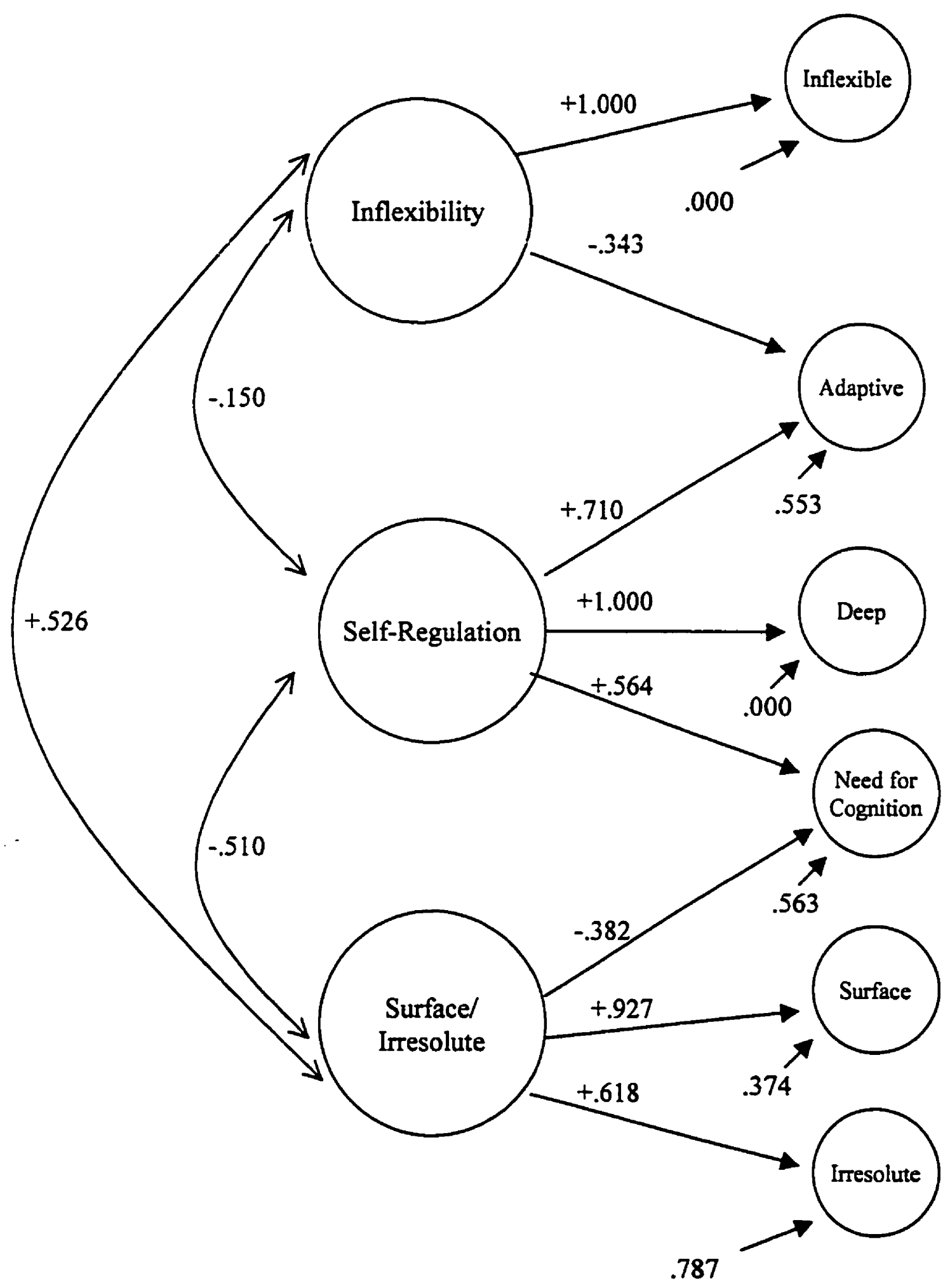


Finally, the two models that were initially hypothesized were tested. The first consisted of one second order factor on which Need for Cognition, Deep, and Adaptive loaded positively, while Surface, Inflexible, and Irresolute loaded negatively. The second model consisted of two second order factors. The first factor included Deep, Need for Cognition, and Adaptive, while the second factor included Surface, Inflexible, and Irresolute. The two factors in this model were allowed to correlate. These two models were shown in Figures 1 and 2, respectively. The two models with standardized solutions for the paths are shown in Appendix G.

The fit indices for one, two and three factor second order models are shown in Table 14. As can be seen, the fit indices for the three second order models are all comparable. However, the fit indices for the three factor second order model are the best. Therefore, the model shown in Figure 11 appears to be the best choice for explaining relationships among the scales. 
Table 14.

Fit Indices for One, Two, and Three Factor Second Order Models

\begin{tabular}{lccc}
\hline \multicolumn{1}{c}{ Fit Index } & $\begin{array}{c}\text { One Factor } \\
\text { Model }\end{array}$ & $\begin{array}{c}\text { Two Factor } \\
\text { Model }\end{array}$ & $\begin{array}{c}\text { Three Factor } \\
\text { Model }\end{array}$ \\
\hline $\begin{array}{l}\text { Bentler-Bonett } \\
\text { Nonnormed }\end{array}$ & .678 & & \\
Bollen (IFI) & .694 & .688 & .697 \\
Standardized RMR & .078 & .704 & .713 \\
RMSEA & .050 & .076 & .073 \\
$\begin{array}{l}\text { RMSEA 90\% } \\
\text { Confidence Interval }\end{array}$ & $.047, .053$ & .050 & .049 \\
\hline
\end{tabular}

\section{Demographic Variables}

Demographic information was also collected to explore correlates of the various scales. Participants were asked to indicate their gender, primary language, age, faculty, father's and mother's highest level of education, and their average grade in final year of high school.

One participant did not provide any demographic information and was therefore excluded from subsequent analyses. Of the remaining 225 participants, two did not indicate faculty and seven did not indicate average grade in high school. In addition, two indicated "unknown" for father's education and three indicated "unknown" for mother's education. This totalled 14 missing items, or $0.78 \%$. Once again, this represents a very 
small proportion of missing data. For these analyses, missing data were excluded.

Total scores on each of the eight scales were used to assess relationships with predictor variables. Since Achieving Motive and Achieving Strategy had been treated separately in previous analyses, this convention was carried through. Descriptive statistics for scale scores are shown in Appendix $\mathrm{H}$.

Since there was no reason to suspect that any variables would interact to influence scale scores, demographic variables were analyzed separately. The effects of faculty, gender, and primary language were each tested by means of one-way MANOVA. Separate analyses were conducted for each group of logically and empirically related scales. With an alpha of .05 , there were no significant differences among faculties for any of the scales. Results were as follows: for Deep, Need for Cognition, and Adaptive, Wilks's $\Lambda=.969, E(6,436)=1.170, \mathrm{p}=.321 ;$ for Surface, Inflexible, and Irresolute, Wilks's $\Lambda=.970, E(6,436)=1.116, \mathrm{p}=.352$; for Achieving motive and strategy, Wilks's $\Lambda=.980, E(4,438)=1.125, \mathrm{p}=.344$. Although the number of students per faculty differed substantially, the larger variances were associated with the smaller groups. This circumstance leads to the $\mathrm{E}$ statistic being liberal; in other words, the actual probability exceeds the estimate (Stevens, 1996). In the present case, where none of the results were significant anyway, this does not pose problems.

For gender, using an alpha of .05, significant differences were found for Achieving motive and strategy, Hotelling's Trace $=.112, \mathrm{E}(2,222)=12.411, \mathrm{p}<.001$. Subsequent univariate tests showed that the difference was due to Achieving strategy, $E(1,223)=$ $22.294, \mathrm{p}<.001$. Females scored higher than males on Achieving strategy (see Appendix 
J for scale descriptive statistics). No other significant differences were found for gender. Results were: for Deep, Need for Cognition, and Adaptive, Hotelling's Trace $=.029$, $E(3,221)=2.173, p=.092 ;$ for Surface, Inflexible, and Irresolute, Hotelling's Trace $=$ $.016, E(3,221)=1.165, p=.324$. Issues of sample variance and sample size were considered for cases where the E statistic might be suspect (Stevens, 1996), but no problematic cases were found.

For primary language, there were several significant differences, using an alpha of .05. For Deep, Need for Cognition, and Adaptive, Hotelling's Trace $=.066, \mathrm{E}(3,222)=$ $4.897, p=.003$. Univariate tests showed differences for Deep, $E(1,224)=12.898$, $p<.001$, and Need for Cognition, $E(1,224)=8.665, p=.004$. In both cases, francophones scored higher than anglophones. For Surface, Inflexible, and Irresolute, Hotelling's Trace $=.079, E(3,222)=5.882, p=.001$. Univariate tests showed a difference for Inflexible, $E(1,224)=7.009, \mathfrak{R}=.009$, with francophones scoring higher on Inflexible than anglophones. The difference for Irresolute should also be considered, $E(1,224)=3.081, \mathfrak{p}=.081$. Although this did not meet the alpha of .05 , in this case the smaller group also had the smaller variance, resulting in an $\mathrm{E}$ statistic that is conservative (Stevens, 1996), meaning that the actual probability is less than .081. Francophones scored lower on Irresolute than anglophones. There were no differences for Achieving, Hotelling's Trace $=.022, \mathrm{E}(2,223)=2.410, \mathfrak{R}=.092$, and no other combinations of variance and group size were problematic.

Continuous variables were analyzed using correlations. Regression was not used because of the potential for multicollinearity due to the presence of correlations between 
some of the variables (for instance, age was negatively correlated with average grade in high school, $\mathrm{r}=-.470$ ). Correlations are shown in Table 15. As can be seen, age was significantly related to the Deep approach, Adaptive control, and negatively to Inflexible control. As age increased, so did reported use of the Deep approach and Adaptive control, while reported use of Inflexible control decreased. Father's education and mother's education were not significantly related to any of the scales. Average grade in high school was positively related to Achieving Motive. However, although statistically significant, these correlations represent very small effects.

Table 15.

Correlations Between Demographic Variables and Scale Scores

\begin{tabular}{lllllllll}
\hline Variable & $\begin{array}{l}\text { Need } \\
\text { for } \\
\text { Cogn. }\end{array}$ & Deep & Surface & $\begin{array}{l}\text { Achieve } \\
\text { Motive }\end{array}$ & $\begin{array}{l}\text { Achieve } \\
\text { Strategy }\end{array}$ & $\begin{array}{l}\text { Adap- } \\
\text { tive }\end{array}$ & $\begin{array}{l}\text { Inflex- } \\
\text { ible }\end{array}$ & $\begin{array}{l}\text { Irres- } \\
\text { olute }\end{array}$ \\
\hline Age & .108 & $.218^{* *}$ & -.109 & .007 & .107 & $.202^{* *}$ & $-.234^{* *}$ & -.127 \\
$\begin{array}{l}\text { Father's } \\
\text { Education }\end{array}$ & -.057 & -.088 & .000 & -.045 & -.041 & -.085 & .104 & .008 \\
$\begin{array}{l}\text { Mother's } \\
\begin{array}{l}\text { Education } \\
\text { Average }\end{array}\end{array}$ & -.090 & -.077 & -.021 & .040 & -.054 & -.054 & .004 & .037 \\
$\begin{array}{l}\text { Grade } \\
\text { *** } R<.01\end{array}$ & .093 & -.053 & -.015 & $.202^{* *}$ & .015 & -.116 & .098 & -.070 \\
\hline
\end{tabular}


Chapter Four

Discussion

\section{Qverview}

The primary purpose of this study was to investigate relationships among the scales measured by the three questionnaires, the NCS, the SPQ, and the SFQ. The specific hypotheses were that all of the scales might be tapping: a) one underlying construct, or b) two constructs, one representing Self-Regulated learning and one representing Ineffective learning. The secondary purpose was to validate the SFQ on a new population. Analyses were also done to explore relationships between demographic variables and the various scales. A general review of the main analysis is presented, followed by discussion of the analysis of demographic variables, more detailed discussion of the possible explanations for the relationships between scales and underlying constructs, and some limitations of the study.

To recap, preliminary analyses were done to determine whether the various constructs hypothesized by the authors of the questionnaires had been replicated in this study. In addition, since the French questionnaires were unvalidated, it was necessary to determine whether the French and English data could be combined. Possible gender differences were also considered, due to the small number of females in the sample. Although there were some differences on individual items relating to gender and primary language, these did not appear to affect the overall factor analyses. The hypothesized constructs were replicated, with the exception of the achieving approach in that motive and strategy items did not combine as expected. The achieving approach was not of primary interest in this study, and as a result was omitted from many of the analyses. The factor structures were replicated for all three questionnaires regardless of whether English 
data, male data, or combined data were used. Therefore, all data were combined for the main analyses.

The current sample was checked to see if total scores on the various scales were comparable to populations tested previously. For the SPQ, means were similar to those of previous Canadian students, but the current sample scored higher on deep and achieving approaches than previous results for Australian and British students. For the SFQ, means were generally similar to results reported for Australian nursing students.

The results of the exploratory factor analyses indicated that, at the item level, the scales are not measuring exactly the same thing. As they are measured, the deep approach is not interchangeable with need for cognition or adaptive control; the surface approach is not interchangeable with inflexible or irresolute control. Furthermore, the surface approach is not the exact opposite of deep, nor adaptive control the exact opposite of inflexible or irresolute.

On the other hand, there clearly are very strong relationships among the constructs measured by the scales. This led to analysis of second order factors using confirmatory factor analysis. The fit of second order models was limited by the fit of the first order model and by sample size.

With respect to the one and two factor models that were initially hypothesized (Figures 1 and 2), neither proved to offer the best explanation of relationships among the scales. The best fit was obtained for the three factor model shown in Figure 11. The three factors consisted of SelfRegulation (Deep, Need for Cognition, Adaptive); Surface/Irresolute (Surface, Irresolute, and negative Need for Cognition); and Inflexibility (Inflexible and negative Adaptive). This was also supported by results of item level exploratory factor analysis. Within the three factor second 
order model, Self-Regulation was negatively related to Surface/Irresolute $(I=-.510)$, and Inflexibility was positively related to Surface/Irresolute $(r=.526)$. Inflexibility also had a small negative relationship with Self-Regulation $(r=-.150)$. These constructs and relationships are discussed in more detail in the section "Scales and Constructs".

The secondary purpose of the study, which was to validate the SFQ, was achieved. The hypothesized factor structure of the SFQ replicated nicely in the current sample.

\section{Demographic Variables}

The current study did not shed much light on relationships between the various scales and demographic variables. Previous research (Biggs, 1987) has shown that female university students score higher on the achieving approach than males. The current research supported that finding with respect to the achieving strategy subscale. However, although this may represent an actual difference between males and females, it is also possible that, among students of a certain age, it is more socially acceptable for females than males to admit to such strategies as doing assignments early instead of at the last minute. Males may believe that it projects an image of being "cool" if they claim to be more cavalier about their studies.

The results showed francophones to have scored more highly on need for cognition, the deep approach, and inflexible control than anglophones and somewhat lower on irresolute control. The inclusion of inflexible control reduces the likelihood of these differences being due to responding in a socially desirable fashion. Interestingly, Biggs (1985) reported that the deep approach was correlated with bilingualism. He suggested that the ongoing search for clarifying meaning and the need to monitor one's speech might facilitate development of the deep approach. At the first-year level, the francophone students at this college are more apt to be bilingual than 
the anglophone students, which might suggest the explanation for the higher scores on the deep approach. Alternative explanations include differences being due to the sample, or possibly due to nuances of the translation.

No differences were found due to effects of faculty in the current study, contrary to previous research reported by Biggs (1987). Howeyer, students in the current study were all first year students and data were collected during the first six weeks of their first term. Consequently it may simply have been too early for any differences between faculties to emerge.

Mother's education and father's education were not significantly related to any of the scales in the current research. This is unlike previous research (Biggs, 1987) which found that children of parents with post-secondary education scored lower on the surface approach and higher on deep. There are several possible explanations for this difference, although all are speculative. It may be due to differences associated with the population of the military college, to cultural differences between Canada and Australia (where Biggs collected most of his data), or to changes over time, as most of the data which he reported in 1987 would now be twenty or more years old:

Average grade in final year of high school was correlated with achieving motive. This finding is not surprising. These students all have good academic potential or they would not have been accepted into the university. An able student who is motivated to excel is likely going to achieve high grades.

Average grade was included with the intention of using it to differentiate between need for cognition and the other scales, particularly the deep approach. The rationale was that need for cognition, which represents a more general construct not specifically related to learning in school, 
would be less likely to show a relationship with academic grades than the deep approach. However, academic grade did not correlate with any scale other than achieving motive. This is unlike previous research which had shown that the deep approach was positively related to academic performance and the surface approach was negatively related (Biggs, 1987). Also, Cantwell and Moore (1998) had found that irresolute control was negatively related to academic performance. The lack of relationships in this study may have been due to the general unreliability of self-report measures of performance, combined with forgetting due to the passage of time since completing school, which in some cases may have been several years. Students who are high in achieving motive, by contrast, would remember high grades because of the personal significance attached to those grades. On the other hand, once again this could be a cultural difference, or related to the sample.

Finally, age was positively related to the deep approach and adaptive control, and negatively related to inflexible control. Bearing in mind that the older participants in this study were mature students, this supports previous findings (Biggs, 1987) that older students (beyond approximately age 22) showed an increase in use of the deep approach. The corresponding increase in adaptive control and decrease in inflexible control seem reasonable based on the relationships between scales found in this study. It was somewhat surprising, however, that there was no increase in need for cognition among older students, since it appears to be so closely related to the deep approach and adaptive control. Although Cacioppo et al. (1996) have reported a small negative correlation between age and need for cognition among the general population, that relationship was not expected to occur with mature students. Unfortunately, given the very small number of mature students (only 19 students, or $8.4 \%$ were older than 21 
years of age), it would be risky to try to draw strong conclusions.

\section{Scales and Constructs}

The Achieving scale in the SPQ did not behave as hypothesized in this study. The motive and strategy items did not combine into one factor as they theoretically should have in exploratory factor analysis, and the presence of the Achieving items appeared to be adversely affecting the structure of the surface approach as well. The achieving approach (or the similar strategic approach in the Approaches to Studying Inventory [ASI]) has been problematic before. Richardson (1994) concluded, based on a literature review, that evidence of the strategic or achieving approaches as discrete entities is ambiguous. Kember et al. (1999) reported that a new version of the SPQ is currently being developed in collaboration with John Biggs. This new version will measure only two approaches: Deep and Surface.

The Surface scale on the SPQ did not hold together well in the combined item exploratory factor analysis, with six items (out of 14) failing to achieve a loading of 300 or higher on any factor. The Surface scale is perhaps more of an amalgam than the Deep or Achieving scales. Although all three consist of both motive and strategy components, the Surface motive subscale actually contains two components (Biggs, 1993). Four of the items relate to the pragmatics of obtaining a qualification, while the other three relate to fear of failure. These represent very different motivations. Furthermore, although both aspects of surface motive may be seen to have negative connotations, since they refer to extrinsic motivations to learn, surface strategies may be very adaptive in certain circumstances. Many of the deep strategies are time consuming and most students lack the time to be deep about everything they have to learn. Also, some disciplines have a base of factual knowledge which must be rote memorized. This point was made by Kirby 
(1993) who suggested that students should be encouraged to use both deep and surface strategies. Recently, Knapper (1995) constructed an Approaches to Work Questionnaire (AWQ) which was adapted from the ASI. The AWQ was intended to measure how workers approach learning in the workplace. Although the deep approach tended to replicate, the surface approach split into two factors, an organized or rational approach, and a disorganized or emotional approach (Gadula, 1996; Carty, 1996). Although these results are from a different questionnaire, they, along with the results of the current study, suggest that existing conceptualizations of the surface approach may be inadequate; there may actually be more than one construct in what is being called the surface approach. Part of the problem may also be that the SPQ needs to be updated. For instance, item \#13 ("Whether I like it or not, I can see that further education is a good way for me to get a well-paid or secure job") consistently failed to load on the hypothesized (Surface) factor in this study. Given the economic climate in which students today have grown up, it is hard to imagine any student disagreeing with that statement, and in fact the item mean was 4.38 (standard deviation .733), which was the highest mean for any item. Consequently that item was not particularly useful for differentiating between approaches in this sample.

The factor analyses indicated that the elements of the surface approach which cohere best are tapping the same construct as irresolute control. This suggests an element of confusion or being overwhelmed by one's studies, and seems related to the Surface-Disorganized factor described by Gadula (1996). Furthermore, when the SPQ was combined with the other questionnaires in exploratory factor analysis, some of the more strategically adaptive items from the Surface scale did not load highly on the Surface/Irresolute factor (see Table 10). This includes items such as "I think browsing around is a waste of time, so I only study what is given 
out in class or in course outlines." While the first clause reveals an undesirable attitude (from an educator's standpoint), the second clause may represent a very adaptive choice for a student facing high workload demands. Unfortunately, there is no way to know how respondents may have weighted those two clauses in formulating their responses. The fact that this potentially adaptive item (and others like it) did not load highly on the Surface/Irresolute factor in the exploratory analysis supports the notion that Surface/Irresolute is tapping a sense of confusion or being overwhelmed by one's studies and unsure of how to proceed.

The negative loading of need for cognition with the surface approach and irresolute control (see Table 10 and Figure 11) was not hypothesized (except in a one factor model), but was not surprising. As discussed previously, there are many similarities between descriptions of people low in need for cognition and students who adopt the surface approach. Both avoid mental effort and elaborative processing. Additionally, Cantwell and Monfries (1999) had reported a small but significant negative correlation between need for cognition and irresolute control. The negative loading of need for cognition on this second order Surface/Irresolute factor therefore seems appropriate. This factor represents learners whose knowledge is superficial and unintegrated because of their reliance on surface strategies and their reluctance to engage in reflection. They are confused and unsure of how to proceed with assignments because they lack meaningful connections within their leaming. Their fear of failure is consequently entirely realistic. From this perspective, irresolute control may be an inevitable result of excessive reliance on the surface approach, as the lack of integrated knowledge and meaningful connections leads to uncertainty in dealing with novel situations.

Inflexible control was also closely related to the surface approach. In the combined item 
exploratory factor analyses, the Inflexible items could be made to load on the Surface/Irresolute factor by extracting one less factor than the optimal solution (see page 56 in the Results). However, the Inflexible scale appears to be measuring a distinct construct as shown by the results of the confirmatory factor analyses and the fact that the best solutions in exploratory factor analyses occurred when Inflexible items were allowed to form a separate factor. Although students exhibiting inflexible control may not be performing optimally, they do not feel confused or overwhelmed. They have found a strategy which allows them to get by and feel that they are coping. On the other hand, students exhibiting inflexible control have more in common with the surface approach and irresolute control than they have with the deep approach and need for cognition. In Figure 11, the correlation between the Inflexibility and Surface//rresolute second order factors is substantial, $\mathrm{r}=.526$.

Adaptive control aiso loaded negatively with inflexible control on the second order factor "Inflexibility". Again, this was not surprising. As noted previously, the theoretical descriptions of the two scales sound like logical opposites. Inflexible control involves using one "tried and trusted"'method regardless of the demands of the assignment; adaptive control involves selecting the best method for the particular demands of the assignment.

The strongest relationships in the study were found among need for cognition, the deep approach, and adaptive control. Retuming to Bouffard et al.'s (1995) conceptualization of selfregulation may be helpful in explaining these relationships. Bouffard et al. identified three major components of self-regulation: cognitive strategies, metacognitive strategies, and motivation. Cognitive strategies, which the authors state are required for learning and understanding, would appear to include the strategy component of the deep approach. (Surface strategies would also be 
an appropriate component in some circumstances, but not surface motives.) Metacognitive strategies, for supervising cognition during task execution, would include adaptive control. Motivation, which determines the amount of effort to expend, would include deep motives and need for cognition. Taking a step further back, these elements can all be seen to form part of metacognition. as conceptualized by Schoenfeld (1987). According to him, self-regulation is one of three categories of intellectual behaviour that comprise metacognition. The other two are knowledge about one's own thought processes, and beliefs and intuitions. These relationships are shown in Figure 12.

Figure 12. Model of Self-Regulation

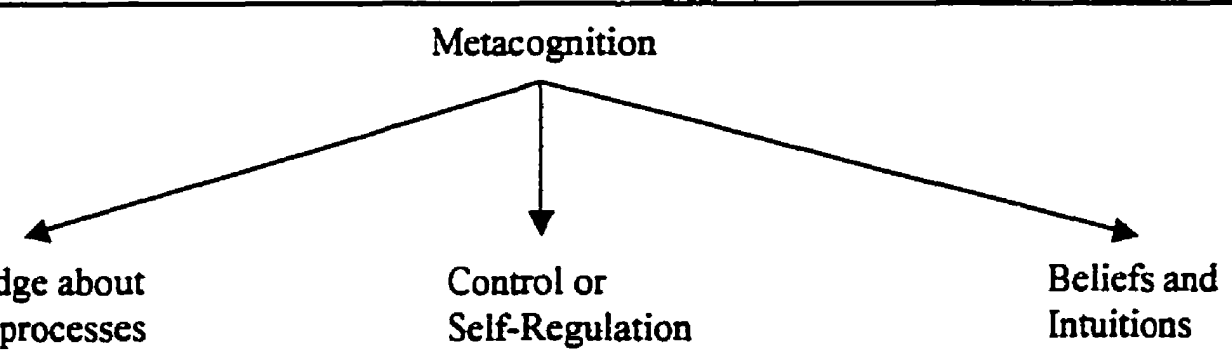

Knowledge about

Self-Regulation

Intuitions

thought processes

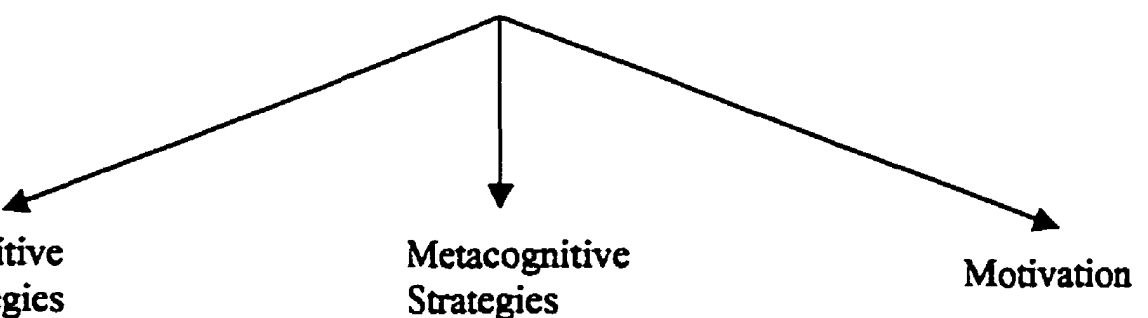

Cognitive

Strategies

Deep Motives

Deep Strategies

Adaptive Control

Need for

Cognition 
Based on the model in Figure 12, the deep approach, need for cognition, and adaptive control might all be closely related because they are all tapping aspects of being a self-regulated learner. Inflexible control, irresolute control, and the negative aspects of the surface approach are all incompatible with effective self-regulation, hence the negative correlations between the SelfRegulation factor and the Surface/Irresolute and Inflexibility factors in the second order model, as shown in Figure 11.

To the extent that the questionnaires used in this study might be measuring aspects of selfregulation, and to the extent that self-regulation is seen as desirable, it might be possible to use these scales to identify students with difficulty self-regulating. This could only be done with caution, because it is not the intended purpose of any of these questionnaires. It could, however, suggest areas where certain students might have weaknesses. If weaknesses in self-regulation are identified, Schoenfeld (1987) has argued that self-regulation is a skill which can be taught. He listed three questions which self-regulators should be able to answer at any point in their work: What are you doing? Why are you doing it? and How does it help you? One of the teaching techniques he described was to ask students these questions, randomly but repeatedly, until they became internalized. (He pointed out, however, that an acceptable response to the first question could be, "I'm mucking around looking for inspiration, and I intend to do so for another five minutes" [Schoenfeld, 1987, p. 206].)

This technique described by Schoenfeld (1987) appears to be most closely related to adaptive control, because it involves evaluating the effectiveness of methods and selecting the most appropriate method for the task. Biggs and Rihn (1984) have shown that it is also possible to teach students to use deep strategies (although it must be noted that they were working with 
highly motivated and highly able students). However, knowledge of deep strategies is no guarantee of their use. As Schiefele (1991) pointed out, deep strategies such as elaboration and seeking out additional information are time-consuming. Schiefele found that use of these strategies was associated with students' levels of individual interest in the subject matter. Those students who were more interested in the subject made greater use of deep strategies than students who had less interest in the subject. So although it may be possible to teach students more effective learning strategies, it may be difficult to get them to use the more demanding deep strategies unless they are interested in the topic. On the other hand, Skinner and Belmont (1993) found that when teachers provided students with clear directions, engaged them in high quality interactions, and offered them a high degree of autonomy when performing tasks, this led to increased student engagement and higher quality outcomes. In turn, the higher level of student engagement inspired teachers to engage students further. Engagement, according to Skinner and Belmont, refers to the intensity and emotional quality of students' involvement in initiating and carrying out learning activities. They connect engagement to intrinsic motivation to learn, which underlies the deep approach and is also related to need for cognition, in the sense of being motivated to think about things--an important component of deep learning. In a similar vein, Schiefele (1991) suggested that if teachers promote students' sense of control, provide challenging activities, and provoke curiosity, this will lead to increased student interest, thereby increasing the likelihood of use of deep strategies.

\section{Limitations of the Study}

Perhaps the greatest limitation of this study is the fact that it relied entirely on self-report responses to questionnaires. There were no other measures to validate that the way students 
responded to the questionnaires is actually reflective of how they normally behave. As noted by Messick (1989), method variance may be responsible for part of the correlations obtained. This is compounded by the potential for response bias, particularly since the items on two of the questionnaires, the SPQ and SFQ, are all positively worded. An approach which incorporated additional corroborating measures such as individual interviews with some participants, or ratings by professors, could have provided evidence to rule out method variance and response bias as explanations. However, this would have come at the cost of anonymity of participants and probably the loss of access to a number of participants since it would have increased their level of involvement considerably.

The limitations of the second order factor analysis, in which structural coefficients were constrained at 1.0 , have already been noted. The study should be replicated with a larger sample.

The length of the questionnaire may have also caused some problems. With eight demographic questions followed by 81 questionnaire items, some of which seem repetitive, some respondents may have found the exercise tedious, reducing motivation to complete the questionnaires. Also, some items are difficult to answer, as they may be true in some circumstances and not in others. Difficulty of the task and reduced motivation of the respondent are two factors which Krosnick (1991) suggested may cause respondents to satisfice when selecting responses. Satisficing may involve selecting the first response that seems reasonable, agreeing with assertions, not differentiating between items on a rating scale, selecting "don't know" (in this case, "neutral"), or responding randomly. Interestingly, Krosnick suggested that respondents who are low in need for cognition may be particularly susceptible to satisficing in surveys. Krosnick's review suggested that the most frequent condition for satisficing may be low 
formal education. Consequently, it is hoped that this sample which consisted of university students who were, furthermore, provided with class time to complete the questionnaires, would not have resorted to excessive satisficing in selecting responses.

The fact that approximately one-third of the sample wrote an unvalidated French translation of the questionnaires must be acknowledged as a limitation. although the francophone results do not appear to have been substantially different in terms of factor structure from the anglophone results. In addition, the population from which the sample was drawn (i.e. military college students) may not be representative of university students in general. Again, however, results at the scale level do not appear to differ greatly from previous studies.

\section{Conclusions}

The strongest conclusion from the study is that, at the scale level, need for cognition, the deep approach, and adaptive control all appear to be measuring something very similar. It has been proposed that they might all be measuring aspects of self-regulated leaming. This suggests that there is benefit to be gained from expanding and integrating knowledge of existing constructs.

The Surface approach scale as it presently exists on the SPQ does not appear to be well defined. It may consist of too many sub-components, such as strategies that can actually be adaptive and two different maladaptive motive components. The scale might also benefit from updating, owing to significant societal changes which affect students and which have occurred since the scale was designed. Some elements of the Surface scale appear to be measuring the same underlying construct as the Irresolute control scale, and there are also commonalities with the Inflexible control scale.

As noted, the Achieving approach scale appears to measure something quite distinct from 
the other scales. The decision, reported by Kember et al. (1999), to leave it out of the new version of the SPQ appears to be a good choice.

The results of this study do not support a conclusion that the three questionnaires are measuring exactly the same thing, which would have suggested redundancy. On the contrary, each questionnaire may have its own specific practical uses. such as for teaching and counselling. However, there are additional gains in theory-building to be obtained from elaborating the relationships between the questionnaires. The study underlines the value of exploring relationships between ostensibly unrelated questionnaires and also supports the need for revision and updating of questionnaires if they are to remain useful. 


\section{References}

Andrews, J., Violato, C., Rabb, K., \& Hollingsworth, M. (1994). A validity study of Biggs' three-factor model of learning approaches: A confirmatory factor analysis employing a Canadian sample. British Joumal of Educational Psychology, 64, 179-185.

Biggs. J. B. (1976). Dimensions of study behaviour: Another look at ATI. British Joumal of Educational Psychology, 46, 68-80.

Biggs, J. B. (1978). Individual and group differences in study processes. British Lournal of Educational Psychology, 48, 274-284.

Biggs, J. B. (1985). The role of metalearning in study processes. British Joumal of Educational Psychology, 55, 185-212.

Biggs, J. B. (1987). Student approaches to learning and studving. Melbourne, Australia: Australian Council for Educational Research.

Biggs, J. B. (1993). What do inventories of students' learning processes really measure? A theoretical review and clarification. British Joumal of Educational Pśchology, 63, 3-19.

Biggs, J. B., \& Kirby, J. R. (1984). Differentiation of learning processes within ability groups. Educational Psychology, 4, 21-38.

Biggs, J. B., \& Rihn, B. A. (1984). The effects of intervention on deep and surface approaches to learning. In J. R. Kirby (Ed.), Cognitive strategies and educational performance (pp. 279-293). Orlando: Academic Press.

Bouffard, T., Boisvert, J., Vezeau, C., \& Larouche, C. (1995). The impact of goal orientation on self-regulation and performance among college students. British 
Joumal of Educational Psychology, 65, 317-329.

Browne, M. W. (1992). FITMOD: A computer program for calculating point and interval estimates of fit measures. Unpublished manuscript.

Cacioppo, J. T., \& Petty, R. E. (1982). The need for cognition. Journal of Personality and Social Psychology. 42, 116-131.

Cacioppo, J. T., Petty, R. E., Feinstein, J. A., \& Jarvis, W. B. G. (1996).

Dispositional differences in cognitive motivation: The life and times of individuals varying in need for cognition. Psychological Bulletin, 119, 197-253.

Cacioppo, J. T., Petty, R. E., \& Kao, C. F. (1984). The efficient assessment of need for cognition. Journal of Personality Assessment, 43, 306-307.

Cantwell, R. H. (1994). Executive control of learning: Its measurement and relationships to leaming in education and nursing. Unpublished doctoral thesis, University of Newcastle, Australia.

Cantwell, R. H., \& Monfries, M. (1999). Need for cognition, self-regulatory control and their relationships to measures of social anxiety. Manuscript submitted for publication.

Cantwell, R. H., \& Moore, P. J. (1996). The development of measures of individual differences in self-regulatory control and their relationship to academic performance. Contemporary Educational Psychology, 21, 500-517.

Cantwell, R. H., \& Moore, P. J. (1998). Relationships among control beliefs, approaches to learning, and the academic performance of final-year nurses. The Alberta Joumal of Educational Research, 44, 98-102. 
Carty, A. E. (1996). Leaming at work: An examination of learming approaches in work settings. Unpublished Master's thesis, Queen's University.

Doherty, S. I. (1991). The relationship between the study approaches of student nurses and objective and subjective learning outcomes. Unpublished master's project, Queen's University.

Dweck, C. S. (1986). Motivational processes affecting learning. American Psychologist, 41, 1040-1048.

Entwistle, N. J. (1988). Motivational factors in students' approaches to learning. In R.R. Schmeck (Ed.), Leaming strategies and learning styles (pp. 21-51). New York: Plenum Press.

Entwistle, N. J., \& Ramsden, P. (1982). Understanding student leaming. New York: Nichols Publishing.

Fabrigar, L. R., Wegener, D. T., MacCallum, R. C., \& Strahan, E. J. (1999). Evaluating the use of exploratory factor analysis in psychological research. Psychological Methods, 4, 272-299.

Flavell, J. H. (1979). Metacognition and cognitive monitoring: A new area of cognitive-developmental inquiry. American Psychologist, 34, 906-911.

Gadula, C. (1996). Approaches to learning in the workplace climate: An analysis of the Approaches to Leaming at Work and Work Climate Inventories. Unpublished Honours thesis, Queen's University.

Glass, G. V., \& Hopkins, K. D. (1996). Statistical methods in education and psychology (3rd ed.). Boston: Allyn and Bacon. 
Hu, L. \& Bentler, P. M. (1998). Fit indices in covariance structure modeling: Sensitivity to underparameterized model misspecification. Psychological Methods, 3, 424.453.

Kember, D., Wong, A., \& Leung, D. Y. P. (1999). Reconsidering the dimensions of approaches to learning. British Joumal of Educational Psychology, 69, 323-343.

Kirby, J. R. (1988). Style, strategy, and skill in reading. In R. R. Schmeck (Ed.), Leaming strategies and learming styles (pp. 227-274). New York: Plenum Press.

Kirby, J. R. (1993). Depth and breadth of processing in summarization and learning from text. Final report to the Social Sciences and Humanities Research Council of Canada. December, 1993.

Knapper, C. K. (1995). Approaches to study and lifelong learning: Some Canadian initiatives. In G. Gibbs (Ed.), Improving student learming through assessment and evaluation (pp. 11-23). Oxford: Oxford Centre for Staff Development.

Krosnick, J. A. (1991). Response strategies for coping with the cognitive demands of attitude measures in surveys. Applied Cognitive Psychology, 5, 213-236.

Marsh, H. W., \& Hocevar, D. (1985). Applications of confirmatory factor analysis to the study of self-concept: first- and higher order factor models and their invariance across groups. Psychological Bulletin, 97, 562-582.

Marton, F., \& Saljo, R. (1976a). On qualitative differences in learning: IOutcome and process. British Journal of Educational Psychology, 46, 4-11. 
Marton F., \& Saljo, R. (1976b). On qualitative differences in learning: IIOutcome as a function of the learner's conception of the task. British Joumal of Educational Psychology, 46, 115-127.

Messick, S. (1989). Validity. In R. L. Linn (Ed.), Educational measurement (3rd ed., pp. 13-105). New York: Macmillan.

Mueller, R. O. (1996). Basic principles of structural equation modeling. New York: Springer.

ONeil, M. J., \& Child, D. (1984). Biggs' SPQ: A British study of its internal structure. British Joumal of Educational Psychology, 54, 228-234.

Pintrich, P. R., \& DeGroot, E. V. (1990). Motivational and self-regulated learning components of classroom academic performance. Journal of Educational Psychology, 82, 33-40.

Richardson, J. T. E. (1994). Cultural specificity of approaches to studying in higher education: A literature survey. Higher Education, 27, 449-468.

Schiefele, U. (1991). Interest, learning, and motivation. Educational Psychologist, 26, 299-323.

Schmeck, R. R. (1988). An introduction to strategies and styles of learning. In R. R. Schmeck (Ed.), Leaming strategies and learming stvles (pp. 3-19). New York: Plenum Press.

Schoenfeld, A. H. (1987). What's all the fuss about metacognition? In A. H. Schoenfeld (Ed.), Cognitive science and mathematics education (pp. 189-215). Hillsdale, NJ: Lawrence Erlbaum. 
Snow, R. E. (1989). Toward assessment of cognitive and conative structures in learning. Educational Researcher, 18, (9), 8-14.

Stevens, J. (1996). Applied multivariate statistics for the social sciences (3rd ed.). Mahwah, NJ: Lawrence Erlbaum.

Winne, P. H. (1995). Inherent details in self-regulated learning. Educational Psychologist, 30, 173-187.

Zimmerman, B. J., \& Martinez-Pons, M. (1988). Construct validation of a strategy model of student self-regulated learning. Joumal of Educational Psychology, $\underline{80}$, 284-290. 


\section{Appendix A}

Questionnaires.

\section{Approaches to Learning Questionnaire}

\section{Demographic Characteristics:}

The following information is requested for making comparisons between groups of people.

1. Are you: Male Female

2. What is your primary language?

French English Other (please specify)

3. What is your age?

4. Which faculty are you currently enrolled in?

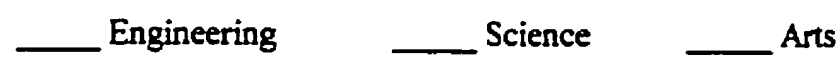

5. What is your present year of study at RMC?

Ist year __ 2nd year __ 3rd year __ 4 th year

6. What was your father's highest level of education?

__ elementary school only
some high school
completed high school
completed trade certificate/
license
some college/CEGEP

$$
\begin{aligned}
& \text { completed college/CEGEP diploma } \\
& \text { some university } \\
& \text { completed university (Bachelor's } \\
& \text { degree) }
\end{aligned}
$$

7. What was your mother's highest level of education?

__ementary school only
some high school
completed high school
completed trade certificate/
license
some college/CEGEP completed college/CEGEP diploma some university completed university (Bachelor's degree) completed Professional, Master's, or $\mathrm{PhD}$ degree don't know

8. What was your average grade in your final year of high school? $\%$ 
For all of the following questions, please read the statement and then circle the response that fits you best. In all cases, 5 means you strongly agree with the statement, and 1 means you strongly disagree with the statement. It is important that you answer each question.

Do not spend too much time thinking about each statement; your first reaction is probably the best. Also, do not worry about projecting a good image. There are no "right" answers, and your answers are confidential.

1. I prefer complex problems to simple ones.

Strongly

Disagree

Disagree

Neutral Agree Strongly

2. I like to have the responsibility of handling a situation that requires a lot of thinking.

3. Thinking is not my idea of fun.

$\begin{array}{lllll}1 & 2 & 3 & 4 & 5 \\ 1 & 2 & 3 & 4 & 5 \\ 1 & 2 & 3 & 4 & 5 \\ 1 & 2 & 3 & 4 & 5\end{array}$

4. I would rather do something that requires little thought than something that is sure to challenge my thinking abilities.

5. I try to anticipate and avoid situations where it is likely I will have to think in depth about something.

6. I find satisfaction in deliberating hard or for long hours.

7. I only think as hard as I have to.

8. I prefer to think about small, daily projects rather than long-ierm ones.

9. I like tasks that require little thought once l've learned them.

10. The idea of relying on thought to make my way to the top appeals to me.

11. I really enjoy a task that involves coming up with new solutions to problems.

12. Learning new ways to think doesn't excite me very much.

13. I prefer my life to be filled with puzzles I must solve.

14. The notion of thinking abstractly is appealing to me.

15. I prefer a task that is intellectual, difficult, and important to one that is somewhat important but does not require much thought.

16. I feel relief rather than satisfaction after completing a task that required a lot of mental effort.

$\begin{array}{lllll}1 & 2 & 3 & 4 & 5 \\ 1 & 2 & 3 & 4 & 5 \\ 1 & 2 & 3 & 4 & 5 \\ 1 & 2 & 3 & 4 & 5 \\ 1 & 2 & 3 & 4 & 5 \\ 1 & 2 & 3 & 4 & 5 \\ 1 & 2 & 3 & 4 & 5 \\ 1 & 2 & 3 & 4 & 5 \\ 1 & 2 & 3 & 4 & 5 \\ 1 & 2 & 3 & 4 & 5 \\ 1 & 2 & 3 & 4 & 5 \\ 1 & 2 & 3 & 4 & 5 \\ 1 & 2 & 3 & 4 & 5 \\ 1 & 2 & 3 & 4 & 5\end{array}$

17. It's enough for me that something gets the job done; I don't care how or why it works.

18. I usually end up deliberating about issues even when they do not affect me personally. 
For the following items, if you think that your answer to a question would depend on the subject being studied, give the answer that would apply to courses in your major.

(This was followed by 42 items constituting the Study Process Questionnaire. This questionnaire is protected by copyright, so has not been reproduced here. Committee members were provided with copies of it.)

As before, if you think that your answer to a question on the items below would depend on the subject being studied, give the answer that would apply to courses in your major.

Strongly
Disagree Disagree Neutral Agree Agree

1. I find that I have one good way of going about completing my assignments, and this is effective nearly all the time.

2. I often find the ideas and methods I come across when preparing for an assignment more confusing than belpful.

3. I place a lot of importance on adjusting my study methods to meet the requirements of particular tasks.

4. While I know that different study tasks sometimes require different approaches, I am usually happier to stick to tried and trusted methods.

5. Although the assignment I am working on may require me to use several different ways of working, I usually end up sticking to my normal methods.

6. Before starting work on a particular problem I like to play with a number of possible ways of attacking the problem.

7. While I usually feel quite confident that I understand how to go about completing an assignment, I often find it hard to fit the material I am using into my assignment plan.

8. I often feel the hardest part of doing assignments is knowing how to do them rather than knowing what to do.

9. I find it challenging when the problem or assignment I have been given requires me to find different ways of studying.

10. I prefer to follow my usual methods of studying, even if this isn't exactly what the assignment requires.

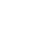

1

2

3

4

5

1

2

3

4

5

1

2

3

4

5

\section{.}

.

.


$\begin{array}{cr}\text { Strongly } & \text { Strongly } \\ \text { Disagree Disagree Neutral Agree Agree }\end{array}$

14. I often find the most interesting part of an assignment is in discovering new ways of tying my material together, and this often leads me to change the way I go about completing the task.

15. Although I usually understand the information I should include in my assignments, I often have difficulty deciding where and when I should use that information.

1

$$
2
$$

34

16. While I usually feel confident about my purpose in completing an assignment, I often lose direetion when dealing with tetailed information and find myseif uncertain of how to deal with this.

17. I often look forward to discovering new or different ways of completing problems or assignments I have been given.

18. I often find I use the same way of working no matter what the particular unit of work is that I am studying.

19. I believe that every problem has a particular way of being completed, and I adjust my way of attacking it accordingly.

20. Although I often know the general ideas relating to a topic, I often get caught out when asked for details, and I'm never sure how to overcome this.

$\begin{array}{llll}2 & 3 & 4 & 5\end{array}$

21. I find that I'm easily distracted from my line of thought as I an working, and this often makes my work disjointed and uneven. 
Appendix B

Covering letter to participants.

Dear Student,

Thank you for allowing me to introduce myself and my study. I am a Personnel Selection Officer in the Canadian Forces, and am currently enrolled in the Master of Education programme at Queen's University. This study will be my thesis.

The purpose of the study is to look at relationships among three existing questionnaires, all of which measure thinking strategies and approaches to learning. I will be attempting to determine whether the three questionnaires are actually measuring the same thing. In addition, I hope to be able to look at differences in approaches to learning between students in different years of study, different faculties, and other relevant characteristics.

Your participation in this study is voluntary and your decision to participate or not will have no impact on your grade in this class. It will take approximately twenty minutes to complete this questionnaire and there will be no further demands on your time. Your individual responses to this questionnaire will be kept completely confidential.

If you agree to participate, please sign the consent form provided. If you are interested in knowing the outcome of the research, a report of the overall results will be provided to the MPL department upon completion.

The three separate questionnaires have been combined into the one booklet which you find here. Please circle your responses directly in the booklet.

If, as a research participant, you have any concerns about this study, now or later, you should feel free to discuss this with me, my supervisor Dr. John Kirby (533-6000, ext. 77231 ) or the Dean of the Faculty of Education at Queen's, Dr. Rena Upitis (533-6000, ext. 77238).

In order to obtain representative data, it is important to me that as many people as possible complete the questionnaire. Your contribution to my research is therefore appreciated.

Sincerely,

Chris Evans (Captain)

530-3731 
Appendix C

\section{Consent Form}

Title of Study: Student Metacognitions About Learning

Purpose of Study: A comparison of three questionnaires related to student approaches to learning.

Principal Researcher: Chris Evans (Captain), Queen's University

I understand the information concerning this study and agree to participate.

\section{Formule de consentement}

Le titre de l'étude: Les métacognitions des étudiants au sujet de l'apprentissage

Le but du projet: Faire une comparaison entre trois questionnaires qui traitent des approches à l'apprentissage.

La chercheuse principale: Chris Evans (Capitaine), luniversité Queen's

Je comprends l'information à l'égard de cet étude et je consens à y paarticiper.

Signature du/de la participant(e)

\section{Date}

Date 
Appendix D

Table D1.

Descriptive Statistics for All Items

\begin{tabular}{|c|c|c|c|c|c|c|c|c|c|}
\hline \multirow[t]{2}{*}{ Item } & \multirow[t]{2}{*}{$\underline{\mathbf{N}}$} & \multirow[t]{2}{*}{ Mean } & \multirow{2}{*}{$\begin{array}{l}\text { Standard } \\
\text { Deviation }\end{array}$} & \multicolumn{3}{|c|}{ Skewness } & \multicolumn{3}{|c|}{ Kurtosis } \\
\hline & & & & Stat. & Std. Err. & $z$ & Stat & Std. Err. & $\underline{z}$ \\
\hline NCS1 & 226 & 3.46 & .86 & -.44 & .16 & -2.68 & -.32 & .32 & -1.00 \\
\hline NCS2 & 225 & 3.79 & .72 & -.62 & .16 & -3.83 & .57 & .32 & 1.76 \\
\hline NCS3 & 226 & 3.81 & .86 & -.68 & .16 & -4.20 & .22 & .32 & 0.69 \\
\hline NCS4 & 226 & 3.83 & .82 & -.69 & .16 & -4.23 & .44 & .32 & 1.36 \\
\hline NCS5 & 226 & 4.00 & .74 & -.66 & .16 & -4.06 & .63 & .32 & 1.95 \\
\hline NCS6 & 224 & 3.26 & 1.07 & -.17 & .16 & -1.07 & -.56 & .32 & 1.73 \\
\hline NCS7 & 226 & 3.60 & .98 & -.63 & .16 & -3.86 & -.32 & .32 & -1.00 \\
\hline NCS8 & 226 & 3.44 & 1.03 & -.35 & .16 & -2.17 & -.73 & .32 & -2.27 \\
\hline NCS9 & 226 & 3.18 & .96 & .12 & .16 & 0.75 & -.91 & .32 & -2.82 \\
\hline NCS10 & 226 & 3.88 & .81 & -.62 & .16 & -3.84 & .66 & .32 & 2.05 \\
\hline NCSII & 226 & 3.93 & .77 & -.71 & .16 & -4.38 & .60 & .32 & 1.85 \\
\hline $\mathrm{NCS} 12$ & 226 & 3.80 & .87 & -.59 & .16 & -3.63 & .03 & .32 & 0.09 \\
\hline NCS13 & 226 & 3.40 & .94 & -.17 & .16 & -1.06 & -.42 & .32 & -1.30 \\
\hline NCS14 & 225 & 3.51 & 1.06 & -.62 & .16 & -3.85 & -.22 & .32 & -0.69 \\
\hline NCS15 & 226 & 3.46 & .92 & -.35 & .16 & -2.15 & -.58 & .32 & 1.79 \\
\hline NCS16 & 225 & 3.61 & 1.03 & -.84 & .16 & -5.19 & .16 & .32 & 0.50 \\
\hline NCS17 & 226 & 3.94 & .90 & -.81 & .16 & -4.99 & .25 & .32 & 0.78 \\
\hline NCS18 & 226 & 3.62 & .88 & -.62 & .16 & -3.85 & .05 & .32 & 0.16 \\
\hline SPQ1 & 226 & 2.59 & 1.29 & .38 & .16 & 2.35 & -1.01 & .32 & -3.15 \\
\hline SPQ2 & 226 & 3.34 & .97 & -1.07 & .16 & -6.59 & 1.05 & .32 & 3.27 \\
\hline SPQ3 & 226 & 3.85 & 1.09 & -.71 & .16 & -4.35 &. .41 & .32 & -1.26 \\
\hline SPQ4 & 226 & 2.52 & 1.01 & .48 & .16 & 2.99 & -.29 & .32 & -0.91 \\
\hline SPQ5 & 226 & 3.63 & .93 & -.54 & .16 & -3.36 &. .16 & .32 & -0.50 \\
\hline SPQ6 & 226 & 2.89 & 1.12 & .03 & .16 & 0.19 & -.87 & .32 & -2.70 \\
\hline SPQ7 & 226 & 3.79 & 1.08 & -.70 & .16 & -4.31 & -.28 & .32 & -0.88 \\
\hline SPQ8 & 226 & 3.69 & .83 & -.54 & .16 & -3.35 & .52 & .32 & 1.61 \\
\hline SPQ9 & 226 & 4.27 & .72 & -.95 & .16 & -5.85 & 1.54 & .32 & 4.78 \\
\hline SPQ10 & 226 & 3.58 & 1.07 & -.83 & .16 & -5.11 & .04 & .32 & 0.13 \\
\hline SPQ11 & 226 & 4.01 & .72 & -.58 & .16 & -3.58 & .54 & .32 & 1.68 \\
\hline SPQ12 & 226 & 3.65 & .89 & -.71 & .16 & -4.40 & .22 & .32 & 0.69 \\
\hline SPQ13 & 226 & 4.38 & .73 & -1.34 & .16 & -8.25 & 2.55 & .32 & 7.93 \\
\hline SPQ14 & 225 & 3.38 & 1.12 & -.26 & .16 & -1.60 & -.96 & .32 & -2.98 \\
\hline SPQ15 & 225 & 4.08 & .85 & -.77 & .16 & -4.75 & .29 & .32 & 0.91 \\
\hline SPQ16 & 226 & 3.23 & 1.02 & .07 & .16 & 0.44 & .49 & .32 & 1.83 \\
\hline SPQ17 & 226 & 3.54 & .84 & -.67 & .16 & -4.11 & .46 & .32 & 1.44 \\
\hline SPQ18 & 226 & 3.16 & 1.11 & -.05 & .16 & -0.31 & -.97 & .32 & -3.00 \\
\hline SPQ19 & 226 & 3.20 & 1.18 & -.35 & .16 & -2.18 & -.90 & .32 & -2.81 \\
\hline
\end{tabular}

Table D1 continues 
Table D1. (continued)

\begin{tabular}{|c|c|c|c|c|c|c|c|c|c|}
\hline \multirow[t]{2}{*}{ Item } & \multirow[t]{2}{*}{$\underline{N}$} & \multirow[t]{2}{*}{ Mean } & \multirow{2}{*}{$\begin{array}{l}\text { Standard } \\
\text { Deviation }\end{array}$} & \multicolumn{3}{|c|}{ Skewness } & \multicolumn{3}{|c|}{ Kuntosis } \\
\hline & & & & Stat. & Std. Err. & $\underline{z}$ & Stat. & Std. Err. & $\underline{z}$ \\
\hline SPQ20 & 226 & 2.99 & 1.21 &. .13 & .16 & -0.81 & -1.06 & .32 & -3.30 \\
\hline SPQ21 & 225 & 3.51 & 1.11 & -.46 & .16 & -2.82 & -.58 & .32 & -1.79 \\
\hline SPQ22 & 226 & 2.59 & .94 & .35 & .16 & 2.20 & -.62 & .32 & -1.93 \\
\hline SPQ23 & 225 & 3.98 & .73 & - .90 & .16 & -5.54 & 1.93 & .32 & 5.97 \\
\hline SPQ24 & 225 & 2.77 & 1.02 & .12 & .16 & 0.75 & -.82 & .32 & -2.55 \\
\hline SPQ25 & 226 & 3.12 & 1.09 & .02 & .16 & 0.13 & -.79 & .32 & -2.46 \\
\hline SPQ26 & 225 & 3.69 & .83 & -.56 & .16 & -3.47 & .33 & .32 & 1.03 \\
\hline SPQ27 & 226 & 2.30 & .97 & .65 & .16 & 3.98 & -.10 & .32 & -0.31 \\
\hline SPQ28 & 226 & 4.04 & 1.01 & -1.19 & .16 & -7.32 & 1.01 & .32 & 3.13 \\
\hline SPQ29 & 226 & 3.11 & .90 & -.26 & .16 & -1.59 & -.30 & .32 & -0.94 \\
\hline SPQ30 & 226 & 3.61 & .78 & -.82 & .16 & -5.07 & .92 & .32 & 2.84 \\
\hline SPQ31 & 224 & 2.90 & 1.27 & .10 & .16 & 0.63 & -1.12 & .32 & -3.45 \\
\hline SPQ32 & 225 & 3.42 & 1.20 & -.42 & .16 & -2.62 & -.72 & .32 & -2.21 \\
\hline SPQ33 & 226 & 3.26 & 1.21 & -.20 & .16 & -1.25 & -1.05 & .32 & -3.26 \\
\hline SPQ34 & 226 & 2.66 & 1.08 & .24 & .16 & 1.46 & -.88 & .32 & -2.73 \\
\hline SPQ35 & 226 & 2.73 & .96 & .39 & .16 & 2.41 & -.33 & .32 & -1.03 \\
\hline SPQ36 & 226 & 3.03 & 1.00 & -.03 & .16 & -0.19 & -.74 & .32 & -2.29 \\
\hline SPQ37 & 226 & 3.33 & 1.21 & -.26 & .16 & -1.57 & -1.02 & .32 & -3.16 \\
\hline SPQ38 & 226 & 3.15 & 1.26 & -.31 & .16 & -1.88 & -1.03 & .32 & -3.20 \\
\hline SPQ39 & 226 & 2.70 & 1.17 & .09 & .16 & 0.56 & -1.02 & .32 & -3.16 \\
\hline SPQ40 & 226 & 3.02 & 1.04 & -.21 & .16 & -1.31 & -.90 & .32 & -2.79 \\
\hline SPQ41 & 225 & 3.98 & .70 & -1.01 & .16 & -6.22 & 2.43 & .32 & 7.53 \\
\hline SPQ42 & 226 & 3.48 & 1.06 & -.52 & .16 & -3.23 & -.32 & .32 & -1.00 \\
\hline SFQ1 & 226 & 3.39 & .93 & -.55 & .16 & -3.41 & -.30 & .32 & -0.94 \\
\hline SFQ2 & 226 & 2.67 & .88 & .11 & .16 & 0.69 & -.70 & .32 & -2.17 \\
\hline SFQ3 & 226 & 3.40 & .84 & -.51 & .16 & -3.12 & .00 & .32 & 0.00 \\
\hline SFQ4 & 226 & 3.51 & .89 & -.59 & .16 & -3.66 & -.17 & .32 & -0.53 \\
\hline SFQ5 & 226 & 3.42 & .92 & -.26 & .16 & -1.58 & -.62 & .32 & -1.91 \\
\hline SFQ6 & 225 & 3.33 & .99 & -.53 & .16 & -3.27 & -.65 & .32 & -1.74 \\
\hline SFQ7 & 226 & 2.92 & .86 & .03 & .16 & 0.19 & -.58 & .32 & -1.81 \\
\hline SFQ8 & 225 & 3.31 & 1.04 & -.45 & .16 & -2.78 & -.59 & .32 & -1.84 \\
\hline SFQ9 & 226 & 3.30 & .94 & -.41 & .16 & -2.53 & -.41 & .32 & -1.27 \\
\hline SFQ10 & 226 & 3.16 & .92 & -.19 & .16 & -1.20 & -.94 & .32 & -2.90 \\
\hline SFQ11 & 226 & 3.27 & .85 & -.24 & .16 & -1.49 & -.43 & .32 & -1.34 \\
\hline SFQ12 & 226 & 3.56 & .85 & -.85 & .16 & -5.22 & .25 & .32 & 0.78 \\
\hline SFQ13 & 226 & 3.23 & 1.00 & -.09 & .16 & -0.56 & -1.08 & .32 & -3.36 \\
\hline SFQ14 & 226 & 3.11 & .94 & -.03 & .16 & -0.19 & -.70 & .32 & -2.16 \\
\hline SFQ15 & 226 & 3.01 & 1.01 & -.08 & .16 & -0.50 & -1.08 & .32 & -3.36 \\
\hline SFQ16 & 226 & 2.65 & .92 & .34 & .16 & 2.09 & -.53 & .32 & -1.64 \\
\hline SFQ17 & 226 & 3.20 & .93 & -.24 & .16 & -1.49 & -.65 & .32 & -2.03 \\
\hline
\end{tabular}


Table DI. (continued)

\begin{tabular}{|c|c|c|c|c|c|c|c|c|c|}
\hline \multirow[t]{2}{*}{ Item } & \multirow[t]{2}{*}{$\mathbf{N}$} & \multirow[t]{2}{*}{ Mean } & \multirow{2}{*}{$\begin{array}{l}\text { Standard } \\
\text { Deviation }\end{array}$} & \multicolumn{3}{|c|}{ Skewness } & \multicolumn{3}{|c|}{ Kurtosis } \\
\hline & & & & Stat. & Std. Err. & $\underline{z}$ & Stat. & Std. & $\underline{z}$ \\
\hline SFQ18 & 226 & 3.31 & .90 & -.51 & .16 & -3.17 & -.80 & .32 & -2.47 \\
\hline SFQ19 & 225 & 3.37 & .81 & -.27 & .16 & -1.68 & -.72 & .32 & -2.24 \\
\hline SFQ20 & 226 & 2.81 & .97 & .13 & .16 & 0.81 & -.76 & .32 & -2.37 \\
\hline SFQ21 & 226 & 3.04 & 1.17 & .12 & .16 & 0.75 & -.99 & .32 & -3.08 \\
\hline
\end{tabular}


Appendix E

Table E1.

t-Tests for Gender and Primary Language

\begin{tabular}{|c|c|c|c|c|c|c|c|c|}
\hline \multirow[b]{3}{*}{ Item } & \multicolumn{4}{|c|}{ Gender } & \multicolumn{4}{|c|}{ Primary Language } \\
\hline & \multicolumn{2}{|c|}{ Mean } & \multirow[b]{2}{*}{$t$} & \multirow[b]{2}{*}{ Sig. } & \multicolumn{2}{|c|}{ Mean } & \multirow[b]{2}{*}{$t$} & \multirow[b]{2}{*}{ Sig. } \\
\hline & Female & Male & & & Franco & Anglo & & \\
\hline $\mathrm{NCSI}$ & 3.25 & 3.54 & 2.31 & .022 & 3.56 & 3.40 & 1.30 & .195 \\
\hline NCS2 & 3.67 & 3.84 & 1.63 & .105 & 3.81 & 3.78 & 0.29 & .771 \\
\hline NCS3 & 3.80 & 3.81 & .13 & .895 & 3.94 & 3.73 & 1.70 & .091 \\
\hline NCS4 & 3.75 & 3.87 & 0.99 & .322 & 3.72 & 3.88 & 1.42 & .156 \\
\hline NCS5 & 4.03 & 4.00 & 0.29 & .773 & 4.08 & 3.96 & 1.13 & .260 \\
\hline NCS6 & 3.22 & 3.28 & 0.37 & .715 & 3.79 & 2.98 & 5.81 & .000 \\
\hline NCS7 & 3.66 & 3.58 & 0.54 & .591 & 3.91 & 3.44 & 3.89 & .000 \\
\hline NCS8 & 3.63 & 3.37 & 1.71 & .089 & 3.58 & 3.37 & 1.50 & .134 \\
\hline NCS9 & 3.08 & 3.23 & 1.07 & .286 & 3.27 & 3.14 & 0.97 & .334 \\
\hline NCS10 & 3.78 & 3.91 & 1.10 & .274 & 4.06 & 3.78 & 2.57 & .011 \\
\hline NCS11 & 3.80 & 3.99 & 1.51 & .135 & 3.89 & 3.95 & 0.62 & .537 \\
\hline NCS12 & 3.84 & 3.79 & 0.43 & .666 & 3.85 & 3.77 & 0.66 & .512 \\
\hline NCS13 & 3.38 & 3.43 & 0.36 & .723 & 3.54 & 3.33 & 1.67 & .096 \\
\hline NCS14 & 3.33 & 3.59 & 1.67 & .096 & 3.48 & 3.52 & 0.27 & .790 \\
\hline NCS15 & 3.53 & 3.44 & 0.67 & .506 & 3.53 & 3.42 & 0.86 & .393 \\
\hline NCS16 & 3.67 & 3.59 & 0.55 & .581 & 3.77 & 3.52 & 1.76 & .080 \\
\hline NCS17 & 3.95 & 3.94 & 0.07 & .946 & 4.11 & 3.85 & 2.12 & .035 \\
\hline NCS18 & 3.67 & 3.60 & 0.58 & .564 & 3.73 & 3.56 & 1.44 & .152 \\
\hline SPQ1 & 2.59 & 2.58 & 0.05 & .959 & 2.33 & 2.73 & 2.27 & .024 \\
\hline SPQ2 & 3.84 & 3.57 & 2.08 & .039 & 3.80 & 3.55 & 1.83 & .069 \\
\hline SPQ3 & 3.98 & 3.79 & 1.21 & .227 & 3.96 & 3.78 & 1.18 & .238 \\
\hline SPQ4 & 2.41 & 2.55 & 0.98 & .327 & 2.46 & 2.55 & 0.67 & .501 \\
\hline SPQ5 & 3.56 & 3.67 & 0.79 & .430 & 3.54 & 3.68 & 1.05 & .296 \\
\hline SPQ6 & 3.47 & 2.67 & 5.10 & .000 & 2.70 & 2.99 & 1.91 & .057 \\
\hline SPQ7 & 3.88 & 3.61 & 1.63 & .105 & 3.63 & 3.71 & 0.54 & .592 \\
\hline SPQ8 & 3.73 & 3.68 & 0.42 & .679 & 3.68 & 3.70 & 0.15 & .883 \\
\hline SPQ9 & 4.31 & 4.25 & 0.60 & .552 & 4.29 & 4.25 & 0.39 & .697 \\
\hline SPQ10 & 3.83 & 3.47 & 2.51 & .013 & 3.42 & 3.66 & 1.62 & .106 \\
\hline SPQ11 & 3.94 & 4.04 & 0.93 & .353 & 4.03 & 4.00 & 0.25 & .803 \\
\hline SPQ12 & 3.88 & 3.56 & 2.43 & .016 & 3.72 & 3.61 & 0.88 & .379 \\
\hline SPQ13 & 4.38 & 4.39 & 0.15 & .878 & 4.27 & 4.44 & 1.66 & .098 \\
\hline SPQ14 & 3.63 & 3.29 & 2.14 & .034 & 3.73 & 3.19 & 3.56 & .000 \\
\hline
\end{tabular}


Table E1. (continued)

\begin{tabular}{|c|c|c|c|c|c|c|c|c|}
\hline \multirow[b]{3}{*}{ Item } & \multicolumn{4}{|c|}{ Gender } & \multicolumn{4}{|c|}{ Primary Language } \\
\hline & \multicolumn{2}{|c|}{ Mean } & \multirow[b]{2}{*}{1} & \multirow[b]{2}{*}{ Sig. } & \multicolumn{2}{|c|}{ Mean } & \multirow[b]{2}{*}{$t$} & \multirow[b]{2}{*}{ Sig. } \\
\hline & Female & Male & & & Franco & Anglo & & \\
\hline SPQ15 & 4.16 & 4.06 & 0.81 & .420 & 4.30 & 3.97 & 2.88 & .004 \\
\hline SPQ16 & 3.27 & 3.21 & 0.40 & .688 & 3.15 & 3.27 & 0.80 & .426 \\
\hline SPQ17 & 3.66 & 3.51 & 1.19 & .234 & 3.63 & 3.50 & 1.17 & .245 \\
\hline SPQ18 & 3.58 & 3.00 & 3.63 & .000 & 3.47 & 3.00 & 3.09 & .002 \\
\hline SPQ19 & 3.66 & 3.02 & 3.75 & .000 & 3.05 & 3.29 & 1.43 & .155 \\
\hline SPQ20 & 3.30 & 2.88 & 2.39 & .018 & 3.23 & 2.86 & 2.22 & .028 \\
\hline SPQ21 & 3.51 & 3.51 & 0.01 & .993 & 3.23 & 3.66 & 2.87 & .004 \\
\hline SPQ22 & 2.34 & 2.68 & 2.43 & .016 & 2.52 & 2.63 & 0.81 & .416 \\
\hline SPQ23 & 3.84 & 3.90 & 0.46 & .648 & 3.90 & 3.86 & 0.33 & .745 \\
\hline SPQ24 & 2.94 & 2.71 & 1.49 & .139 & 2.87 & 2.72 & 1.08 & .282 \\
\hline SPQ25 & 3.08 & 3.13 & 0.32 & .747 & 3.16 & 3.09 & 0.50 & .619 \\
\hline SPQ26 & 3.73 & 3.68 & 0.43 & .666 & 3.68 & 3.70 & 0.18 & .856 \\
\hline SPQ27 & 2.20 & 2.34 & 0.92 & .360 & 2.19 & 2.36 & 1.26 & .210 \\
\hline SPQ28 & 4.02 & 4.05 & 0.23 & .820 & 3.97 & 4.08 & 0.76 & .449 \\
\hline SPQ29 & 3.11 & 3.12 & 0.07 & .948 & 3.08 & 3.13 & 0.42 & .672 \\
\hline SPQ30 & 3.63 & 3.61 & 0.14 & .888 & 3.81 & 3.50 & 2.85 & .005 \\
\hline SPQ31 & 2.60 & 3.01 & 2.20 & .029 & 3.05 & 2.82 & 1.32 & .188 \\
\hline SPQ32 & 3.44 & 3.43 & 0.07 & .944 & 3.92 & 3.15 & 4.84 & .000 \\
\hline SPQ33 & 3.41 & 3.21 & 1.12 & .262 & 3.15 & 3.31 & 0.95 & .342 \\
\hline SPQ34 & 2.72 & 2.65 & 0.42 & .678 & 2.73 & 2.63 & 0.72 & .475 \\
\hline SPQ35 & 2.83 & 2.70 & 0.94 & .349 & 2.89 & 2.64 & 1.85 & .065 \\
\hline SPQ36 & 3.23 & 2.94 & 2.03 & .044 & 3.11 & 2.98 & 0.97 & .335 \\
\hline SPQ37 & 3.27 & 3.35 & 0.46 & .646 & 3.14 & 3.43 & 1.73 & .086 \\
\hline SPQ38 & 3.27 & 3.09 & 0.92 & .357 & 3.81 & 2.79 & 6.63 & .000 \\
\hline SPQ39 & 2.41 & 2.83 & 2.50 & .013 & 2.51 & 2.81 & 1.87 & .063 \\
\hline SPQ40 & 2.94 & 3.06 & 0.77 & .443 & 3.04 & 3.01 & 0.17 & .867 \\
\hline SPQ41 & 4.09 & 3.95 & 1.46 & .147 & 4.08 & 3.92 & 1.56 & .121 \\
\hline SPQ42 & 3.92 & 3.32 & 3.98 & .000 & 3.52 & 3.46 & 0.38 & .705 \\
\hline SFQ1 & 3.48 & 3.35 & 0.94 & .346 & 3.49 & 3.33 & 1.23 & .219 \\
\hline SFQ2 & 2.69 & 2.66 & 0.22 & .824 & 2.57 & 2.72 & 1.24 & .218 \\
\hline SFQ3 & 3.52 & 3.35 & 1.30 & .196 & 3.51 & 3.34 & 1.42 & .158 \\
\hline SFQ4 & 3.45 & 3.54 & 0.66 & .509 & 3.84 & 3.34 & 4.40 & .000 \\
\hline SFQ5 & 3.52 & 3.39 & 0.87 & .384 & 3.65 & 3.29 & 2.80 & .005 \\
\hline SFQ6 & 3.41 & 3.29 & 0.77 & .442 & 3.52 & 3.23 & 2.15 & .033 \\
\hline SFQ7 & 3.22 & 2.80 & 3.35 & .001 & 2.90 & 2.93 & 0.28 & .783 \\
\hline SFQ8 & 3.46 & 3.25 & 1.42 & .157 & 3.30 & 3.31 & 0.03 & .976 \\
\hline
\end{tabular}

Table E1 continues 
Table EI. (continued)

\begin{tabular}{|c|c|c|c|c|c|c|c|c|}
\hline \multirow[b]{3}{*}{ Item } & \multicolumn{4}{|c|}{ Gender } & \multicolumn{4}{|c|}{ Primary Language } \\
\hline & \multicolumn{2}{|c|}{ Mean } & \multirow[b]{2}{*}{1} & \multirow[b]{2}{*}{ Sig. } & \multicolumn{2}{|c|}{ Mean } & \multirow[b]{2}{*}{1} & \multirow[b]{2}{*}{ Sig. } \\
\hline & Female & Male & & & Franco & Anglo & & \\
\hline SFQ9 & 3.38 & 3.27 & 0.73 & .467 & 3.27 & 3.32 & $0.4 i$ & .683 \\
\hline SFQ10 & 3.08 & 3.20 & 0.88 & .378 & 3.13 & 3.18 & 0.44 & .658 \\
\hline SFQ11 & 3.45 & 3.19 & 2.09 & .038 & 3.28 & 3.27 & 0.11 & .912 \\
\hline SFQ12 & 3.56 & 3.57 & 0.02 & .983 & 3.53 & 3.58 & 0.39 & .696 \\
\hline SFQ13 & 3.30 & 3.21 & 0.62 & .533 & 3.51 & 3.07 & 3.17 & .002 \\
\hline SFQ14 & 3.13 & 3.11 & 0.14 & .890 & 3.33 & 2.99 & 2.59 & .010 \\
\hline SFQ15 & 3.23 & 2.93 & 2.05 & .042 & 2.82 & 3.12 & 2.10 & .037 \\
\hline SFQ16 & 2.75 & 2.61 & 0.90 & .323 & 2.42 & 2.78 & 2.82 & .005 \\
\hline SFQ17 & 3.23 & 3.18 & 0.39 & .695 & 3.33 & 3.13 & 1.54 & .125 \\
\hline SFQ18 & 3.27 & 3.33 & 0.48 & .633 & 3.52 & 3.20 & 2.55 & .011 \\
\hline SFQ19 & 3.38 & 3.37 & 0.05 & .959 & 3.27 & 3.42 & 1.34 & .182 \\
\hline SFQ20 & 2.88 & 2.78 & 0.69 & .493 & 2.70 & 2.87 & 1.29 & .199 \\
\hline SFQ21 & 2.95 & 3.07 & 0.66 & .507 & 3.03 & 3.04 & 0.10 & .925 \\
\hline
\end{tabular}


Appendix F

Table F1.

Standardized Factor Loadings for First Order Model.

Confirmatory Factor Analysis

\begin{tabular}{|c|c|c|c|c|c|c|}
\hline Item & $\begin{array}{l}\text { Need for } \\
\text { Cognition }\end{array}$ & Surface & Deep & Inflexible & Irresolute & Adaptive \\
\hline NCS1 & .529 & & & & & \\
\hline NCS2 & .533 & & & & & \\
\hline NCS3 & .512 & & & & & \\
\hline NCS4 & .440 & & & & & \\
\hline NCS5 & .520 & & & & & \\
\hline NCS6 & .413 & & & & & \\
\hline NCS7 & .401 & & & & & \\
\hline NCS8 & .216 & & & & & \\
\hline NCS9 & .352 & & & & & \\
\hline NCS 10 & .500 & & & & & \\
\hline NCS11 & .565 & & & & & \\
\hline $\mathrm{NCS} 12$ & .494 & & & & & \\
\hline $\mathrm{NCS} 13$ & .605 & & & & & \\
\hline NCS14 & .599 & & & & & \\
\hline NCS15 & .411 & & & & & \\
\hline NCS16 & .339 & & & & & \\
\hline NCS17 & .437 & & & & & \\
\hline NCS18 & .321 & & & & & \\
\hline SPQ1 & & .527 & & & & \\
\hline SPQ2 & & & .392 & & & \\
\hline SPQ4 & & .477 & & & & \\
\hline SPQ5 & & & .347 & & & \\
\hline SPQ7 & & .398 & & & & \\
\hline SPQ8 & & & .375 & & & \\
\hline SPQ10 & & .406 & & & & \\
\hline SPQ11 & & & .483 & & & \\
\hline SPQ13 & & .146 & & & & \\
\hline SPQ14 & & & .480 & & & \\
\hline SPQ16 & & .330 & & & & \\
\hline SPQ17 & & & .404 & & & \\
\hline
\end{tabular}


Table F1. (continued)

\begin{tabular}{|c|c|c|c|c|c|c|}
\hline Item & $\begin{array}{l}\text { Need for } \\
\text { Cognition }\end{array}$ & Surface & Deep & Inflexible & Irresolute & Adaptive \\
\hline SPQ19 & & .307 & & & & \\
\hline SPQ20 & & & .519 & & & \\
\hline SPQ22 & & .599 & & & & \\
\hline SPQ23 & & & .595 & & & \\
\hline SPQ25 & & .480 & & & & \\
\hline SPQ26 & & & .533 & & & \\
\hline SPQ28 & & .386 & & & & \\
\hline SPQ29 & & & .462 & & & \\
\hline SPQ31 & & .463 & & & & \\
\hline SPQ32 & & & .462 & & & \\
\hline SPQ34 & & .360 & & & & \\
\hline SPQ35 & & & .490 & & & \\
\hline SPQ37 & & .651 & & & & \\
\hline SPQ38 & & & .276 & & & \\
\hline SPQ40 & & 399 & & & & \\
\hline SPQ4I & & & .584 & & & \\
\hline SFQ1 & & & & .368 & & \\
\hline SFQ2 & & & & & .310 & \\
\hline SFQ3 & & & & & & .456 \\
\hline SFQ4 & & & & .605 & & \\
\hline SFQ5 & & & & .692 & & \\
\hline SFQ6 & & & & & & .621 \\
\hline SFQ7 & & & & & .519 & \\
\hline SFQ8 & & & & & .414 & \\
\hline SFQ9 & & & & & & .241 \\
\hline SFQ10 & & & & .668 & & \\
\hline SFQ11 & & & & & & .614 \\
\hline SFQ12 & & & & .619 & & \\
\hline SFQ13 & & & & .787 & & \\
\hline SFQ14 & & & & & & .621 \\
\hline SFQ15 & & & & & .687 & \\
\hline SFQ16 & & & & & .642 & \\
\hline SFQ17 & & & & & & .714 \\
\hline SFQ18 & & & & .786 & & \\
\hline SFQ19 & & & & & & .444 \\
\hline SFQ20 & & & & & .558 & \\
\hline SEO21 & & & & & 575 & \\
\hline
\end{tabular}


Appendix G

Figure G1. One Factor Second Order Model

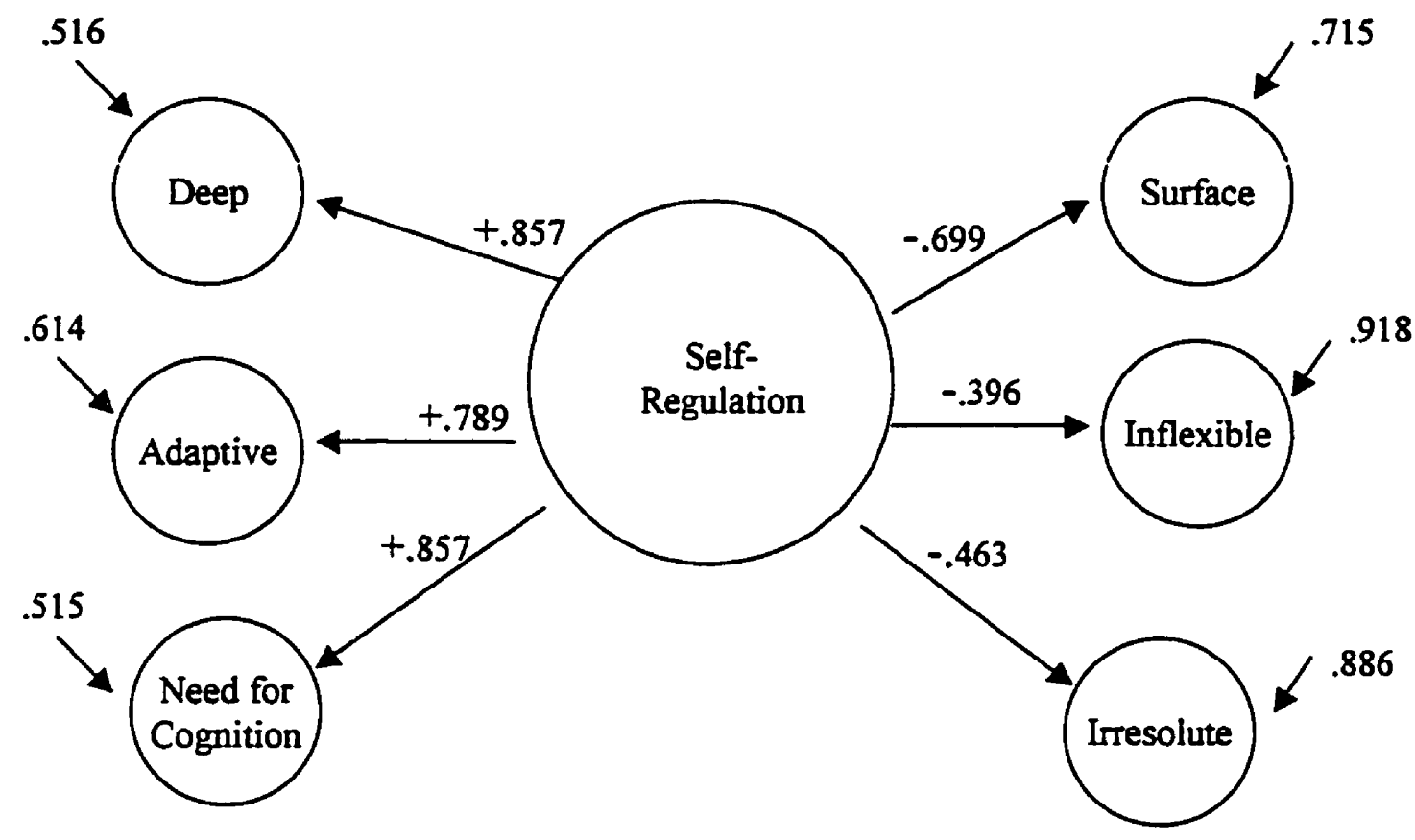


Appendix G

Figure G2. Two Factor Second Order Model.

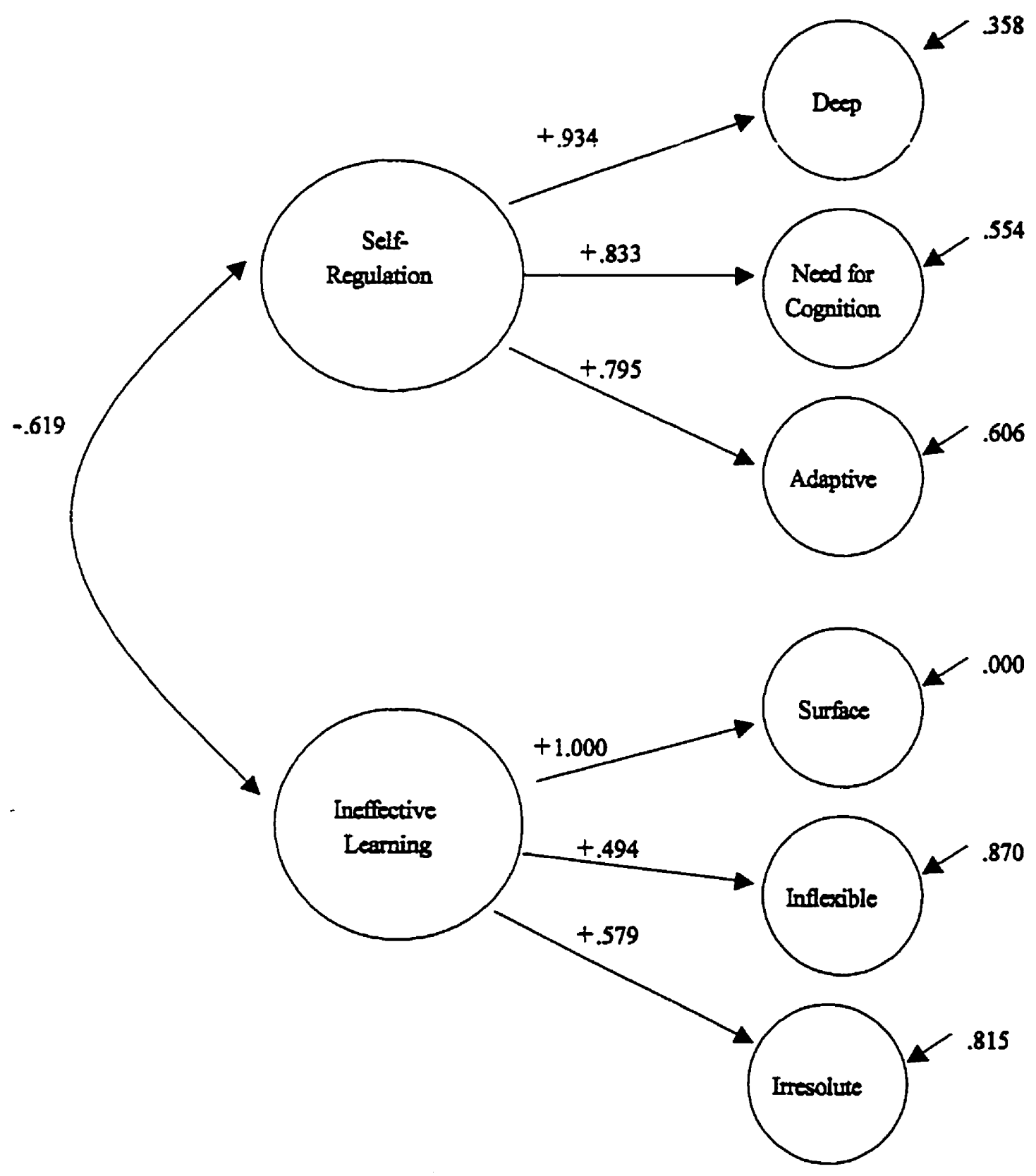


Appendix $\mathrm{H}$

Table H1.

Descriptive Statistics for Scale Scores

\begin{tabular}{|c|c|c|c|c|c|c|c|}
\hline \multirow[t]{2}{*}{ Scale } & \multirow[t]{2}{*}{$\underline{N}$} & \multirow[t]{2}{*}{ Mean } & \multirow{2}{*}{$\begin{array}{l}\text { Standard } \\
\text { Deviation }\end{array}$} & \multicolumn{2}{|c|}{ Skewness } & \multicolumn{2}{|c|}{ Kurtosis } \\
\hline & & & & Stat. & Std. Err. & Stat. & Std. Err. \\
\hline $\begin{array}{l}\text { Need for } \\
\text { Cognition }\end{array}$ & 226 & 65.51 & 8.02 & 0.15 & .16 & -0.44 & .32 \\
\hline Deep & 226 & 48.84 & 6.79 & -0.06 & .16 & 0.45 & .32 \\
\hline Surface & 226 & 44.84 & 7.45 & -0.36 & .16 & -0.22 & .32 \\
\hline $\begin{array}{l}\text { Achieve } \\
\text { Motive }\end{array}$ & 226 & 23.97 & 3.91 & -0.11 & .16 & -0.34 & .32 \\
\hline $\begin{array}{l}\text { Achieve } \\
\text { Strategy }\end{array}$ & 226 & 22.60 & 4.24 & -0.24 & .16 & 0.39 & .32 \\
\hline Adaptive & 226 & 22.98 & 3.89 & -0.26 & .16 & 0.08 & .32 \\
\hline Inflexible & 226 & 23.58 & 4.53 & -0.36 & .16 & -0.34 & .32 \\
\hline Irresolute & 226 & 20.40 & 4.22 & 0.17 & .16 & -0.15 & .32 \\
\hline
\end{tabular}


Appendix J

Table J1.

Scale Level Statistics for Faculty

\begin{tabular}{|c|c|c|c|c|c|c|}
\hline \multirow[b]{2}{*}{ Scale } & \multicolumn{2}{|c|}{ Engineering } & \multicolumn{2}{|c|}{ Science } & \multicolumn{2}{|l|}{ Arts } \\
\hline & Mean & $\mathrm{SD}$ & Mean & $\mathrm{SD}$ & Mean & SD \\
\hline & \multicolumn{2}{|c|}{$\mathrm{N}=121$} & \multicolumn{2}{|c|}{$N=30$} & \multicolumn{2}{|c|}{$N=72$} \\
\hline Need for Cognition & 65.62 & 7.73 & 67.87 & 9.22 & 64.73 & 7.77 \\
\hline Deep & 48.74 & 6.51 & 49.37 & 7.12 & 49.34 & 6.69 \\
\hline Surface & 45.43 & 7.29 & 42.60 & 8.42 & 44.74 & 7.27 \\
\hline Achieve Motive & 24.29 & 3.63 & 23.93 & 3.69 & 23.65 & 4.33 \\
\hline Achieve Strategy & 22.34 & 4.20 & 23.63 & 4.59 & 22.74 & 4.18 \\
\hline Adaptive & 22.98 & 3.66 & 23.63 & 4.20 & 22.78 & 4.20 \\
\hline Inflexible & 23.78 & 4.23 & 23.27 & 5.38 & 23.38 & 4.73 \\
\hline Irresolute & 20.98 & 3.99 & 19.03 & 4.23 & 20.18 & 4.39 \\
\hline
\end{tabular}


Appendix J

Table J2.

Scale Level Statistics for Gender Differences

\begin{tabular}{|c|c|c|c|c|}
\hline \multirow[t]{2}{*}{ Scale } & \multicolumn{2}{|c|}{ Female } & \multicolumn{2}{|c|}{ Male } \\
\hline & Mean & $\mathrm{SD}$ & Mean & $\mathrm{SD}$ \\
\hline & \multicolumn{2}{|c|}{$N=64$} & \multicolumn{2}{|c|}{$N=161$} \\
\hline Need for Cogn. & 65.03 & 8.61 & 65.79 & 7.73 \\
\hline Deep & 49.97 & 6.14 & 48.51 & 6.87 \\
\hline Surface & 44.97 & 6.81 & 44.76 & 7.73 \\
\hline Achieve Motive & 23.98 & 3.95 & 23.98 & 3.92 \\
\hline Achieve Strategy & 24.64 & 3.88 & 21.81 & 4.12 \\
\hline Adaptive & 23.48 & 3.86 & 22.77 & 3.91 \\
\hline Inflexible & 23.66 & 5.09 & 23.58 & 4.31 \\
\hline Irresolute & 21.18 & 4.57 & 20.11 & 4.07 \\
\hline
\end{tabular}


Appendix J

Table J3.

Scale Level Statistics for Language Differences

\begin{tabular}{|c|c|c|c|c|}
\hline \multirow[t]{2}{*}{ Scale } & \multicolumn{2}{|c|}{ Erench } & \multicolumn{2}{|c|}{ English } \\
\hline & Mean & SD & Mean & SD \\
\hline & \multicolumn{2}{|c|}{$N=79$} & \multicolumn{2}{|c|}{$N=147$} \\
\hline Need for Cogn. & 67.61 & 7.93 & 64.37 & 7.87 \\
\hline Deep & 50.99 & 6.95 & 47.68 & 6.43 \\
\hline Surface & 43.92 & 7.53 & 45.33 & 7.38 \\
\hline Achieve Motive & 23.63 & 3.71 & 24.15 & 4.01 \\
\hline Achieve Strategy & 23.20 & 4.32 & 22.27 & 4.18 \\
\hline Adaptive & 23.50 & 4.26 & 22.70 & 3.66 \\
\hline Inflexible & 24.66 & 3.97 & 23.01 & 4.72 \\
\hline Irresolute & 19.73 & 3.82 & 20.76 & 4.40 \\
\hline
\end{tabular}


Appendix J

Table J4.

Erequency Distributions for Father's and Mother's Education

\begin{tabular}{lcc}
\hline Level of Education & Father & Mother \\
\hline 1. elementary school & 2 & 3 \\
2. some high school & 24 & 13 \\
3. completed high school & 43 & 51 \\
4. trade certificate/license & 26 & 8 \\
5. some college/CEGEP & 14 & 41 \\
6. college diploma & 20 & 22 \\
7. some university & 23 & 50 \\
8. Bachelor's degree & 44 & 15 \\
\hline 9. Master's or PhD & 27 & 27 \\
\hline
\end{tabular}


Appendix J

Table J5.

Descriptive Statistics for Age and Average Grade

\begin{tabular}{lcc}
\hline Variable & Mean & SD \\
\hline & & \\
Age & 19.41 & 3.39 \\
Average grade in high school & 84.82 & 6.33 \\
\hline
\end{tabular}

